Supporting Information for

\title{
Sigmatropic rearrangements of polymer backbones: Vinyl polymers from polyesters in one step
}

Rachael A. J. Ditzler and Aleksandr V. Zhukhovitskiy*

Department of Chemistry, University of North Carolina at Chapel Hill, Chapel Hill, North Carolina 27599, United States.

*alexzhuk@email.unc.edu 


\section{Table of Contents}

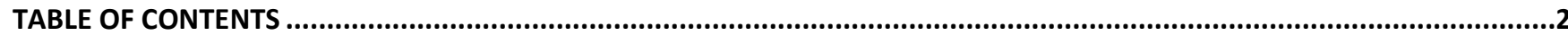

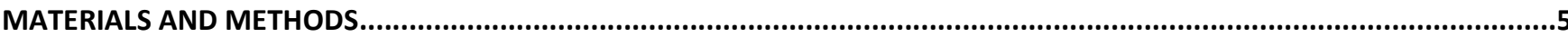

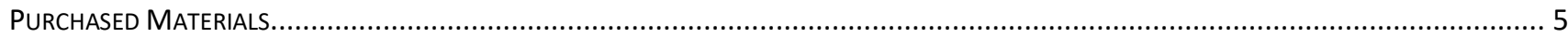

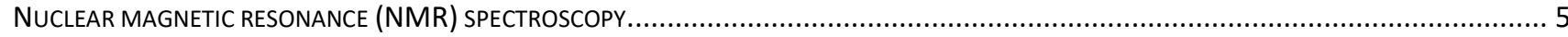

MATRIX ASSISTED LASER DESORPTION/IONIZATION TIME OF FLIGHT (MALDI-TOF) SPECTROSCOPY ................................................. 5

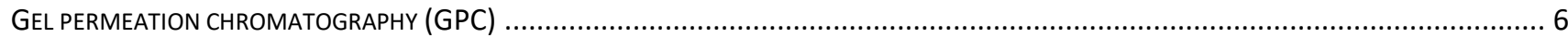

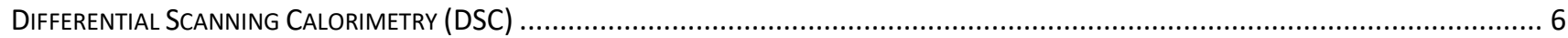

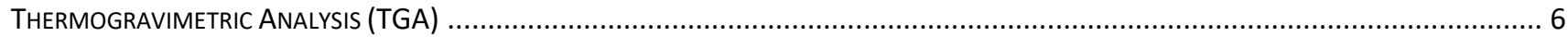

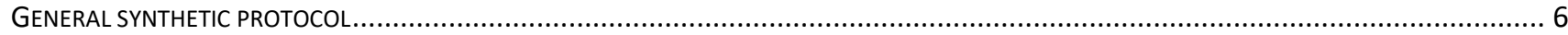

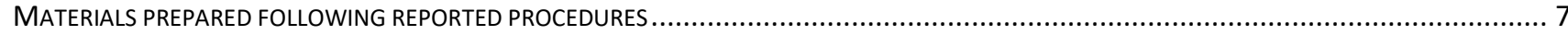

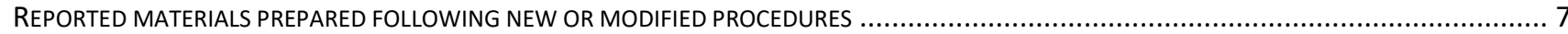

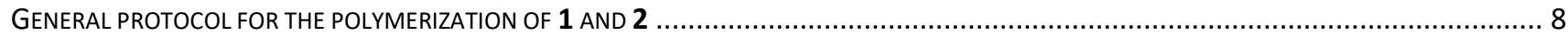

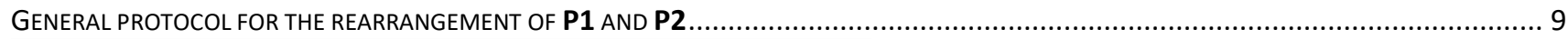

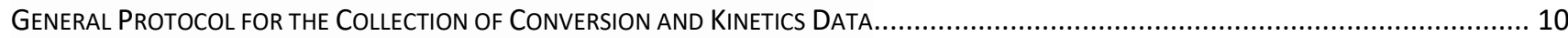

KINETIC ANALYSIS OF THE IRELAND-CLAISEN REARRANGEMENT OF P1 AND P2 TO P1' AND P2' ................................................... 10

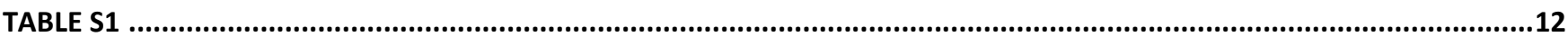

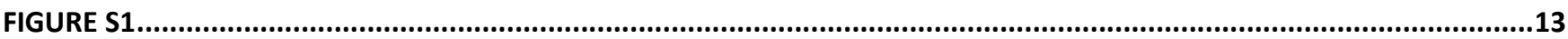

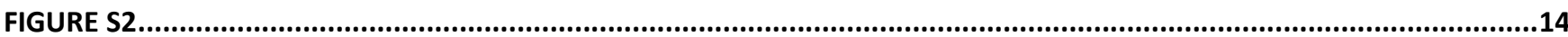

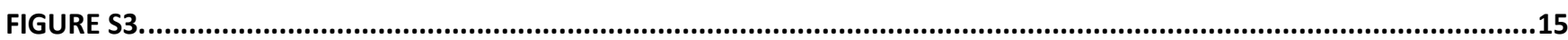

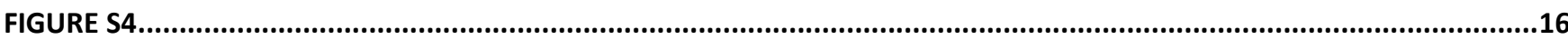

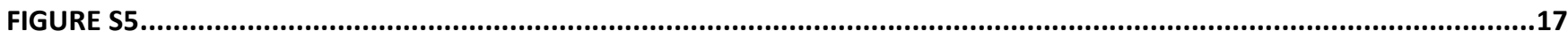

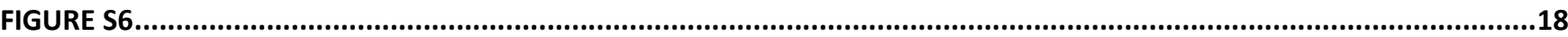

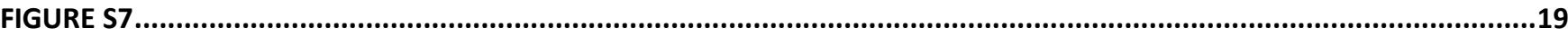

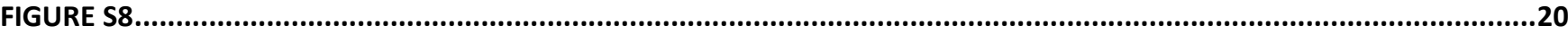

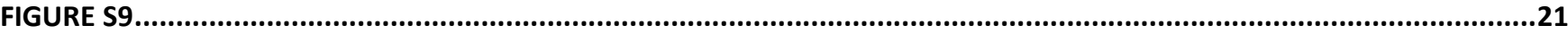

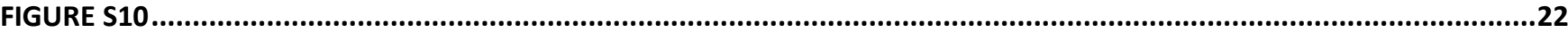

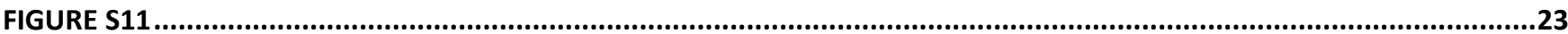

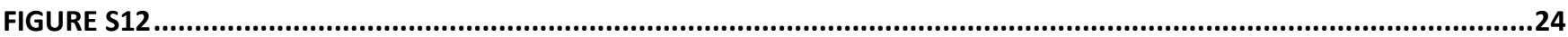

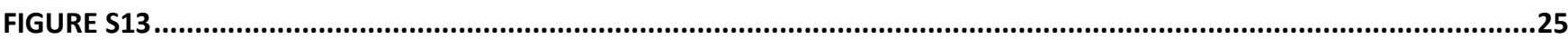

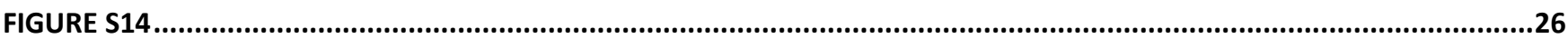

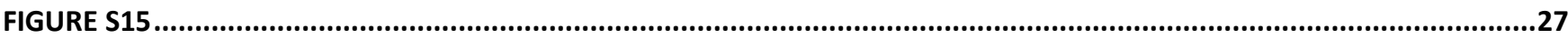

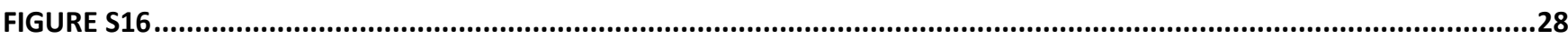

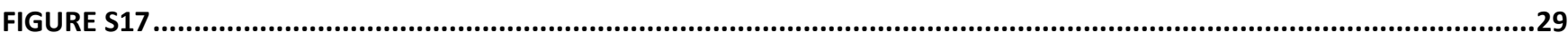

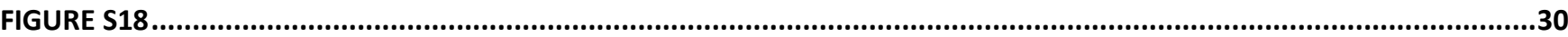

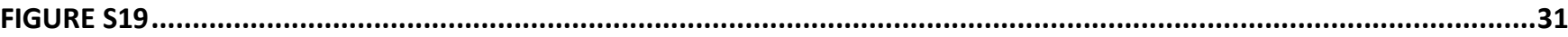

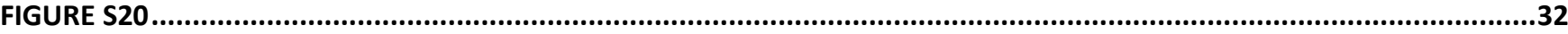

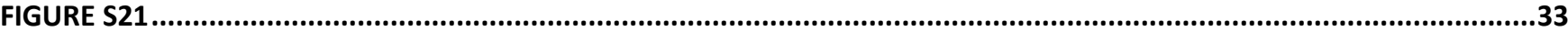

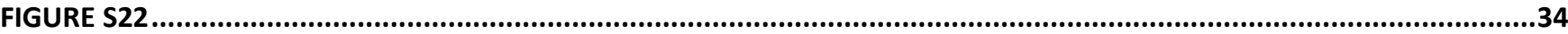

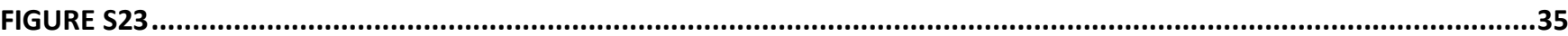

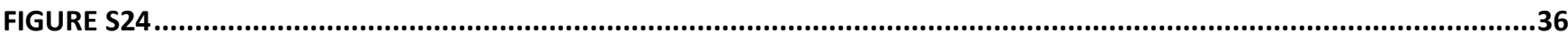




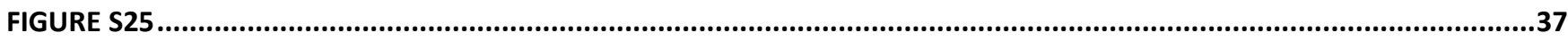

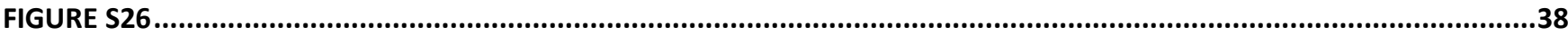

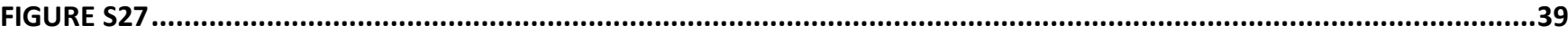

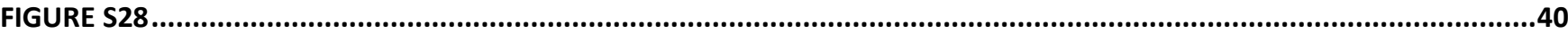

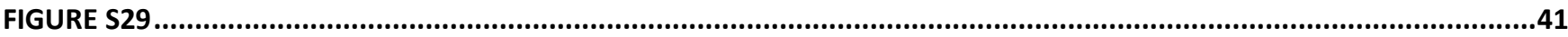

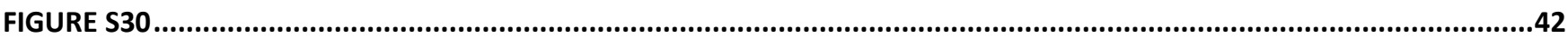

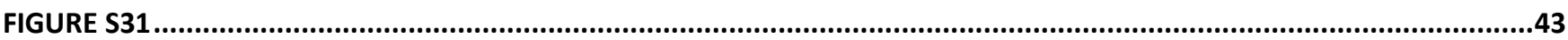

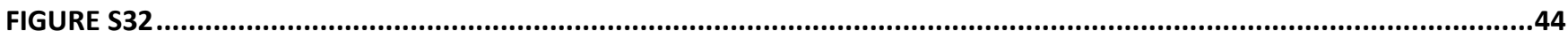

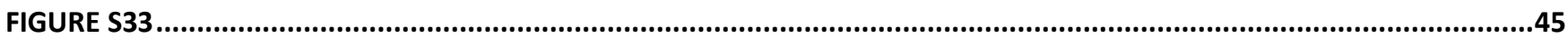

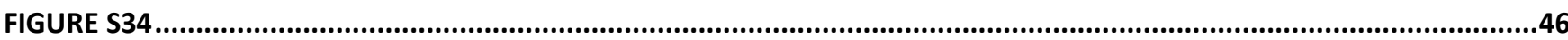

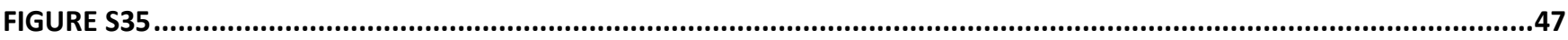

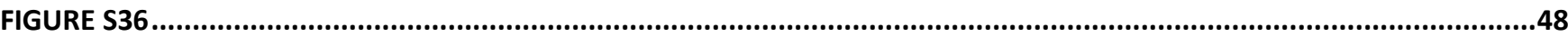

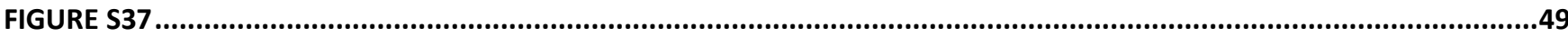

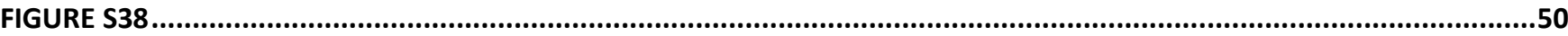

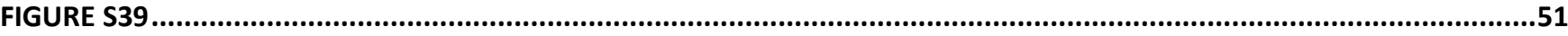

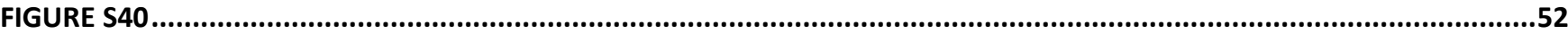

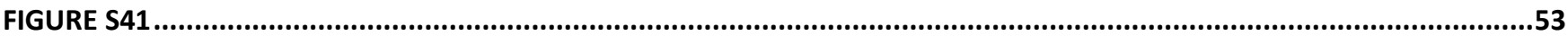

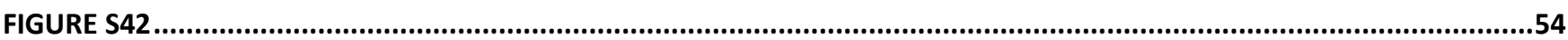

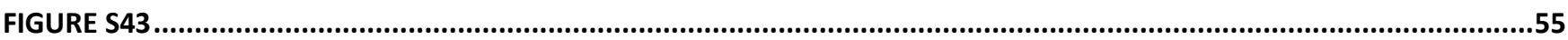

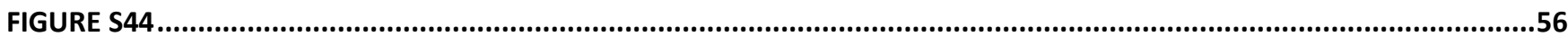

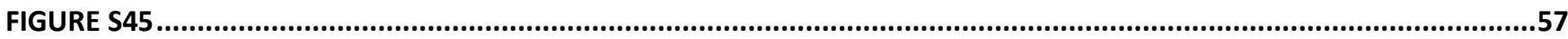

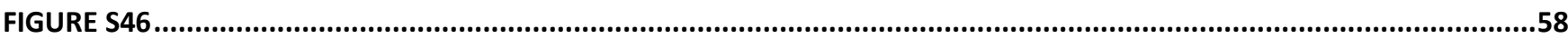

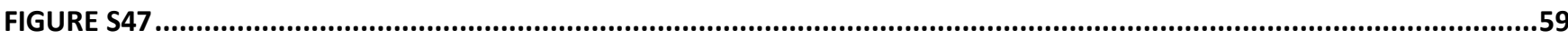

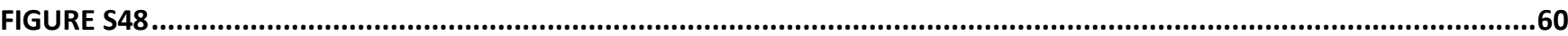

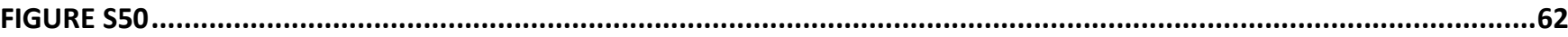

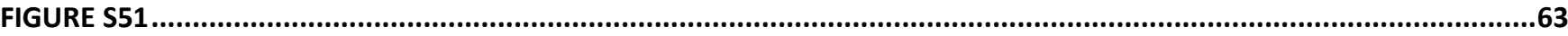

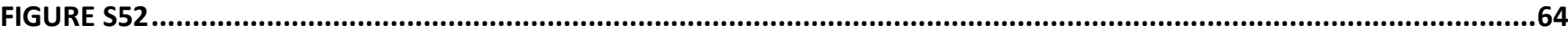

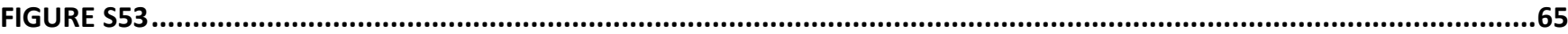

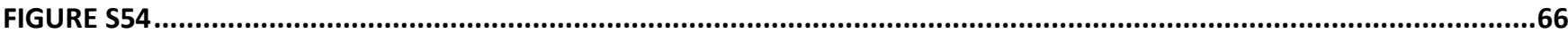

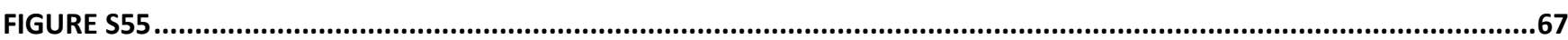

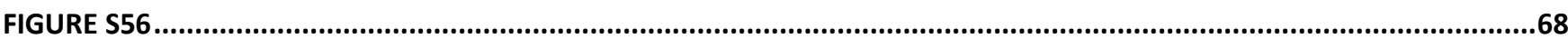

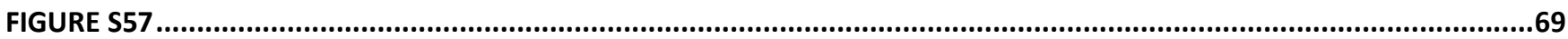

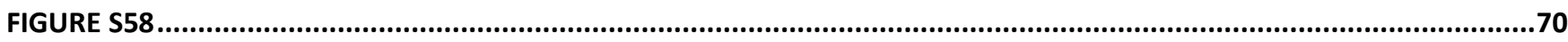

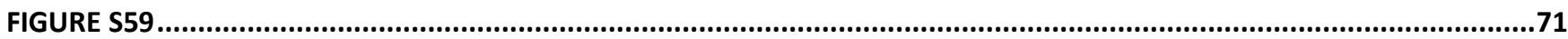

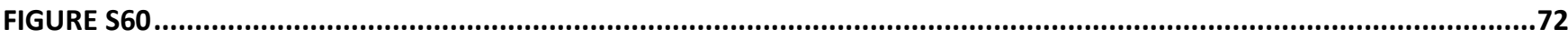

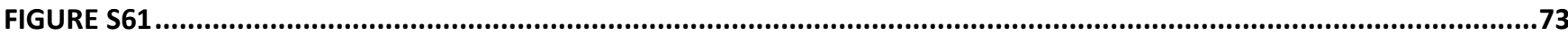

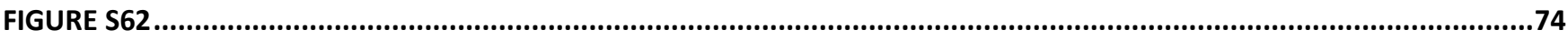

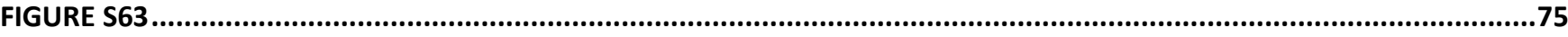

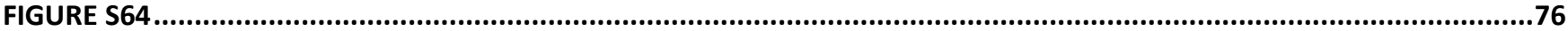




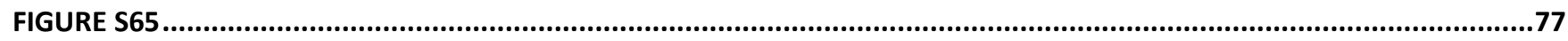

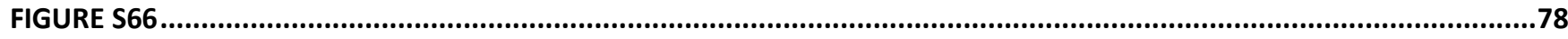

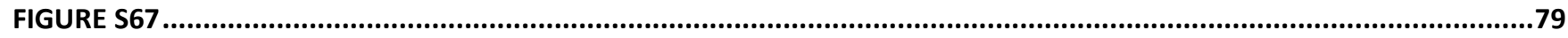

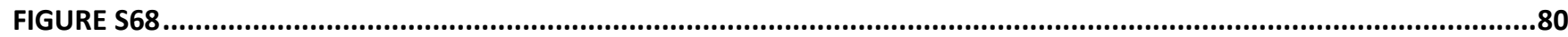

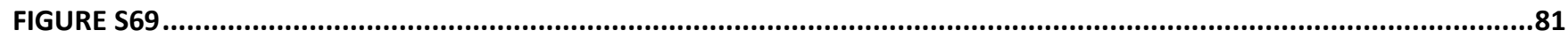

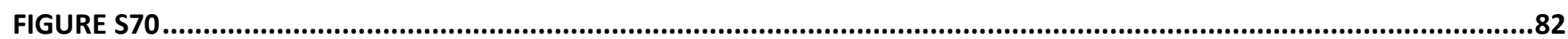

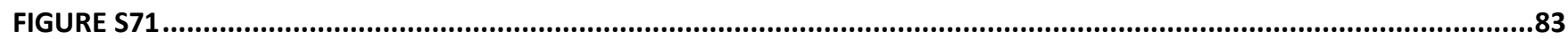

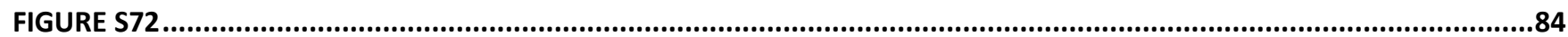

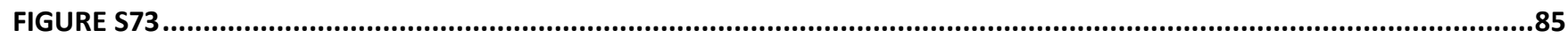

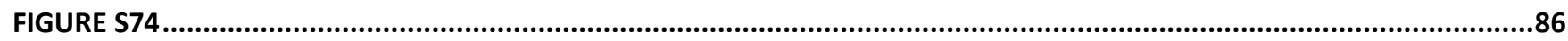

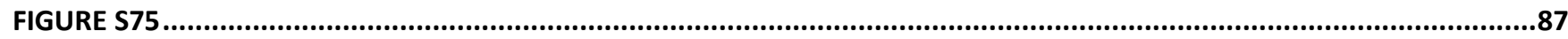

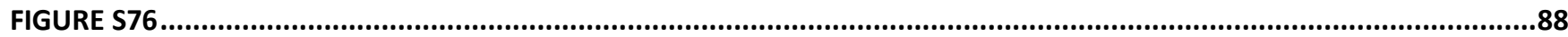

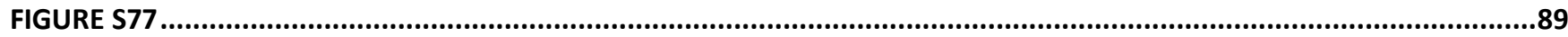

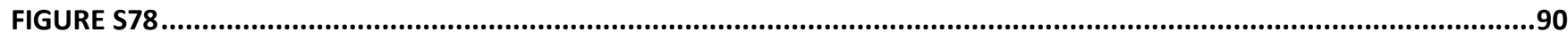

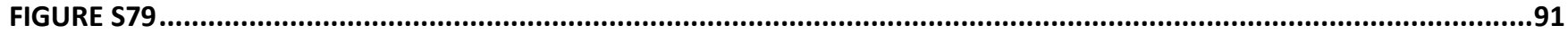

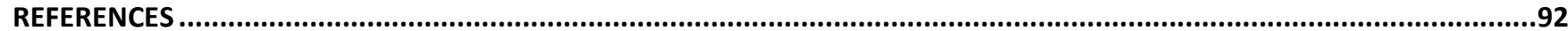




\section{Materials and Methods}

Purchased Materials

Glutaraldehyde (S5) was purchased from Alfa Aesar as a 50\% aqueous solution and purified via reported procedures. ${ }^{1}$ Deuterated solvents were purchased from Cambridge Isotope Laboratories, Inc. and were used as received. Molecular sieves were purchased from both Fisher Scientific and Sigma Aldrich and were activated by heating at $250{ }^{\circ} \mathrm{C}$ under dynamic vacuum ( $\left.\sim 60 \mathrm{mTorr}\right)$ for $6 \mathrm{~h}$. For anhydrous reactions, deuterated solvents were degassed using the freeze-pump-thaw technique and stored over $3 \AA$ molecular sieves. 1,8-Diazabicyclo[5.4.0] undec-7-ene (DBU), $1.0 \mathrm{M}$ vinylmagnesium bromide solution in tetrahydrofuran (THF), benzoic acid, pyridine, pyridinium chlorochromate (PCC), ethyl-6hydroxyhexanoate (S1), trimethylsilyl trifluoromethanesulfonate (TMSOTf), 4-(dimethylamino)pyridine (DMAP) and 1,5,7-triazabicyclo[4.4.0]dec-5-ene (TBD) were purchased from Sigma Aldrich and used as received. Potassium hydroxide, diethyl ether, and concentrated $\mathrm{HCl}$ were purchased from Fisher Scientific and used as received. 1-(3-dimethylaminopropyl)-3-ethylcarbodiimide hydrochloride (EDC $\cdot \mathrm{HCl})$ was purchased from TCI America and used as received. Tin(II) trifluoromethanesulfonate (tin triflate) was purchased from Strem Chemicals and used as received. Ammonium fluoride was purchased from Alfa Aesar and used as received. 1,3,5-tri-tert-butyl benzene was purchased from Combi-Blocks and dried by heating at $80{ }^{\circ} \mathrm{C}$ under vacuum ( $\sim 60$ mTorr). Diphenyl phosphate (DPP) and 1,3-diphenylurea (DPU) were purchased from Oakwood Chemicals and dried by heating at $80{ }^{\circ} \mathrm{C}$ under vacuum. 3-phenylpropan1-ol was purchased from Oakwood Chemicals and was degassed by three freeze-pump-thaw cycles and stored over $3 \AA$ molecular sieves. 3,5-Bis(trifluoromethyl)bromobenzene was purchased from Matrix Scientific and was degassed by three freeze-pump-thaw cycles and stored over $3 \AA$ molecular sieves. Dichloromethane (DCM), THF, hexanes and, ethyl acetate were purchased from VWR and used as received. Reactions requiring anhydrous and air-free DCM, diethyl ether, THF, and triethylamine were dispensed through a Pure Process Technologies solvent purification system. ${ }^{1}$ SiliaFlash F60 silica gel size 230-400 mesh (40-63 $\mu \mathrm{m})$ and glass backed TLC plates were purchased from Silicycle and used as received.

Nuclear magnetic resonance (NMR) spectroscopy

${ }^{1} \mathrm{H}$ and ${ }^{13} \mathrm{C}$ NMR spectra were recorded on Bruker NMR spectrometers operating at 400, 500, and 600 $\mathrm{MHz}$ for ${ }^{1} \mathrm{H}\left(100,125\right.$, and $150 \mathrm{MHz}$ for ${ }^{13} \mathrm{C}$, respectively). These instrument models are listed here with the corresponding supporting federal grants: Bruker AVANCE III Nanobay $400 \mathrm{MHz}$ (NSF Grant No. CHE-0922858), Bruker AVANCE III 500 MHz (NSF Grant No. CHE-0922858), Bruker AVANCE III $600 \mathrm{MHz}$ (NSF Grant No. CHE-0922858), and Bruker AVANCE NEO 600 MHz (NSF Grant No. CHE1828183). Chemical shifts are expressed in parts per million (ppm), and splitting patterns are designated as s (singlet), d (doublet), $\mathrm{t}$ (triplet), q (quartet), sept (septet), oct (octet), m (multiplet), b (broad), and combinations thereof. Scalar coupling constants $J$ are reported in Hertz (Hz). MestReNova v14.1.0-24037 software (Mestrelab Research S.L.) was used to analyze the NMR spectra. ${ }^{1} \mathrm{H}$ and ${ }^{13} \mathrm{C}$ NMR spectra were referenced to residual monoproteo-solvent peaks as reported in literature. ${ }^{2}$

Matrix assisted laser desorption/ionization time of flight (MALDI-TOF) spectroscopy

MALDI-TOF mass spectrometry was performed on a Bruker Microflex LRF with 15k resolution. Samples were prepared as follows. The purified polymer synthesized at a target degree of polymerization of 25:1:1 $[\mathrm{M}]:[\mathrm{C}]:[\mathrm{I}]$ was concentrated to dryness and redissolved in high-performance liquid chromatography (HPLC)-grade tetrahydrofuran (THF) at a concentration of $\sim 1 \mathrm{mg} / \mathrm{mL}$ (Solution A). Next, a $\sim 15 \mathrm{mg} / \mathrm{mL}$ solution of 2,5-dihydroxybenzoic acid (DHB) was prepared in HPLC-grade THF (solution B). Lastly, sodium iodine was dissolved in acetone at a concentration of $1 \mathrm{mg} / \mathrm{mL}$ (solution $\mathrm{C}$ ). $5 \mu \mathrm{L}$ of Solution A were mixed with $5 \mu \mathrm{L}$ of Solution B. $1 \mu \mathrm{L}$ of Solution $\mathrm{C}$ was spotted onto a MALDI plate and allowed to evaporate at $24{ }^{\circ} \mathrm{C}$. After complete evaporation of acetone was achieved, $1 \mu \mathrm{L}$ of the resulting mixture was spotted onto a MALDI plate and allowed to evaporate at $24^{\circ} \mathrm{C}$. The calibration was carried out using 
a mix of peptides, ranging in mass from $\sim 300 \mathrm{~g} / \mathrm{mol}$ to $\sim 3000 \mathrm{~g} / \mathrm{mol}$, and the samples were ionized using $90-100 \%$ laser power.

Gel permeation chromatography (GPC)

Analytical GPC was performed on an Agilent Technologies 1260 Infinity II instrument equipped with two PL gel $10 \mu \mathrm{m}$ mixed-B LS columns connected in series, with tetrahydrofuran (THF) $\left(35^{\circ} \mathrm{C}\right)$ as the eluent, a Wyatt Technologies DAWN 8-angle light scattering (MALS) detector $(\lambda=658 \mathrm{~nm})$, a Wyatt Technologies ViscoStar differential viscometer, and a Wyatt Technologies Optilab T-rEX differential refractometer. The samples were prepared by dissolution of the polymer samples at a concentration of $\sim 3$ $\mathrm{mg} / \mathrm{mL}$ in HPLC-grade THF stabilized with butylated hydroxytoluene (BHT), followed by filtration through a $0.22-\mu \mathrm{m}$ syringe filter. The $d \mathrm{n} / d \mathrm{c}$ values were calculated for purified polymers in Astra software using the $100 \%$ mass recovery method.

GPC for Figure S59 was performed on an Agilent 1260 Infinity instrument equipped with two Agilent Resipore Columns (PL1113-6300) with $0.1 \mathrm{wt} \% \mathrm{LiBr}$ in $N, N$-dimethylformamide (DMF) as an eluent, and an Agilent 1260 RID G1362A refractive index detector at $50{ }^{\circ} \mathrm{C}$.

Preparative-scale GPC (prep-GPC) was performed on Recycling Preparative HPLC LaboACE LC-5060 Series equipped with JAIGEL-2HR column and a UV and RI detectors, with dichloromethane (DCM) at room temperature ( $\mathrm{rt}$ ) as the eluent. The samples were prepared by dissolution of the polymer samples up to a concentration of $40 \mathrm{mg} / \mathrm{mL}$ in HPLC-grade DCM stabilized with amylene, followed by filtration through a $0.22-\mu \mathrm{m}$ syringe filter. Samples were injected into the sample loop and recycled through the columns until baseline separation was obtained for the desired peak.

\section{Differential Scanning Calorimetry (DSC)}

This analysis was carried out using a TA Instruments Discovery DSC using aluminum pans, in air, with a heating and cooling rate of $10{ }^{\circ} \mathrm{C} / \mathrm{min}$. Melting-transition temperature $\left(T_{\mathrm{m}}\right)$ and glass-transition temperature $\left(T_{\mathrm{g}}\right)$ were obtained from the second heating scan.

\section{Thermogravimetric Analysis (TGA)}

This analysis was carried out using a TA Instruments Q5000 Thermogravimetric Analyzer. Characterization was performed under nitrogen using aluminum pans with a heating rate of $10{ }^{\circ} \mathrm{C} / \mathrm{min}$ from room temperature to $600{ }^{\circ} \mathrm{C}$. Values for the decomposition onset temperature were obtained from weight percent vs temperature $\left({ }^{\circ} \mathrm{C}\right)$ plots.

General synthetic protocol

All air-sensitive reactions were carried out in flame-dried glassware in a nitrogen-filled glove box or using standard Schlenk techniques. Hamilton gas-tight syringes were cleaned by rinsing with copious amounts of DCM and drying under a stream of $\mathrm{N}_{2}$. Reactions were monitored via ${ }^{1} \mathrm{H}$ NMR and TLC, and TLC plates were visualized via standard staining procedures. Removal of solvents in vacuo was achieved using a IKA rotary evaporator and a Schlenk line ( 12-60 mTorr, dynamic vacuum). Purification via flash chromatography was carried out following standard procedures. ${ }^{3}$ 

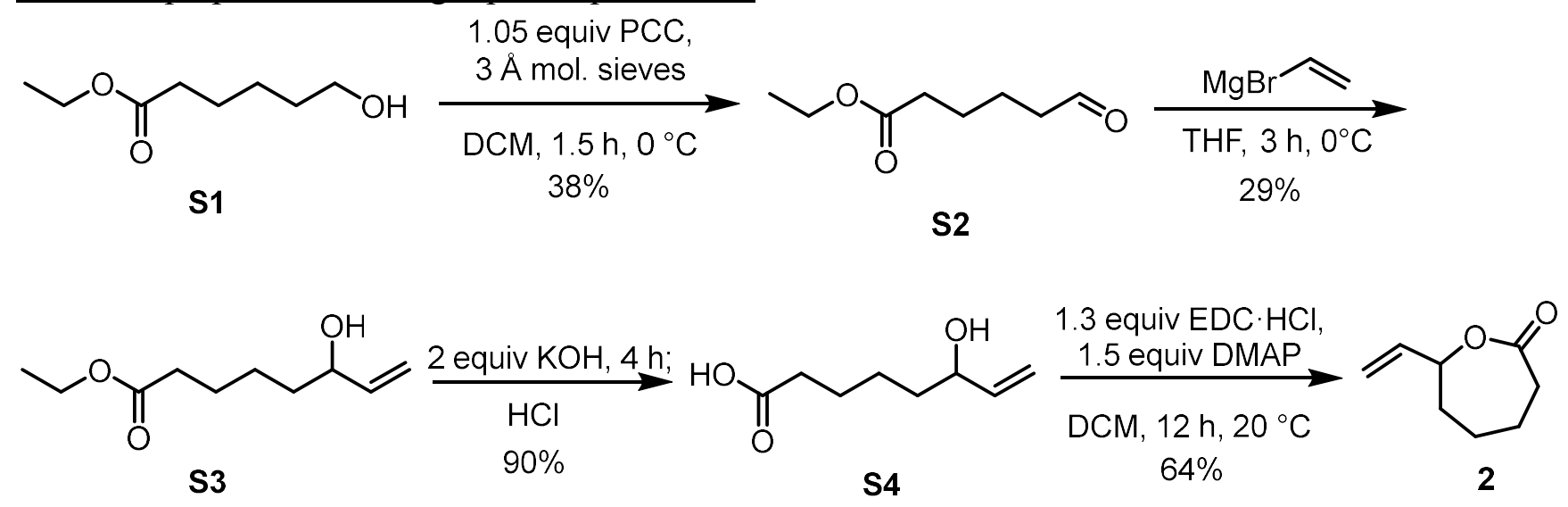

Ethyl 6-oxohexanoate, S2 (20.245 g, 90\% purity, 38\% yield) was synthesized from ethyl-6hydroxyhexanoate, S1, (48.06 g) and PCC according to the cited reference, except powdered $3 \AA$ molecular sieves $(105.0 \mathrm{~g})$ were added to the suspension instead of sodium acetate. ${ }^{4} \mathrm{H}$ NMR spectra matched reported. ${ }^{4}$

Ethyl 6-hydroxy-7-octenoate, $\mathbf{S 3}$ (6.925 g, 29.4\% yield) was synthesized from S2 (20.0 g) and vinylmagnesium bromide $\left(1.0 \mathrm{M}\right.$ in THF) according to the cited reference. ${ }^{4} \mathrm{H}$ NMR spectra matched reported. $^{4}$

6-hydroxy-7-octenoic acid, $\boldsymbol{S 4}$ (4.79 g, $90.4 \%$ yield) was synthesized from S3 (6.24 g), potassium hydroxide, and hydrochloric acid according to the cited reference, except the reaction was carried out as a $1.34 \mathrm{M}$ solution and the product was used without purification by flash silica gel chromatography. ${ }^{5} \mathrm{H}$ NMR spectra matched reported. ${ }^{5}$

7-vinyloxepan-2-one, 2 (2.98 g, 63.5\% yield) was synthesized S4 (5.300 g), EDC $\cdot \mathrm{HCl}$, and 4dimethylaminepyridine according to the cited reference, except the reaction was run for 12 hours and the product was purified by silica gel flash chromatography in DCM $\left(R_{\mathrm{f}}=0.27\right) .{ }^{5}{ }^{1} \mathrm{H} \mathrm{NMR}$ spectra matched reported..$^{5}$

$\underline{\text { Reported materials prepared following new or modified procedures }}$

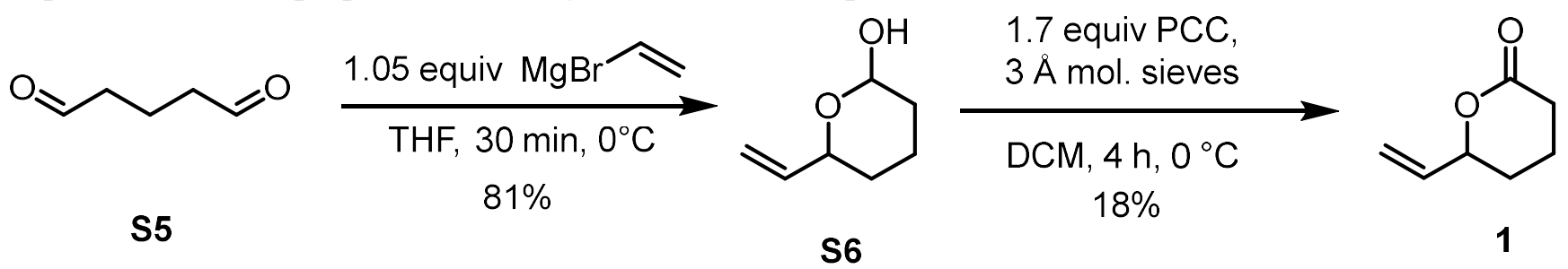

6-vinyltetrahydro-2H-pyran-2-ol, S6. To a 2-neck 2 L round-bottom equipped with a stir bar under an inert atmosphere containing glutaraldehyde, S5, $(41.18 \mathrm{~g}, 411.3 \mathrm{mmol})$ in THF $(600 \mathrm{~mL})$, a solution of vinyl magnesium bromide in THF $(1.0 \mathrm{M}, 432 \mathrm{~mL})$ was added dropwise over 30 minutes at $0{ }^{\circ} \mathrm{C}$. After complete addition of the vinyl magnesium bromide solution, all starting material was consumed. The reaction was quenched with saturated aqueous ammonium chloride $(200 \mathrm{~mL})$. The aqueous layer was extracted with diethyl ether $(3 \times 300 \mathrm{~mL})$, washed with brine $(4 \times 500 \mathrm{~mL})$, dried over magnesium sulfate, filtered, and concentrated in vacuo. S6 was obtained as a viscous, yellow oil (mixture of diastereomers, $42.9 \mathrm{~g}, 81.4 \%$ crude yield) and used without further purification. ${ }^{1} \mathrm{H}$ NMR spectra matched reported literature spectra. ${ }^{6}$ 
$\delta$-vinyl- $\delta$-valerolactone, 1 . To a 3 -neck $500 \mathrm{~mL}$ round-bottom equipped with a stir bar under an inert atmosphere containing PCC $(94.712 \mathrm{~g}, 439.4 \mathrm{mmol})$ and powdered $3 \AA$ molecular sieves $(92.60 \mathrm{~g})$ in DCM (262 mL), S6 (42.91 g, $334.8 \mathrm{mmol})$ in DCM (104 mL) was added slowly via cannula at $0{ }^{\circ} \mathrm{C}$. After 30 minutes, the reaction was warmed to $25{ }^{\circ} \mathrm{C}$ and stirred for another $1.5 \mathrm{hr}$. Additional PCC (36.02 g, 167.1 mmol) was added and stirred for 2 hours. The resulting material was filtered over celite, concentrated in vacuo, passed through a silica plug (7-8 in) with diethyl ether as eluent to remove PCC byproducts, and concentrated in vacuo. 1 was purified via flash silica gel chromatography in DCM $\left(R_{\mathrm{f}}=0.20\right)$ to afford pure material as a pale yellow oil (7.51 g, 18\% yield). ${ }^{1} \mathrm{H}$ NMR spectra matched reported literature spectra. ${ }^{6}$

\section{$\underline{\text { General protocol for the polymerization of } \mathbf{1} \text { and } \mathbf{2}}$}

In a glove box with nitrogen atmosphere, to a $2.0 \mathrm{~mL}$ scintillation vial containing a stir bar, stock solutions of diphenyl phosphate (0.01 equiv) and 3-phenylpropan-1-ol (0.0100 equiv) in DCM were added via Hamilton syringe and solvent was removed in vacuo. To the vial, 1 (1.00 equiv) and internal standard 1bromo-3,5-bis(trifluoromethyl)benzene $(10.0 \mu \mathrm{L})$ were added. The reaction was stirred at a specified temperature until conversion stopped as judged by ${ }^{1} \mathrm{H}$ NMR. The reaction was quenched with triethylamine (1.50 equiv) and removed from the glove box. Product was purified via prep-GPC in DCM, concentrated in vacuo, and dried by sparging with $\mathrm{N}_{2}$.

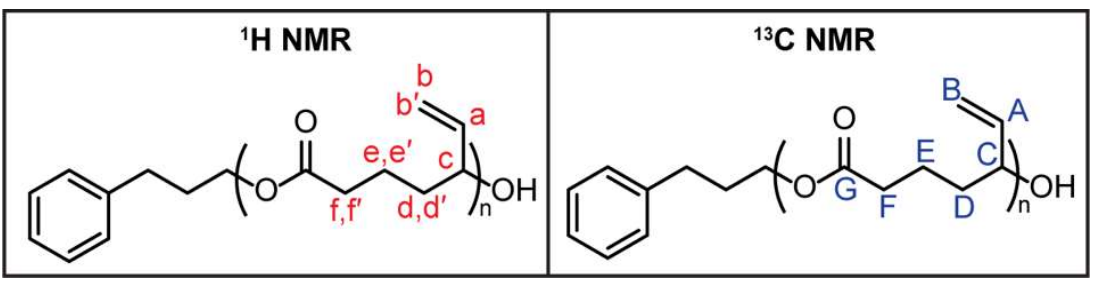

P1. Prepared from 1 following the general procedure on a $599.4 \mathrm{mg}$ scale at $60{ }^{\circ} \mathrm{C}$ for $20 \mathrm{~h}$; isolated as a viscous pale-yellow liquid (404 mg, 67.4\% yield). ${ }^{1} \mathrm{H}$ NMR $\left(600 \mathrm{MHz}, \mathrm{CDCl}_{3}\right) \delta 5.81-5.71$ (ddd, $\left.1 \mathrm{H}, \mathrm{a}\right)$, 5.29-5.20 (m, 2H, b' and c), 5.20-5.13 (d, 1H, b), 2.43-2.27 (m, 2H, f, f') 1.74-1.59 (m, 4H, d, d', e, and e'). ${ }^{13} \mathrm{C} \mathrm{NMR}\left(150 \mathrm{MHz}, \mathrm{CDCl}_{3}\right) \delta 172.6(\mathrm{G}), 136.3(\mathrm{~A}), 117.2(\mathrm{~B}), 74.4(\mathrm{C}), 34.1(\mathrm{~F}), 33.6(\mathrm{D}), 20.6(\mathrm{E})$. $\mathrm{dn} / \mathrm{dc}$ in THF at $35^{\circ} \mathrm{C}: 0.0771 \mathrm{~mL} / \mathrm{g} ; M_{\mathrm{n}}=5.52 \mathrm{~kg}^{\circ} \mathrm{mol}^{-1} ; M_{\mathrm{w}}=6.86 \mathrm{~kg}^{\circ} \mathrm{mol}^{-1} ; \mathrm{Ð}=1.24$. Assignments were confirmed by a combination of HSQC, HMBC, and COSY (see Supplementary Figures S34-S36). Of particular importance were the following observations: (1) coupling between proton "a" and both of the protons " $\mathrm{b}$ " " and " $\mathrm{c}$ " corresponding to the overlapping resonances at 5.29-5.20 ppm. Proton "a" is also coupled to the proton " $b$ " at $5.20-5.13 \mathrm{ppm}$ and is the only proton attached to carbon "A" at 136.3 ppm. (2) Proton "c" at 5.29-5.20 ppm is coupled to protons " $\mathrm{d}$ " and " $\mathrm{d}$ "' at 1.74-1.59 ppm. Additionally, proton "c" at 5.29-5.20 ppm is attached to carbon "C" at 74.4 ppm while proton "b" at 5.29-5.20 ppm and proton " $\mathrm{b}$ " at 5.20-5.13 ppm are both attached to carbon " $\mathrm{B}$ " at $117.2 \mathrm{ppm}$. (3) Carbon G is not directly attached to any protons and shows only HMBC correlation to protons " $\mathrm{f}$ " and " $\mathrm{f}$ " " at 2.43-2.27 ppm and weaker correlation to protons "e" and " $\mathrm{e}$ "” at 1.74-1.59 ppm. Additionally, protons " $\mathrm{f}$ " and " $\mathrm{f}$ " are coupled only to protons "e" and "e'" at 1.74-1.59 ppm.

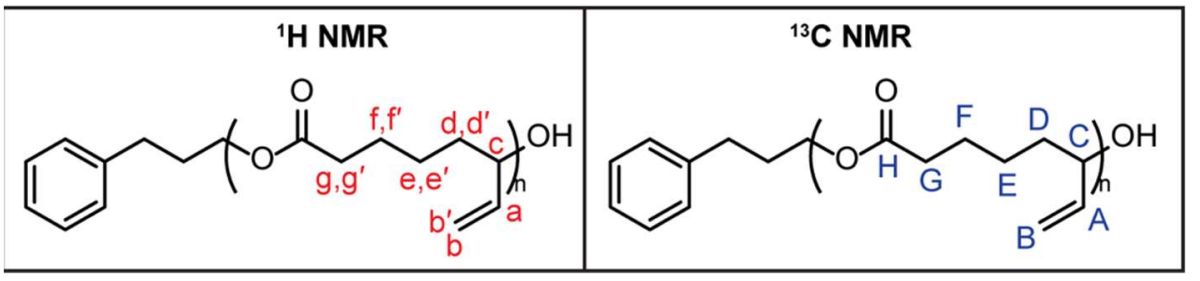


P2. Prepared from 2 following the general procedure on a $321.6 \mathrm{mg}$ scale at $60{ }^{\circ} \mathrm{C}$ for $65 \mathrm{~h}$; isolated as a viscous pale-yellow liquid (254 mg, 79.0\% yield). ${ }^{1} \mathrm{H} \mathrm{NMR}\left(600 \mathrm{MHz}, \mathrm{CDCl}_{3}\right) \delta 5.80-5.68(\mathrm{ddd}, 1 \mathrm{H}, \mathrm{a})$, 5.30-5.18 (m, 2H, b' and c), 5.18-5.12 (d, 1H, b), $2.30\left(\mathrm{t}, 2 \mathrm{H}, \mathrm{g}\right.$ and $\left.\mathrm{g}^{\prime}\right)$ 1.71-1.58 (m, 4H, d, $\mathrm{d}^{\prime}, \mathrm{f}$, and $\left.\mathrm{f}^{\prime}\right)$, 1.39-1.29 (m, 2H, e and $\left.\mathrm{e}^{\prime}\right) .{ }^{13} \mathrm{C} \mathrm{NMR}\left(150 \mathrm{MHz}, \mathrm{CDCl}_{3}\right) \delta 172.9(\mathrm{H}), 136.6(\mathrm{~A}), 117.0(\mathrm{~B}), 74.6(\mathrm{C})$, 34.5 (G), 34.0 (D), 24.9 (F), $24.8(\mathrm{E}) . \mathrm{dn} / \mathrm{dc}$ in THF at $35^{\circ} \mathrm{C}: 0.0775 \mathrm{~mL} / \mathrm{g} ; M_{\mathrm{n}}=4.91 \mathrm{~kg}^{\circ} \mathrm{mol}^{-1} ; M_{\mathrm{w}}=$ $5.66 \mathrm{~kg}^{\circ} \mathrm{mol}^{-1} ; \mathrm{Ð}=1.15$. Assignments were confirmed by a combination of HSQC, HMBC, and COSY (see Supplementary Figures S40-S42). Of particular importance were the following observations: (1) coupling between proton " $\mathrm{a}$ " and both of the protons " $\mathrm{b}$ "' and " $\mathrm{c}$ " corresponding to the overlapping resonances at 5.30-5.18 ppm. Proton "a" is also coupled to the proton "b" at 5.18-5.12 ppm and is the only proton attached to carbon "A" at $136.6 \mathrm{ppm}$. (2) Proton "c" at 5.30-5.18 ppm is coupled to protons "d" and " $\mathrm{d}$ "' at 1.71-1.58 ppm. Additionally, proton "c" at 5.30-5.18 ppm is attached to carbon "C" at $74.6 \mathrm{ppm}$ while proton " $\mathrm{b}$ "” at 5.30-5.18 ppm and proton " $\mathrm{b}$ " at 5.18-5.12 ppm are both attached to carbon "B" at 117.0 ppm. (3) Carbon " $\mathrm{H}$ " is not directly attached to any protons and shows only HMBC correlation to protons " $\mathrm{g}$ " and " $\mathrm{g}$ "' at $2.30 \mathrm{ppm}$ and weaker correlation to protons "f" and "f'" at 1.71$1.58 \mathrm{ppm}$. Additionally, protons " $\mathrm{f}$ " and " $\mathrm{f}$ " " are coupled to protons "e" and " $\mathrm{e}$ "" at 1.39-1.29 ppm as well as protons " $\mathrm{g}$ " and " $\mathrm{g}$ "' at $2.30 \mathrm{ppm}$. (4) Protons " $\mathrm{f}$ " and " $\mathrm{f}$ " at 1.71-1.58 ppm are attached to carbon " $\mathrm{F}$ " at 24.9 ppm and protons "e" and "e" " at 1.39-1.29 ppm are attached to carbon "E" at $24.8 \mathrm{ppm}$.

\section{$\underline{\text { General protocol for the rearrangement of } \mathbf{P 1} \text { and } \mathbf{P 2}}$}

In a glove box with nitrogen atmosphere, to a $20 \mathrm{~mL}$ scintillation vial with a stir bar, P2 (1.00 equiv) and 1,3,5-tritertbutylbenzene $(20.0 \mathrm{mg})$ were mixed in deuterated DCM $(0.14 \mathrm{M})$. To the reaction mixture, triethylamine (1.20 equiv) was added first, followed by trimethylsilyl triflate (1.15 equiv). The reaction was monitored via ${ }^{1} \mathrm{H}$ NMR until conversion reached a plateau $(48 \mathrm{~h})$ and then quenched with pyridine (0.4 equiv). The sample was transferred to a polypropylene Eppendorf tube, mixed with equal volume of aqueous ammonium fluoride solution (1M), and agitated for 5 minutes. After 30 minutes at rest, all volatiles were removed in vacuo, and the residue was washed with DCM (volume equal to original sample $\mathrm{x} 4)$, and dried. To the dried sample, water $(15 \mathrm{~mL})$ was added and treated with conc. $\mathrm{HCl}$ to obtain a $1 \mathrm{M}$ $\mathrm{HCl}$ solution. Aqueous wash was removed, sample was dried, and transferred to a glass vial, assisted with pentane. The sample was dissolved in THF $(10 \mathrm{mg} / \mathrm{mL}, 15 \mathrm{~mL}$ total $)$, precipitated into $1 \mathrm{M} \mathrm{HCl}(30 \mathrm{~mL})$, and centrifuged. Precipitate was removed after washing with pentane $(5.5 \mathrm{~mL})$ and dried in vacuo.

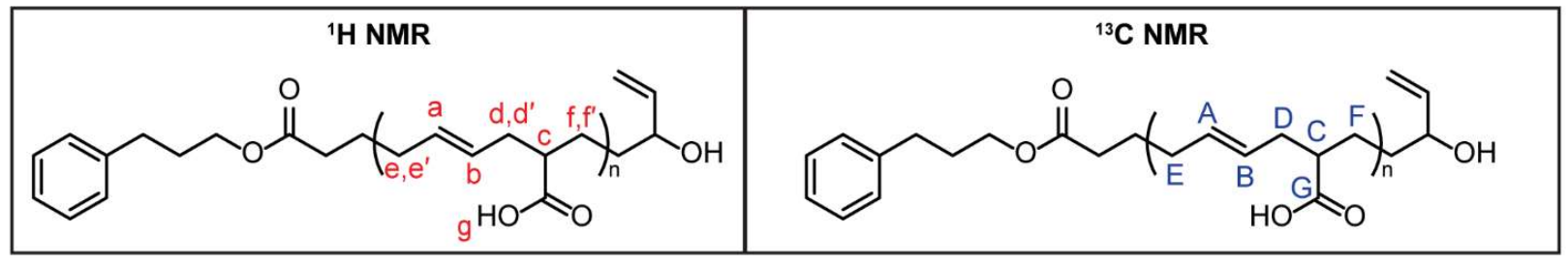

P1". Prepared from P1 following the general procedure on a $48.9 \mathrm{mg}$ scale; isolated as a pale-yellow solid (42.4 mg, 80\% yield). ${ }^{1} \mathrm{H}$ NMR (600 MHz, THF- $\left.d_{8}\right) \delta 13.98-8.03(\mathrm{~s}, 1 \mathrm{H}, \mathrm{g}), 5.52-5.35(\mathrm{~m}, 2 \mathrm{H}, \mathrm{a}$ and b), 2.35-2.29 (m, 1H, c), 2.29-2.21 (m, 1H, d), 2.18-2.09 (m, 1H, d'), 2.06-1.92 (m, 2H, e and e'), 1.68-1.55 $(\mathrm{m}, 1 \mathrm{H}, \mathrm{f}), 1.52-1.43\left(\mathrm{~m}, 1 \mathrm{H}, \mathrm{f}^{\prime}\right) .{ }^{13} \mathrm{C}$ NMR (150 MHz, THF- $\left.d_{8}\right) \delta 176.4(\mathrm{G}), 132.3(\mathrm{~A}), 128.6(\mathrm{~B}), 45.4$ (C), 35.9 (D), 32.2 (F), 31.0 (E). Assignments were confirmed by a combination of HSQC, HMBC, and COSY (see Supplementary Figures S71-S73). Of particular importance were the following observations: (1) coupling between proton "a" and protons " $\mathrm{e}$ " and " $\mathrm{e}$ "" corresponding to the resonances at 2.06-1.92 ppm and coupling between proton " $\mathrm{b}$ " and protons " $\mathrm{d}$ " and " $\mathrm{d}$ "' corresponding to the resonances at 2.29$2.21 \mathrm{ppm}$ and 2.18-2.09 ppm. Proton " $\mathrm{a}$ " is the only proton attached to carbon " $\mathrm{A}$ " at $132.3 \mathrm{ppm}$ and proton " $\mathrm{b}$ " is the only proton attached to carbon " $\mathrm{B}$ " at $128.6 \mathrm{ppm}$. (2) Protons "e" and "e" " at 2.06-1.92 ppm are coupled to protons "f" and " $\mathrm{f}$ "' at 1.68-1.55 ppm and 1.52-1.43 ppm. Additionally, protons "e" 
and "e" at 2.06-1.92 ppm are attached to carbon "E" at 31.0 ppm while protons " $\mathrm{f}$ " and " $\mathrm{f}$ " at 1.68-1.55 ppm and 1.52-1.43 ppm are both attached to carbon "F" at 32.2 ppm. (3) Proton "c" at 2.35-2.29 ppm is coupled to protons " $\mathrm{f}$ " and " $\mathrm{f}$ "' at 1.68-1.55 ppm and 1.52-1.43 ppm and is the only proton coupled to carbon "C" at 45.4 ppm.

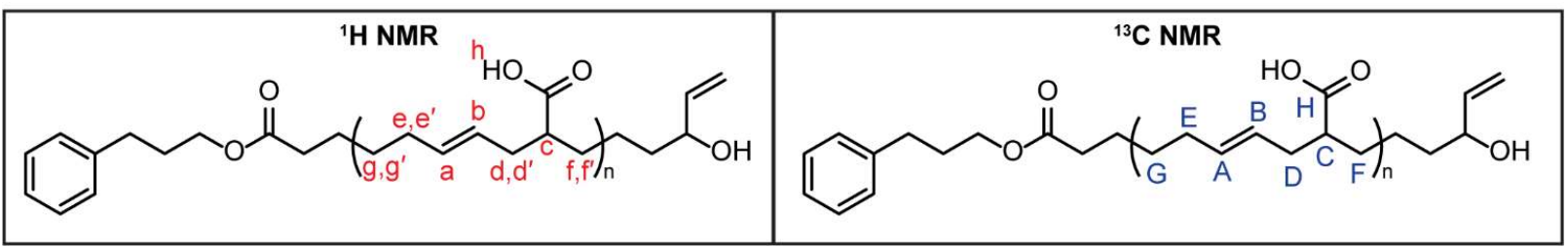

P2". Prepared from P2 following the general procedure on a $108.8 \mathrm{mg}$ scale; isolated as a pale-yellow solid (56.5 mg, 55\% yield). ${ }^{1} \mathrm{H}$ NMR $\left(600 \mathrm{MHz}, \mathrm{THF}-d_{8}\right) \delta 14.16-8.10(\mathrm{~s}, 1 \mathrm{H}, \mathrm{h}), 5.49-5.33(\mathrm{~m}, 2 \mathrm{H}, \mathrm{a}$ and b), 2.31-2.22 (m, 2H, c and d), 2.15-2.07 (m, 1H, d'), 2.02-1.92 (m, 2H, e and $\left.\mathrm{e}^{\prime}\right), 1.63-1.50(\mathrm{~m}, 1 \mathrm{H}$, f), $1.49-1.40\left(\mathrm{~m}, 1 \mathrm{H}, \mathrm{f}^{\prime}\right), 1.40-1.27\left(\mathrm{~m}, 2 \mathrm{H}, \mathrm{g}\right.$ and $\left.\mathrm{g}^{\prime}\right) .{ }^{13} \mathrm{C}$ NMR $\left(150 \mathrm{MHz}\right.$, THF- $\left.d_{8}\right) \delta 176.5(\mathrm{H}), 132.6$ (A), 128.4 (B), 46.1 (C), 36.1 (D), 33.3 (E), 32.0 (F), 28.0 (G). Assignments were confirmed as above for P1" by a combination of HSQC, HMBC, and COSY (see Supplementary Figures S76-S78). The additional protons ( $\mathrm{g}$ and $\mathrm{g}^{\prime}$ ) and carbon $(\mathrm{G})$ present in P2" were assigned as follows: protons " $\mathrm{g}$ " and " $\mathrm{g}$ "' at 1.40-1.27 ppm are attached to carbon "G" at $28.0 \mathrm{ppm}$ and show HMBC correlation to carbons "F" and "E" at $32.0 \mathrm{ppm}$ and $33.3 \mathrm{ppm}$ respectively.

$\underline{\text { General Protocol for the Collection of Conversion and Kinetics Data }}$

Polymerization: Conversion was monitored by ${ }^{1} \mathrm{H}$ NMR as follows: resonances corresponding to protons "a" and "A" in 1 and P1, respectively, (Figure 2A in the manuscript) were integrated separately, and the total area of integration was set to 10.00 . The percent conversion was taken as the area of integration for P1 multiplied by 10. Comparison of the total integration of these resonances to the internal standard (1bromo-3,5-bis(trifluoromethyl)benzene) was unchanged between the beginning and end of the polymerization (Supplementary Figure S79).

Ireland-Claisen rearrangement: Conversion was calculated by dividing the starting polymer resonance at the end of the reaction to the same resonance before the start of the reaction. The internal standard (1,3,5-tri-tert-butylbenzene) resonance at $7.28 \mathrm{ppm}$ was integrated as set equal to 1.00 . The starting material and product resonances were then integrated relative to the standard.

Kinetic Analysis of the Ireland-Claisen rearrangement of P1 and P2 to P1' and P2'.

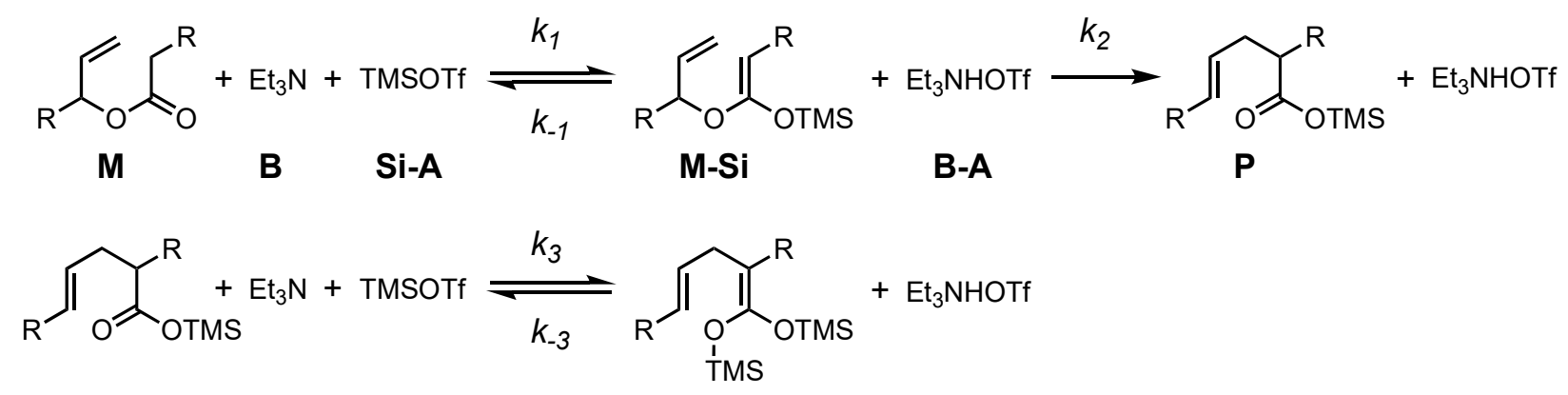

rate $=-\frac{\partial[\mathbf{M}]}{\partial t}=k_{1}[\mathbf{M}][\mathbf{B}][\mathbf{S i}-\mathbf{A}]-k_{-1}[\mathbf{M}-\mathbf{S i}][\mathbf{B}-\mathbf{A}]$ 
Until we get to high conversions, we can ignore the second equilibrium process. Thus, the analysis below will hold only until we reach sufficiently high conversions. Furthermore, we never observe accumulation of [M-Si]. Therefore, we can assume steady - state of [M-Si], which implies the following:

$-\frac{\partial([\mathbf{M}-\mathbf{S i}])}{\partial t}=0=k_{2}[\mathbf{M}-\mathbf{S i}]-k_{1}[\mathbf{M}][\mathbf{B}][\mathbf{S i}-\mathbf{A}]+k_{-1}[\mathbf{M}-\mathbf{S i}][\mathbf{B}-\mathbf{A}]$

Because $\mathbf{M}, \mathbf{B}$, and $\mathbf{S i}-\mathbf{A}$ are consumed in a 1:1:1 fashion, and initial concentrations of $\mathbf{M}, \mathbf{B}$, and $\mathbf{S i}-\mathbf{A}$ are approximately the same, we get $[\mathbf{M}] \approx[\mathbf{B}] \approx[\mathbf{S i}-\mathbf{A}]$.

$\therefore[\mathbf{M - S i}]=\frac{k_{1}[\mathbf{M}]^{3}}{k_{2}+k_{-1}\left([\mathbf{M}]_{0}-[\mathbf{M}]\right)}$,

and

$\therefore$ rate $=-\frac{\partial[\mathbf{M}]}{\partial t}=k_{1}[\mathbf{M}]^{3}-\frac{k_{-1} k_{1}[\mathbf{M}]^{3}\left([\mathbf{M}]_{\circ}-[\mathbf{M}]\right)}{k_{2}+k_{-1}\left([\mathbf{M}]_{\circ}-[\mathbf{M}]\right)}=\frac{k_{1} k_{2}[\mathbf{M}]^{3}}{k_{2}+k_{-1}\left([\mathbf{M}]_{\circ}-[\mathbf{M}]\right)}$

Because the rearrangement is rate-limiting, $k_{2} \ll k_{-1}$, and we expect that at intermediate to high conversions $k_{2} \ll k_{-1}\left([\mathbf{M}]_{\circ}-[\mathbf{M}]\right)$. For this regime, we have

rate $=-\frac{\partial[\mathbf{M}]}{\partial t}=k_{o b s}[\mathbf{M}]^{3}$, where $k_{o b s}=\frac{k_{1} k_{2}}{k_{-1}}$

Integration of this differential rate law yields the standard integrated rate law for $3^{\text {rd }}$-order kinetics:

$$
[\mathbf{M}]^{-2}=k_{o b s} \cdot t+[\mathbf{M}]_{0}^{-2}
$$

Note that in the regime where $k_{2} \ll k_{-1}\left([\mathbf{M}]_{\circ}-[\mathbf{M}]\right)$ does not hold, integration gives a mixed-order rate law:

$\frac{k_{-1} k_{2}^{-1}[\mathbf{M}]_{\circ}+1}{2[\mathbf{M}]_{\circ}}[\mathbf{M}]^{-2}+\frac{1}{[\mathbf{M}]_{\circ}^{2}}[\mathbf{M}]^{-1}+\frac{1}{[\mathbf{M}]_{\circ}^{3}} \ln \frac{[\mathbf{M}]_{\circ}-[\mathbf{M}]}{[\mathbf{M}]}=k_{1} t+C$

However, this low-conversion regime was not probed in our study, and (7) has a logarithmic term that diverges at low and high conversions, so we use (6) to fit our data. 
Table S1. Lactone ring-opening transesterification polymerization (ROTEP) studies.<smiles>C=CC1CCCCC1COC(=O)O</smiles>

m

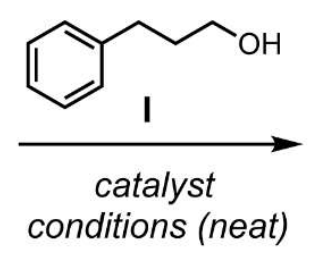

conditions (neat)<smiles>C=CC(CCCC(=O)OCCCc1ccccc1)C(C)OC(C)C</smiles>

Pm

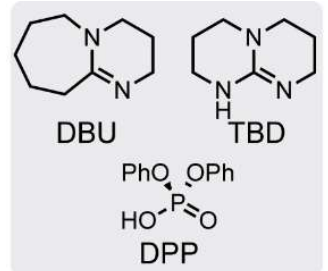

Entry \# Mon. Cat. Mon.:Cat.:I Temp. $I^{\circ} \mathrm{C}$ Time $/ \mathrm{h} \%$ Conv. $M_{\mathrm{n}}{ }^{\mathrm{d}} / \mathrm{kg}^{\circ} \mathrm{mol}^{-1}$ DP

\begin{tabular}{|c|c|c|c|c|c|c|c|c|c|}
\hline 1 & 1 & DBU & $100: 1: 1$ & 40 & 31.5 & $5.0^{\mathrm{a}}$ & -- & -- & -- \\
\hline 2 & 1 & TBD & $100: 1: 1$ & 40 & 31.5 & $0^{\mathrm{a}}$ & -- & -- & -- \\
\hline 3 & 1 & $\mathrm{Sn}(\mathrm{OTf})_{2}$ & 100:1:1 & 40 & 31.5 & $92.1^{\mathrm{b}}$ & 3.49 & 27 & 1.59 \\
\hline 4 & 1 & DPP & 100:1:1 & 40 & 51.5 & $82.4^{c}$ & 4.06 & 31 & 1.31 \\
\hline 5 & 1 & DPP & $100: 1: 1$ & 24 & 63.5 & $81.6^{c}$ & 4.00 & 31 & 1.35 \\
\hline $6^{f}$ & 1 & DPP & $100: 1: 1$ & 60 & 25.0 & $71.4(5)^{c}$ & 4.1(1) & $31(1)$ & $1.24(1)$ \\
\hline $7^{f}$ & 1 & DPP & $25: 1: 1$ & 60 & 5.0 & $77.1(6)^{c}$ & $2.3(2)$ & $16(2)$ & $1.35(5)$ \\
\hline $8^{f}$ & 1 & DPP & $50: 1: 1$ & 60 & 7.5 & $78.4(3)^{c}$ & $3.6(3)$ & $25(2)$ & $1.26(1)$ \\
\hline $9^{f}$ & 1 & DPP & $250: 1: 1$ & 60 & 60.0 & $69.3(8)^{c}$ & $4.9(5)$ & $37(3)$ & $1.34(9)$ \\
\hline $10^{f}$ & 1 & DPP & $500: 2: 1^{e}$ & 60 & 65.0 & $60(4)^{c}$ & $6.21(9)$ & $43(1)$ & $1.32(4)$ \\
\hline $11^{g}$ & 2 & DPP & $25: 1: 1$ & 60 & 7.5 & $74.2(9)^{c}$ & $2.4(5)$ & $20(0)$ & $1.3(1)$ \\
\hline $12^{f}$ & 2 & DPP & $50: 1: 1$ & 60 & 23.5 & $88(1)^{c}$ & $4.3(1)$ & $30(1)$ & $1.16(2)$ \\
\hline $13^{9}$ & 2 & DPP & 100:1:1 & 60 & 65.5 & $78(2)^{c}$ & $5.7(9)$ & $40(7)$ & $1.2(1)$ \\
\hline $14^{\mathrm{g}}$ & 2 & DPP & $250: 1: 1$ & 60 & 118.0 & $34(3)^{c}$ & $5.2(5)$ & $34(4)$ & $1.14(7)$ \\
\hline $15^{g}$ & 2 & DPP & $500: 2: 1^{\mathrm{e}}$ & 60 & 122.0 & $25(4)^{c}$ & $5.0(7)$ & $34(5)$ & $1.4(1)$ \\
\hline
\end{tabular}

a-cMonitored by ${ }^{1} \mathrm{H}$ NMR with internal standard $=$ (a) 1,3,5-trimethoxybenzene, (b) 1,3,5-tri-tert-butylbenzene, and (c) 1-bromo-3,5-bis(trifluoromethyl)benzene

${ }^{\mathrm{d}}$ Measured via GPC-MALS (THF, $35^{\circ} \mathrm{C}$ ), using $d \mathrm{n} / \mathrm{dc}=0.0771 \mathrm{~mL} \cdot \mathrm{g}^{-1}$ for 1 and $d \mathrm{n} / \mathrm{dc}=0.0775 \mathrm{~mL}^{\circ} \mathrm{g}^{-1}$ for 2

e1,4-phenylenedimethanol was used as the initiator instead of I

$\mathrm{f}, \mathrm{g}$ Reactions run in triplicate (f) and duplicate $(\mathrm{g})$; standard deviations shown in parentheses next to average value 


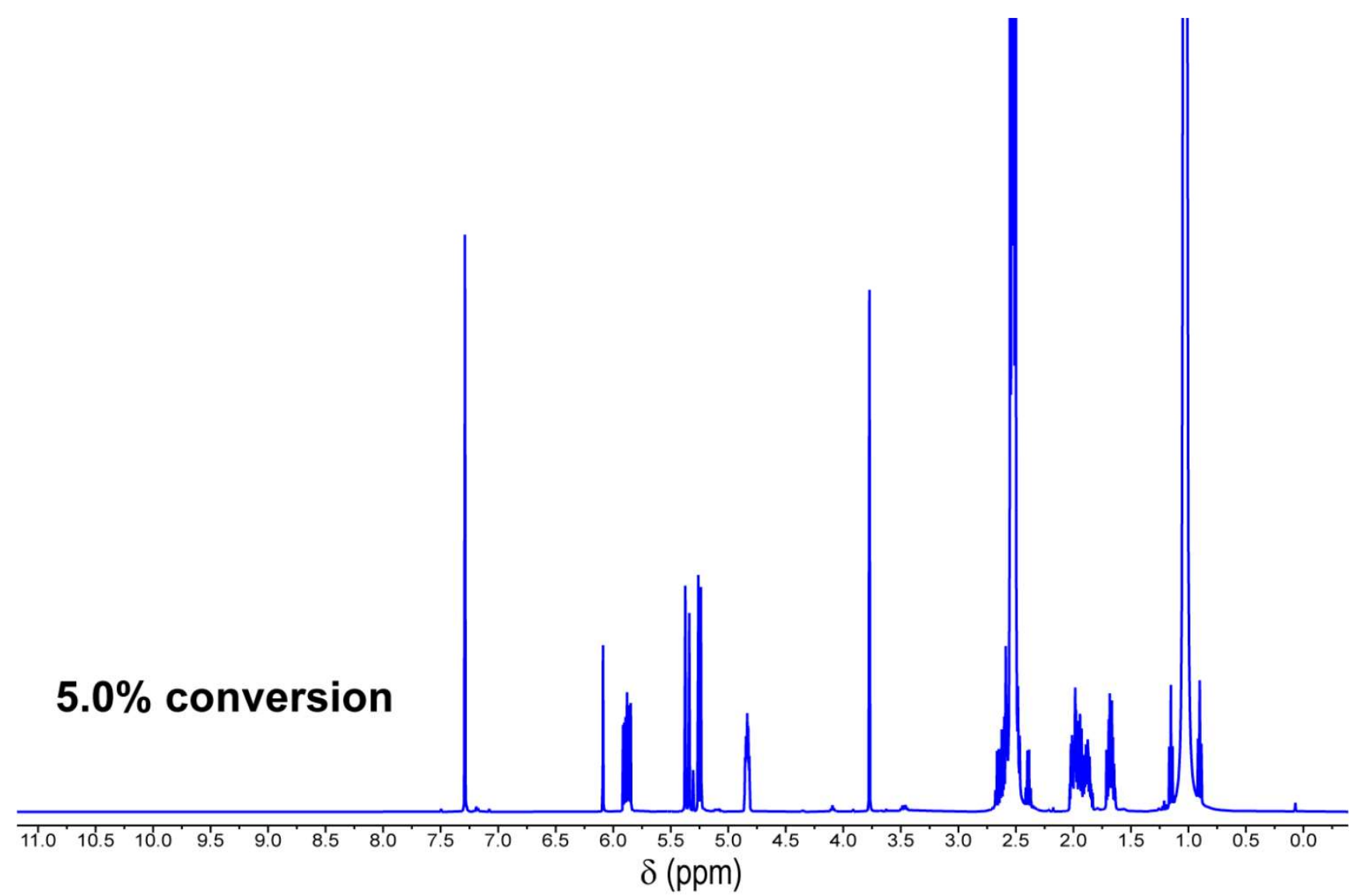

Figure S1. ${ }^{1} \mathrm{H} \mathrm{NMR}\left(500 \mathrm{MHz}, \mathrm{CDCl}_{3}, 23{ }^{\circ} \mathrm{C}\right)$ of the polymerization of 1 with DBU and 3-phenylpropan1 -ol at $40{ }^{\circ} \mathrm{C}$. 


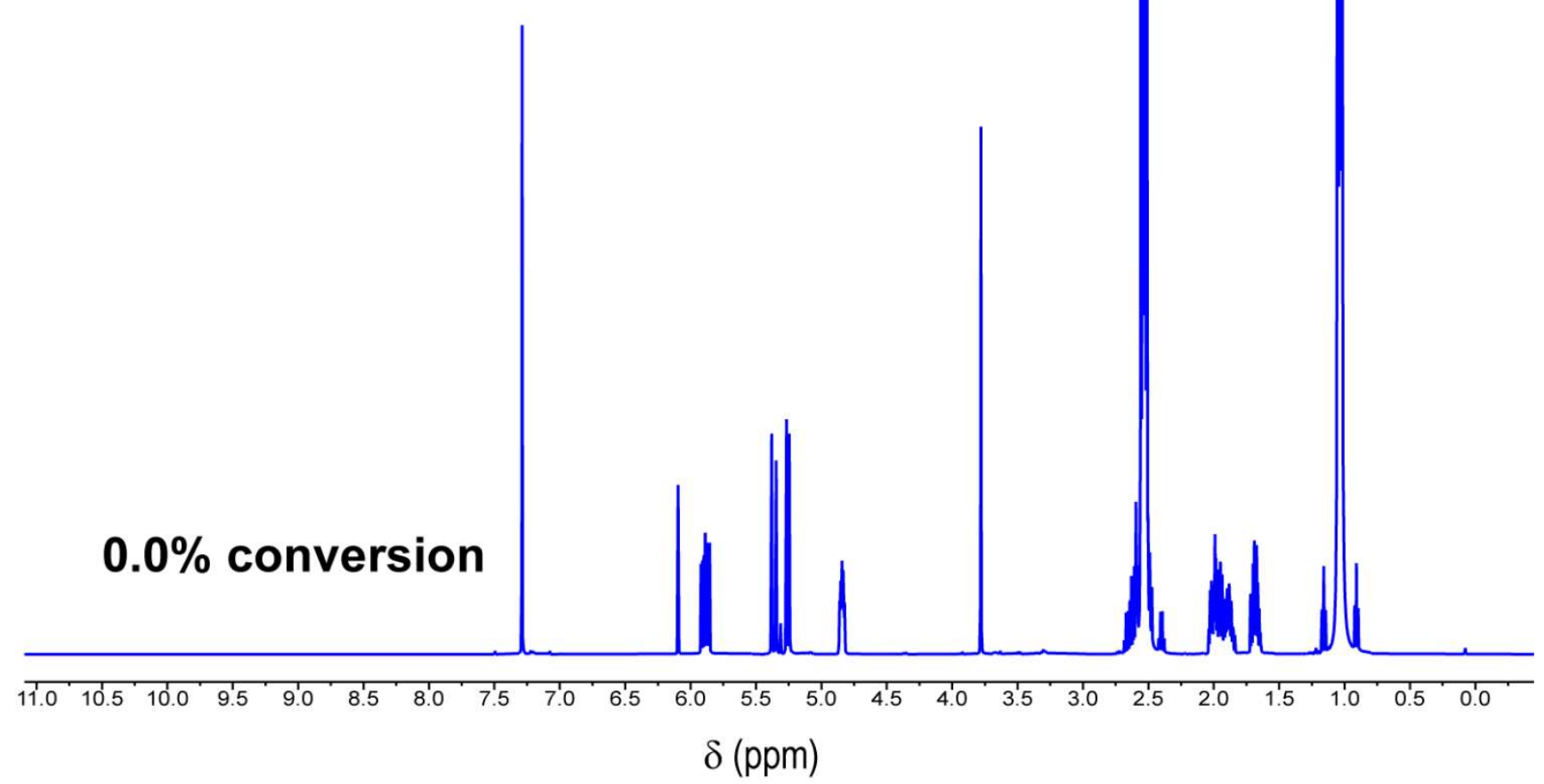

Figure S2. ${ }^{1} \mathrm{H} \mathrm{NMR}\left(500 \mathrm{MHz}, \mathrm{CDCl}_{3}, 23^{\circ} \mathrm{C}\right)$ of the polymerization of 1 with TBD and 3-phenylpropan1 -ol at $40{ }^{\circ} \mathrm{C}$. 


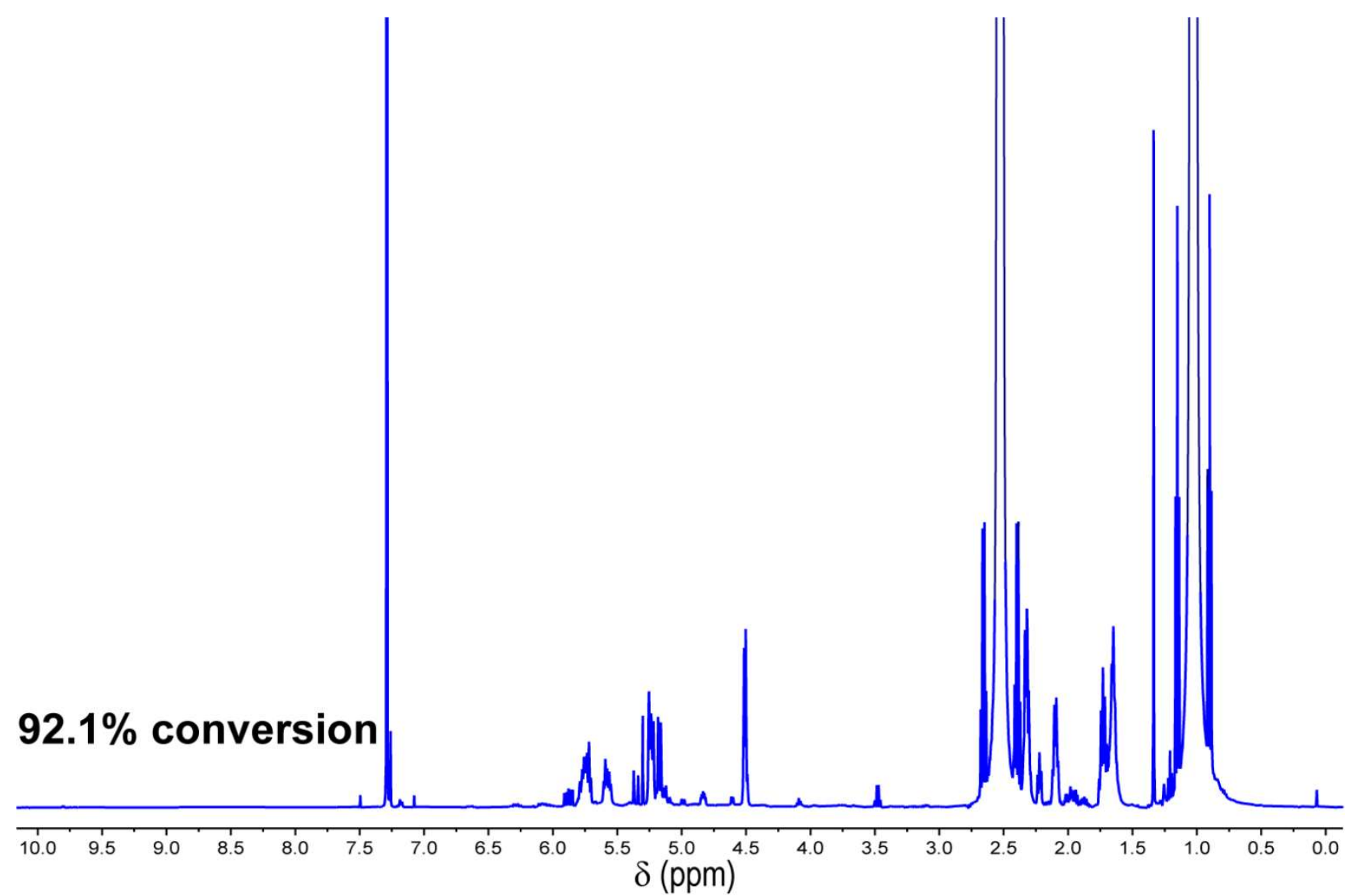

Figure S3. ${ }^{1} \mathrm{H}$ NMR $\left(500 \mathrm{MHz}, \mathrm{CDCl}_{3}, 23{ }^{\circ} \mathrm{C}\right)$ of the polymerization of 1 with $\mathrm{Sn}(\mathrm{OTf})_{2}$ and 3phenylpropan-1-ol at $40{ }^{\circ} \mathrm{C}$. 


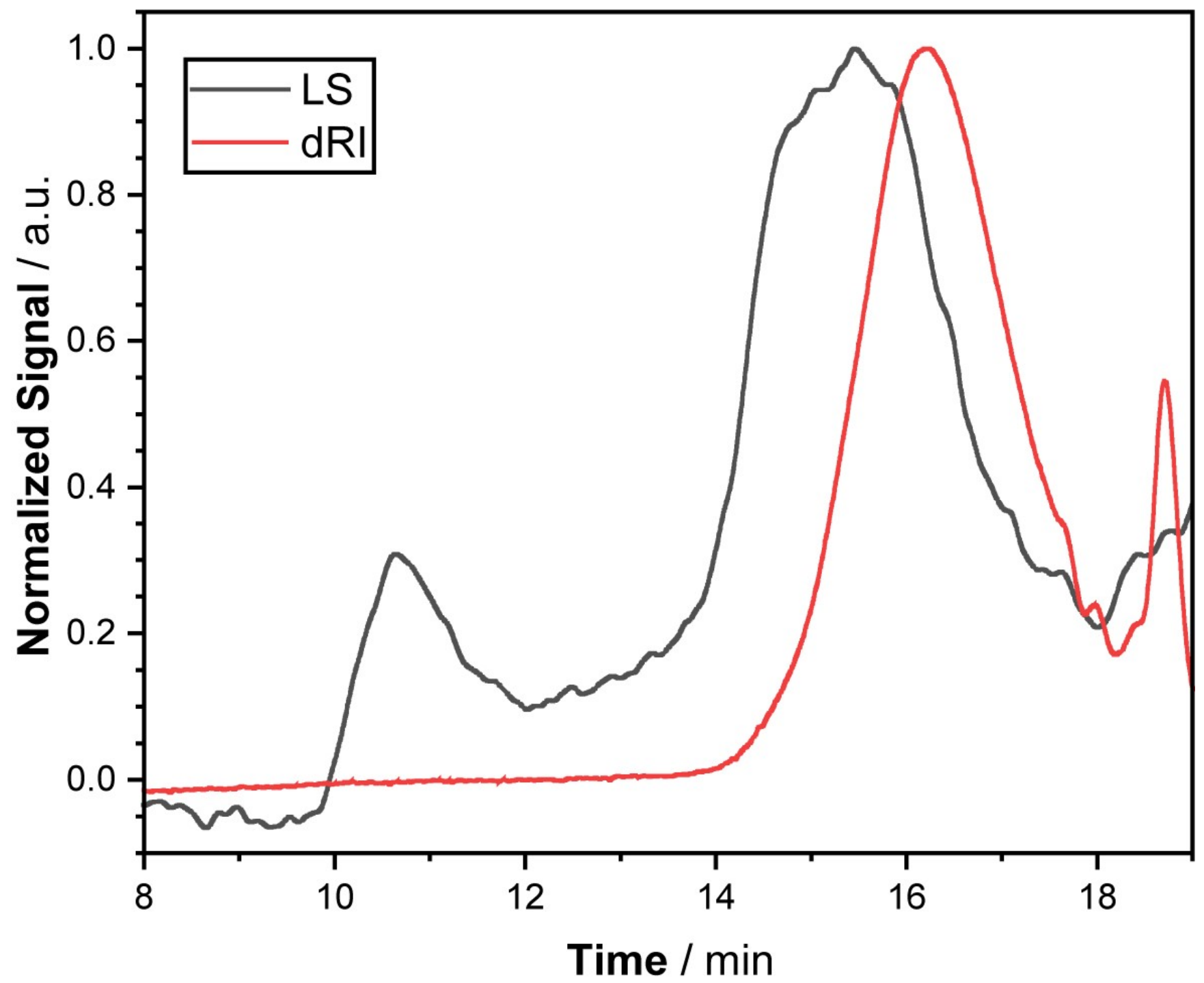

Figure S4. Normalized GPC-MALS differential refractive index (dRI) and light scattering (LS) traces of the polymerization of 1 with $\mathrm{Sn}(\mathrm{OTf})_{2}$ and 3-phenylpropan-1-ol at $40{ }^{\circ} \mathrm{C}$ with a [M]:[I]:[C] ratio of 100:1:1. 


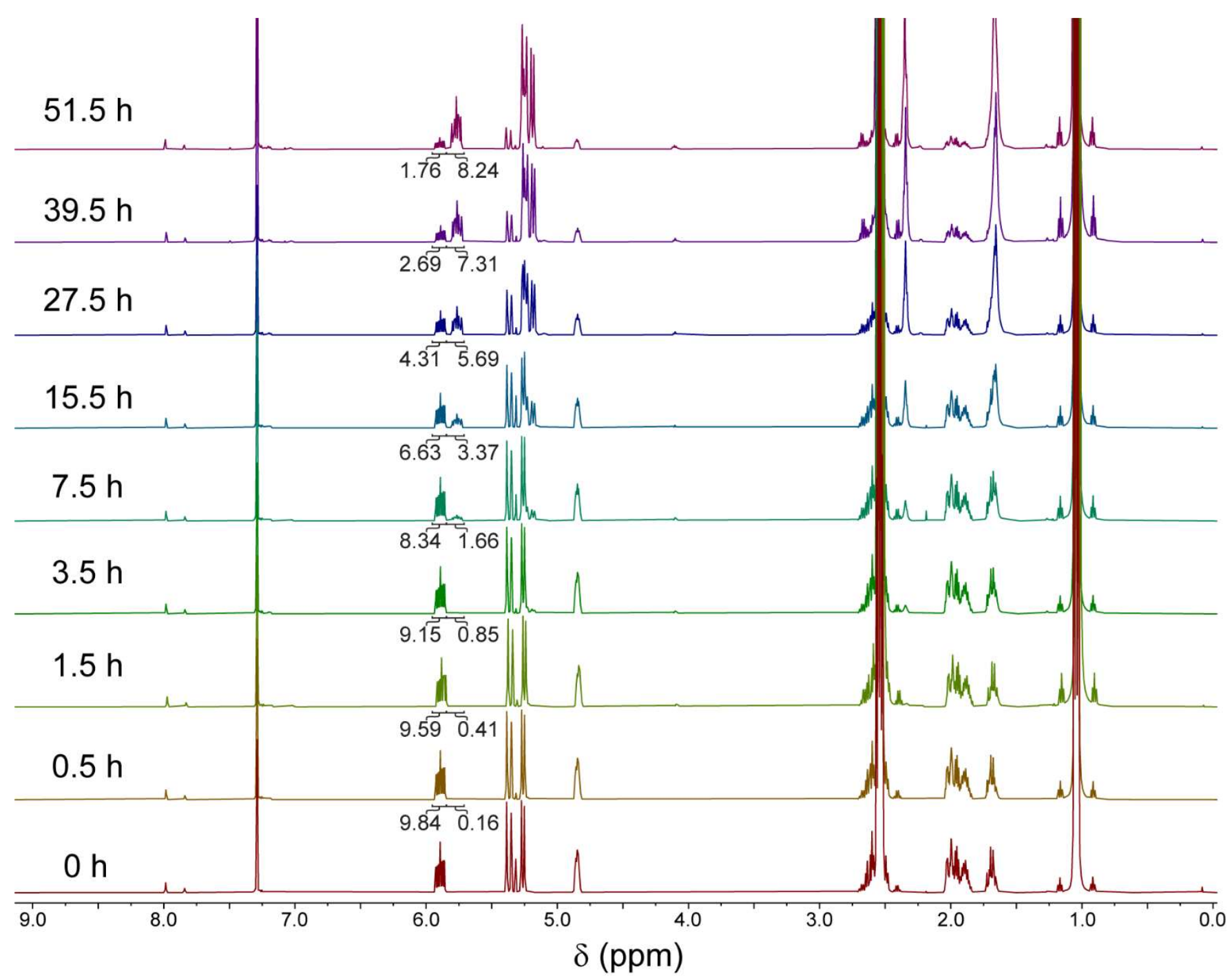

Figure S5. ${ }^{1} \mathrm{H}$ NMR $\left(500 \mathrm{MHz}, \mathrm{CDCl}_{3}, 23{ }^{\circ} \mathrm{C}\right)$ at various times throughout the polymerization of 1 with DPP and 3-phenylpropan-1-ol at $40{ }^{\circ} \mathrm{C}$. 

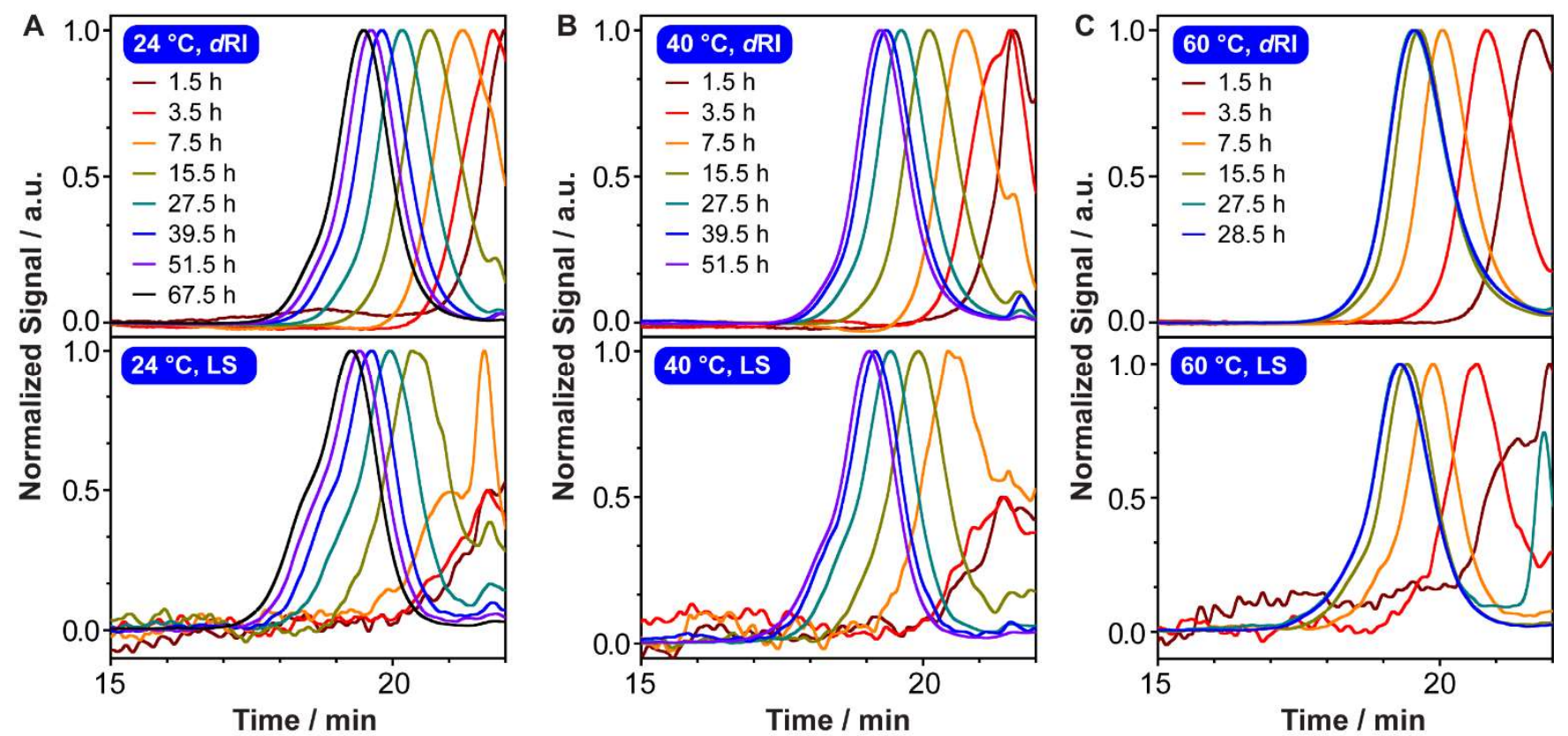

Figure S6. Refractive index and light scattering traces obtained from the polymerization of 1 with DPP and 3-phenol-1-propanol at $24{ }^{\circ} \mathrm{C}(\mathrm{A}), 40^{\circ} \mathrm{C}(\mathrm{B})$, and $60^{\circ} \mathrm{C}(\mathrm{C})$. 


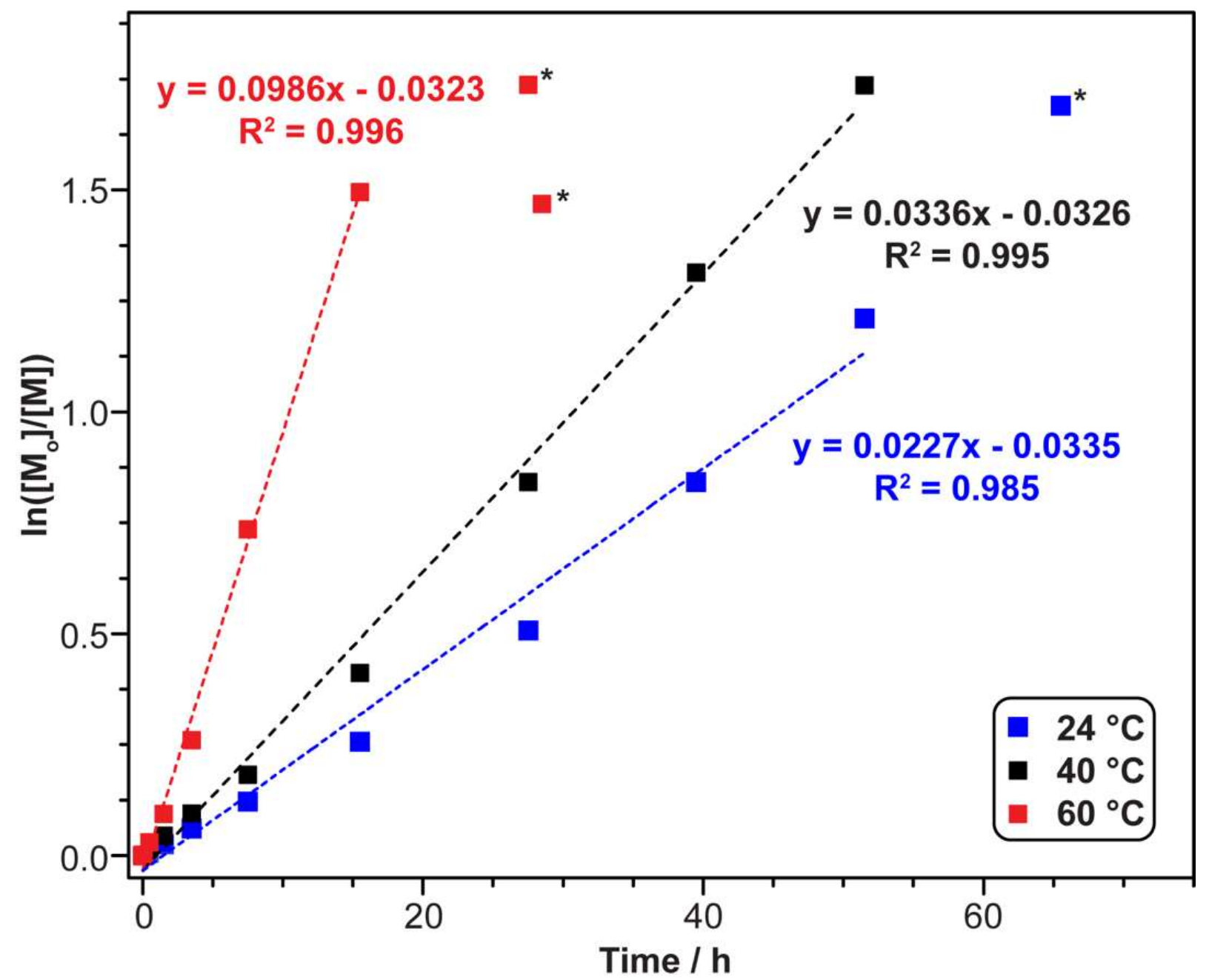

Figure S7. Semilogarithmic kinetic plots for the polymerization of 1 with DPP and 3-phenylpropan-1-ol at $24{ }^{\circ} \mathrm{C}, 40{ }^{\circ} \mathrm{C}$, and $60^{\circ} \mathrm{C}$. ${ }^{*}$ These data points toward the end of the polymerization deviated considerably from $1^{\text {st }}$-order kinetics because the polymerization reaches ring-chain equilibrium regime at that point. Because the reactions would no longer be expected to follow $1^{\text {st }}$-order kinetics then, we excluded these points from the corresponding linear fits. 


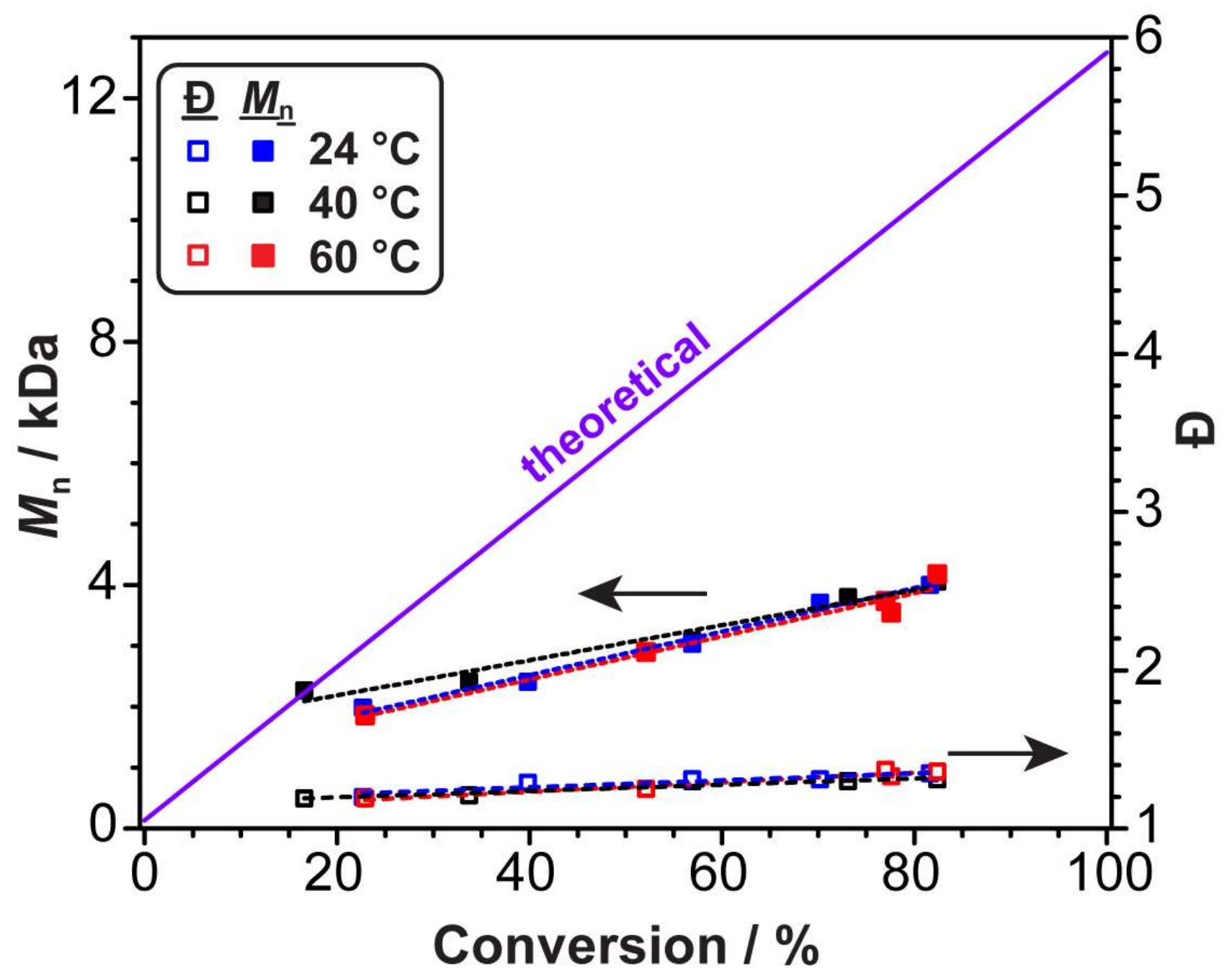

Figure S8. The dependence of $M_{\mathrm{n}}$ and $Đ$ on monomer conversion for the polymerization of 1 with DPP and 3-phenol-1-propanol at $24^{\circ} \mathrm{C}, 40{ }^{\circ} \mathrm{C}$, and $60^{\circ} \mathrm{C}$. 


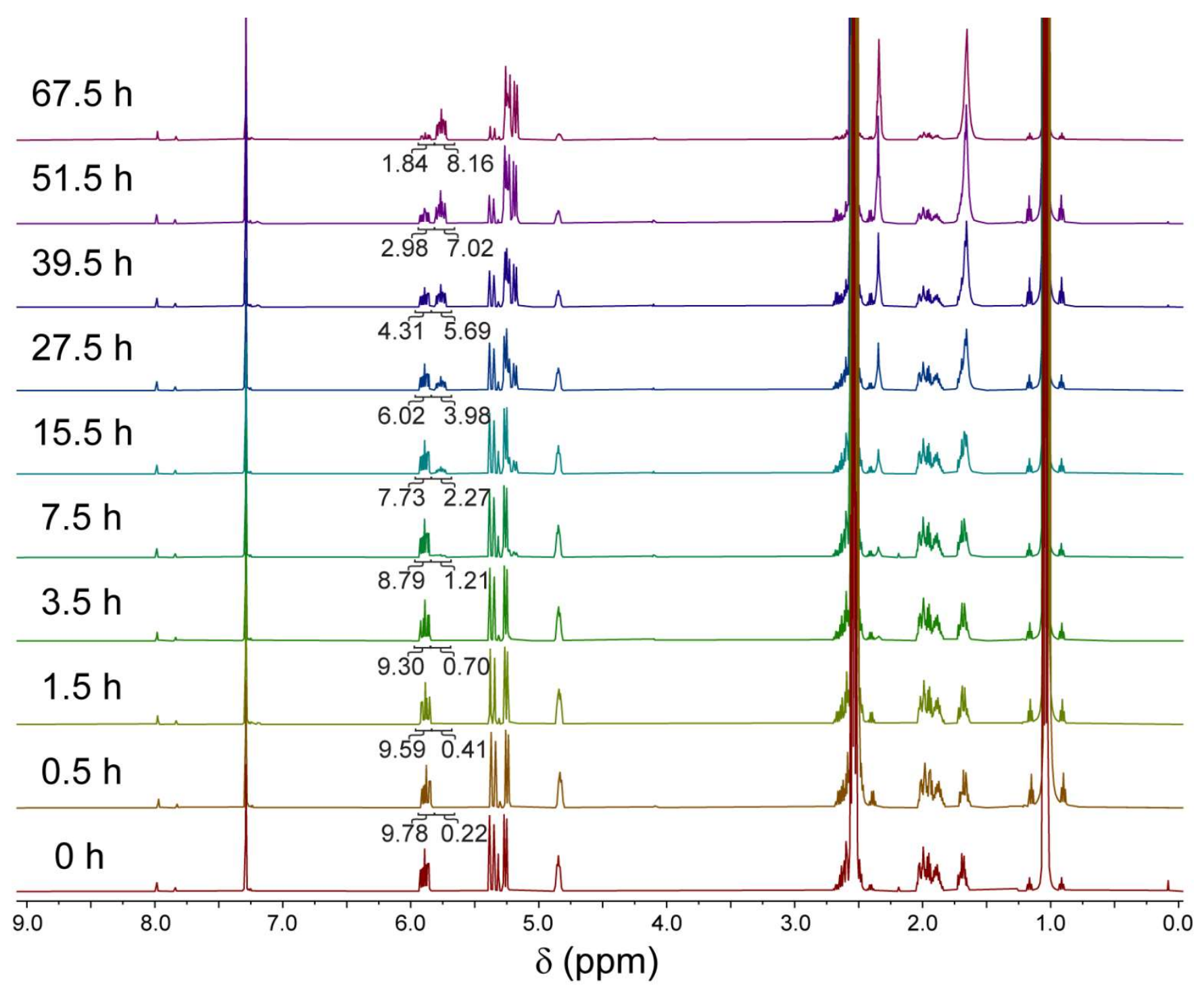

Figure S9. ${ }^{1} \mathrm{H} \mathrm{NMR}\left(500 \mathrm{MHz}, \mathrm{CDCl}_{3}, 23{ }^{\circ} \mathrm{C}\right)$ at various times throughout the polymerization of 1 with DPP and 3-phenylpropan-1-ol at $24{ }^{\circ} \mathrm{C}$. 


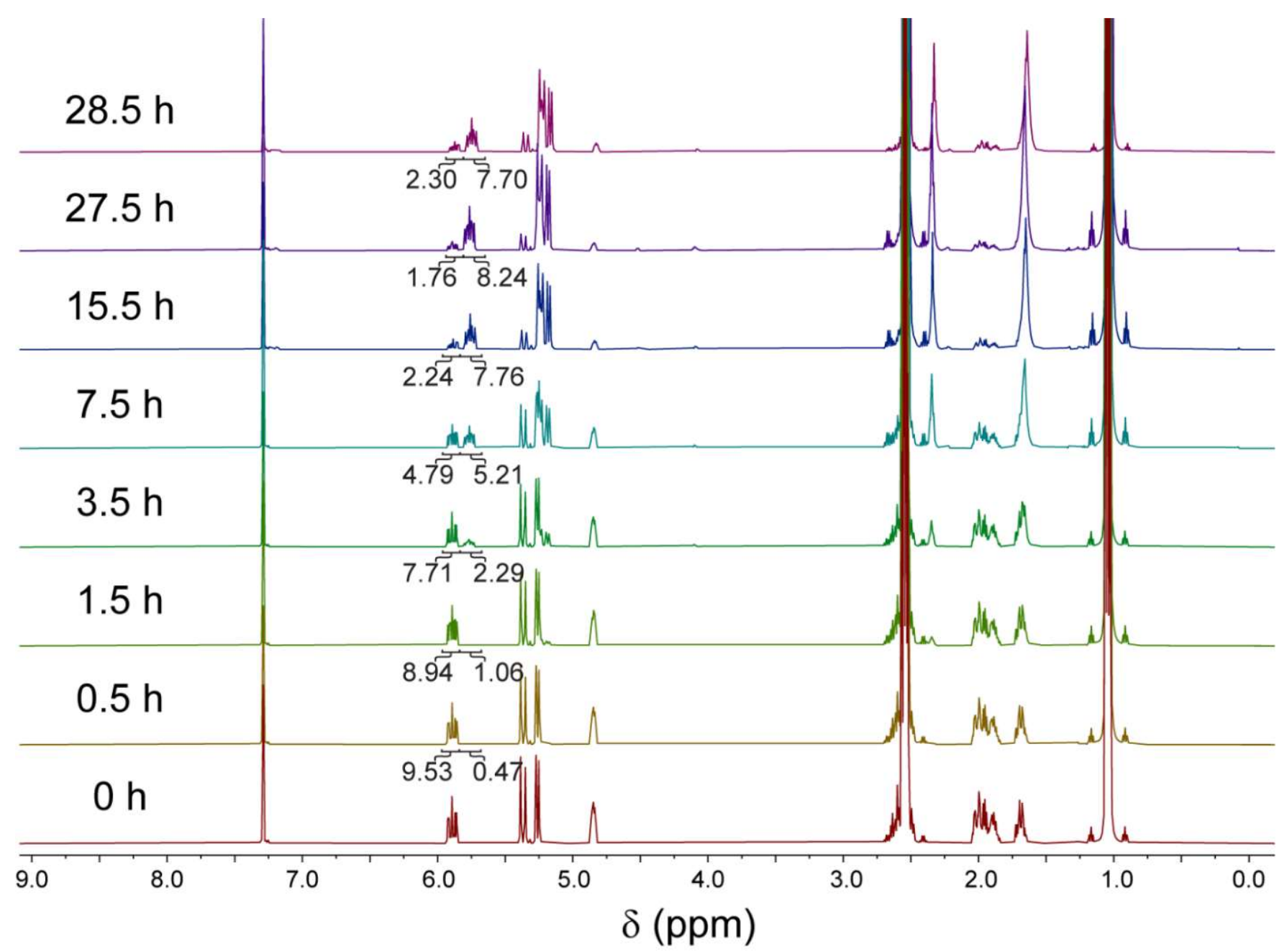

Figure S10. ${ }^{1} \mathrm{H}$ NMR $\left(500 \mathrm{MHz}, \mathrm{CDCl}_{3}, 23{ }^{\circ} \mathrm{C}\right)$ at various times throughout the polymerization of 1 with DPP and 3-phenylpropan-1-ol at $60{ }^{\circ} \mathrm{C}$. 


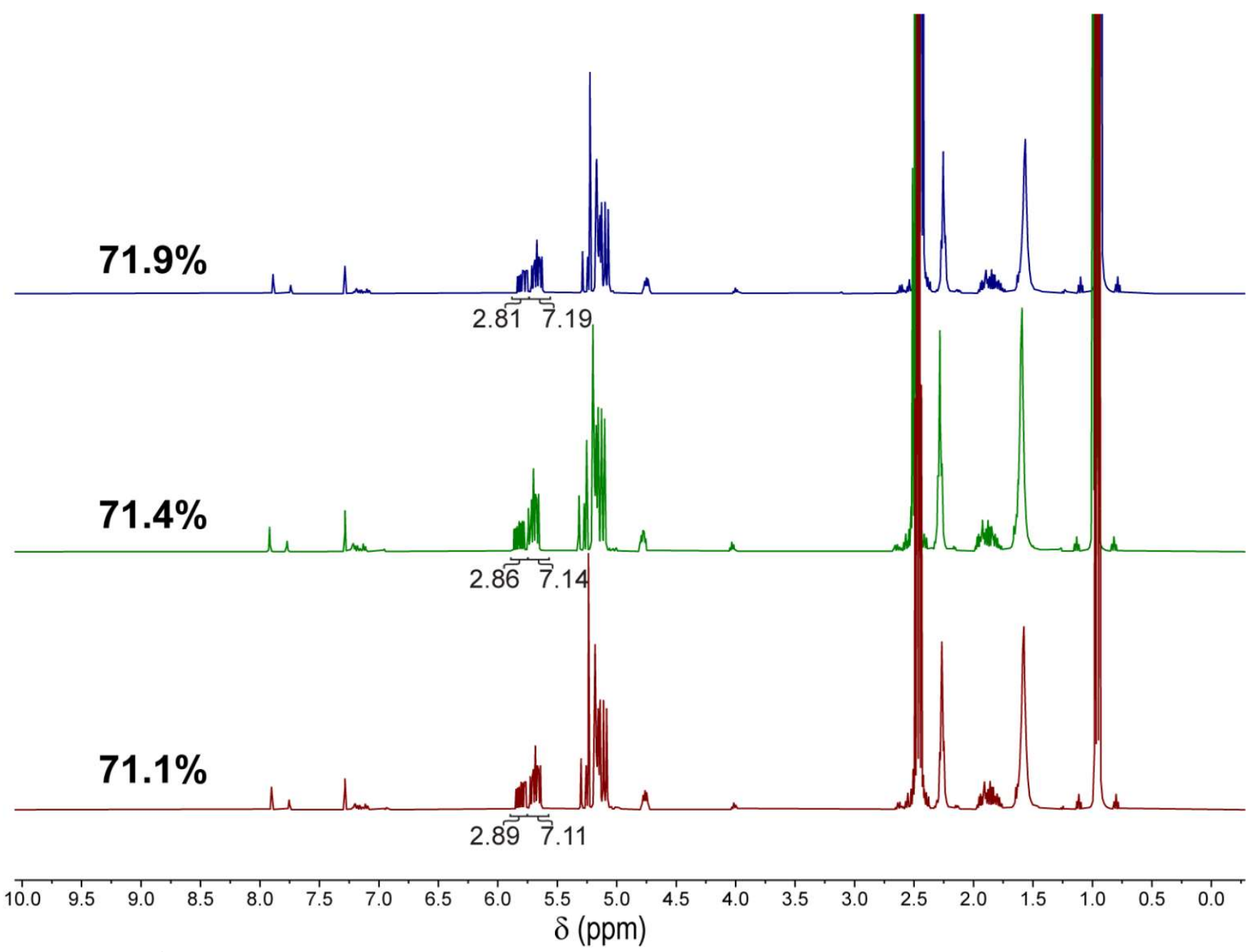

Figure S11. ${ }^{1} \mathrm{H}$ NMR $\left(500 \mathrm{MHz}, \mathrm{CDCl}_{3}, 23{ }^{\circ} \mathrm{C}\right)$ at the conclusion of the polymerizations of 1 with DPP and 3-phenylpropan-1-ol at $60^{\circ} \mathrm{C}$ with a [M]:[I]:[C] ratio of 100:1:1 in triplicate. 

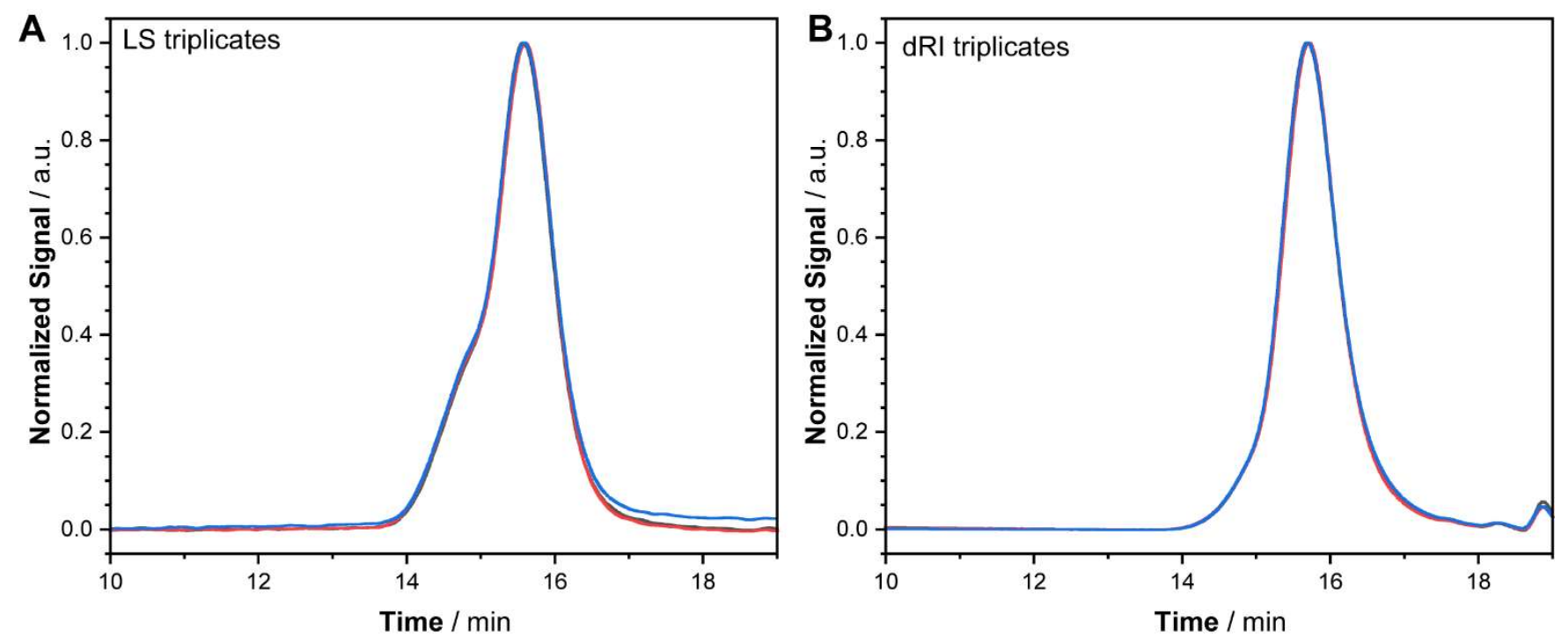

Figure S12. A.-B. Normalized GPC-MALS (A) light scattering (LS) and (B) differential refractive index (dRI) traces of the polymerization of 1 with DPP and 3-phenylpropan-1-ol at $60{ }^{\circ} \mathrm{C}$ with a [M]:[I]:[C] ratio of 100:1:1 in triplicate. 


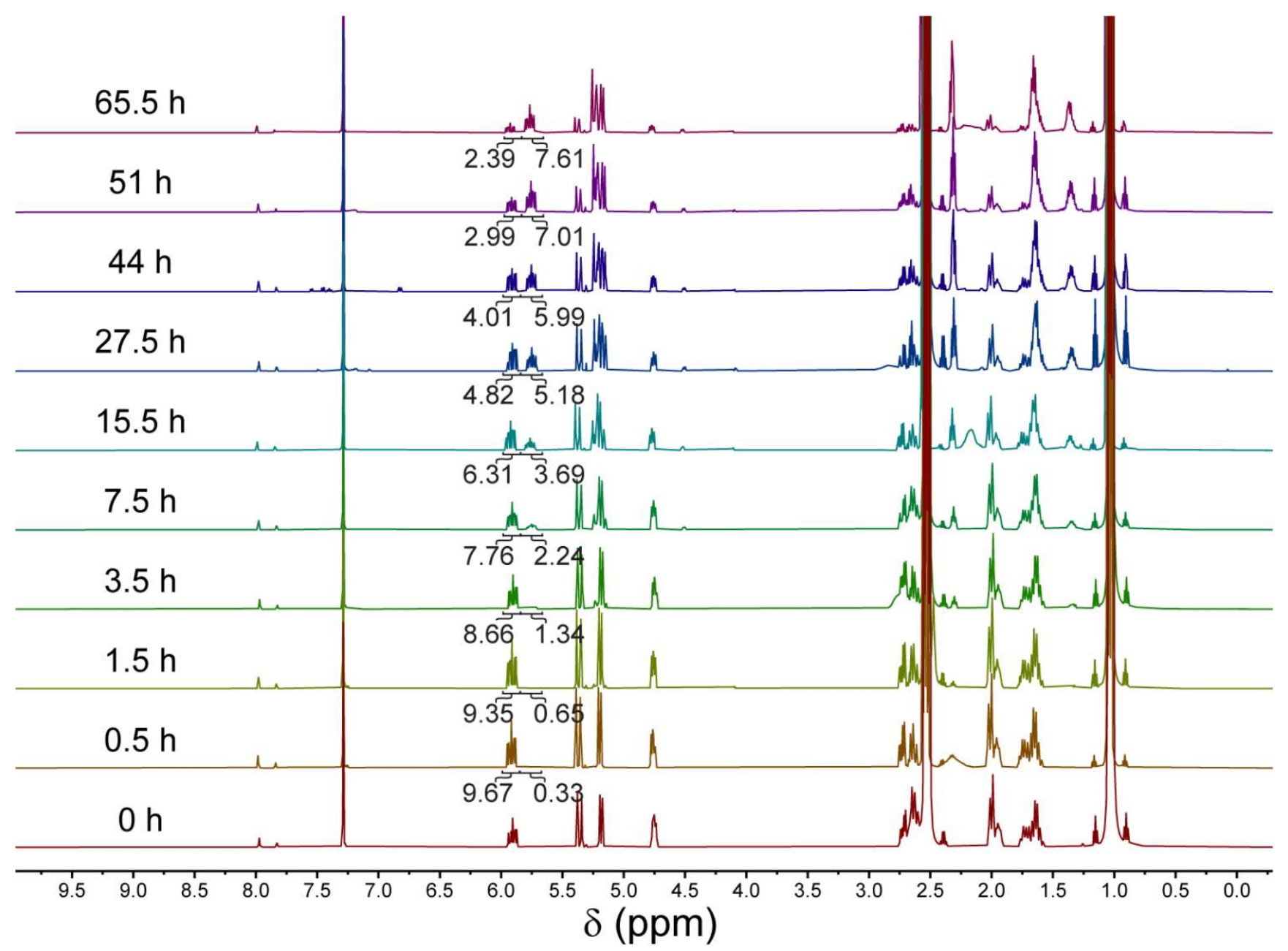

Figure S13. ${ }^{1} \mathrm{H}$ NMR $\left(500 \mathrm{MHz}, \mathrm{CDCl}_{3}, 23^{\circ} \mathrm{C}\right)$ at various times throughout the polymerization 2 with DPP and 3-phenylpropan-1-ol at $60{ }^{\circ} \mathrm{C}$ with a [M]:[I]:[C] ratio of 100:1:1. 

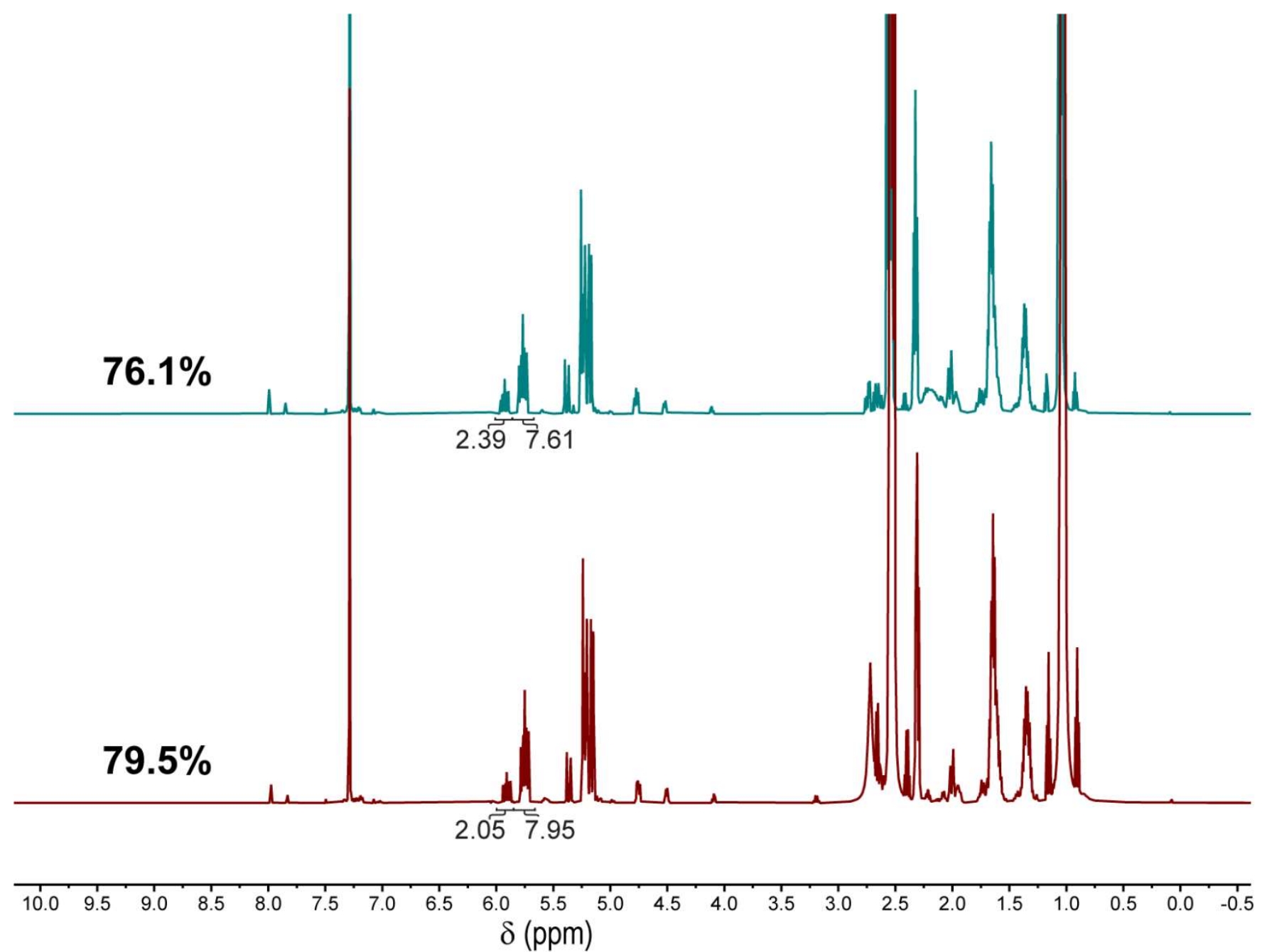

Figure S14. ${ }^{1} \mathrm{H}$ NMR $\left(500 \mathrm{MHz}, \mathrm{CDCl}_{3}, 23{ }^{\circ} \mathrm{C}\right)$ at the conclusion of the polymerizations of 2 with DPP and 3-phenylpropan-1-ol at $60^{\circ} \mathrm{C}$ with a [M]:[I]:[C] ratio of 100:1:1 in duplicate. 

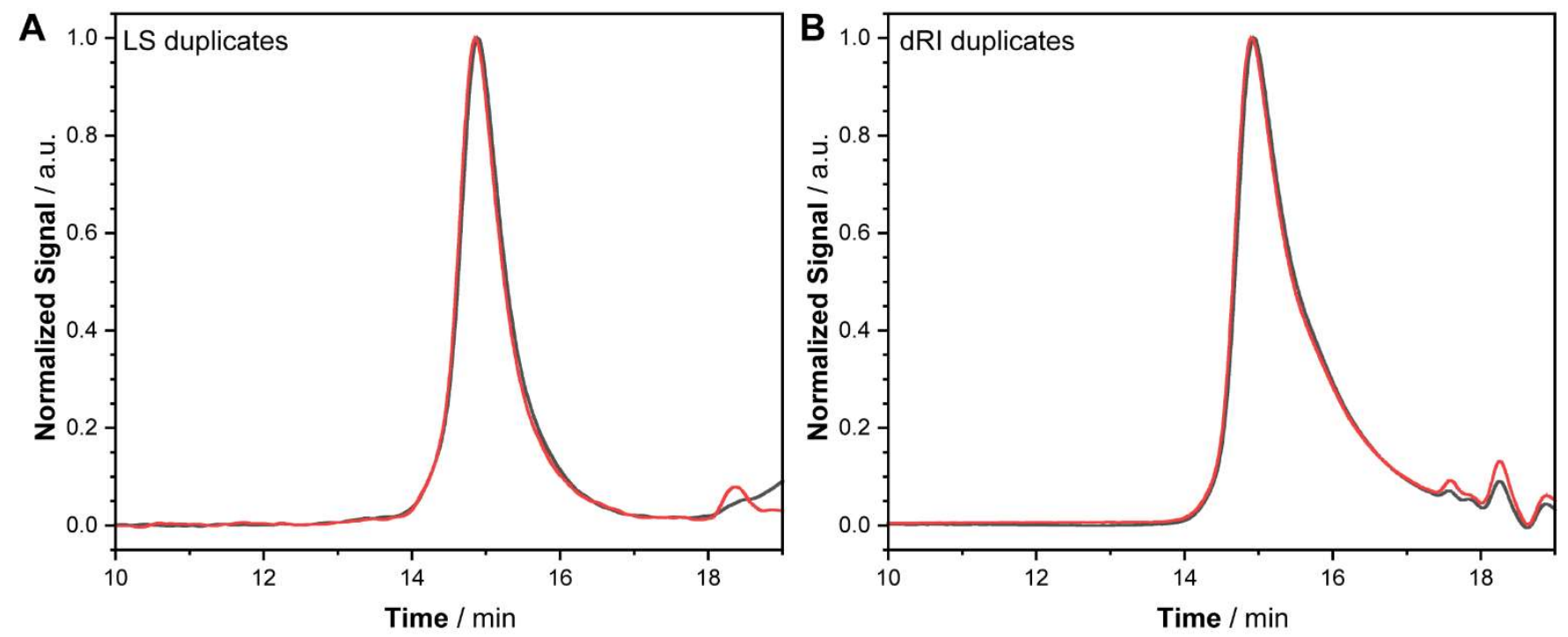

Figure S15. A.-B. Normalized GPC-MALS (A) light scattering (LS) and (B) differential refractive index (dRI) traces of the polymerization of 2 with DPP and 3-phenylpropan-1-ol at $60{ }^{\circ} \mathrm{C}$ with a [M]:[I]:[C] ratio of 100:1:1 in duplicate. 


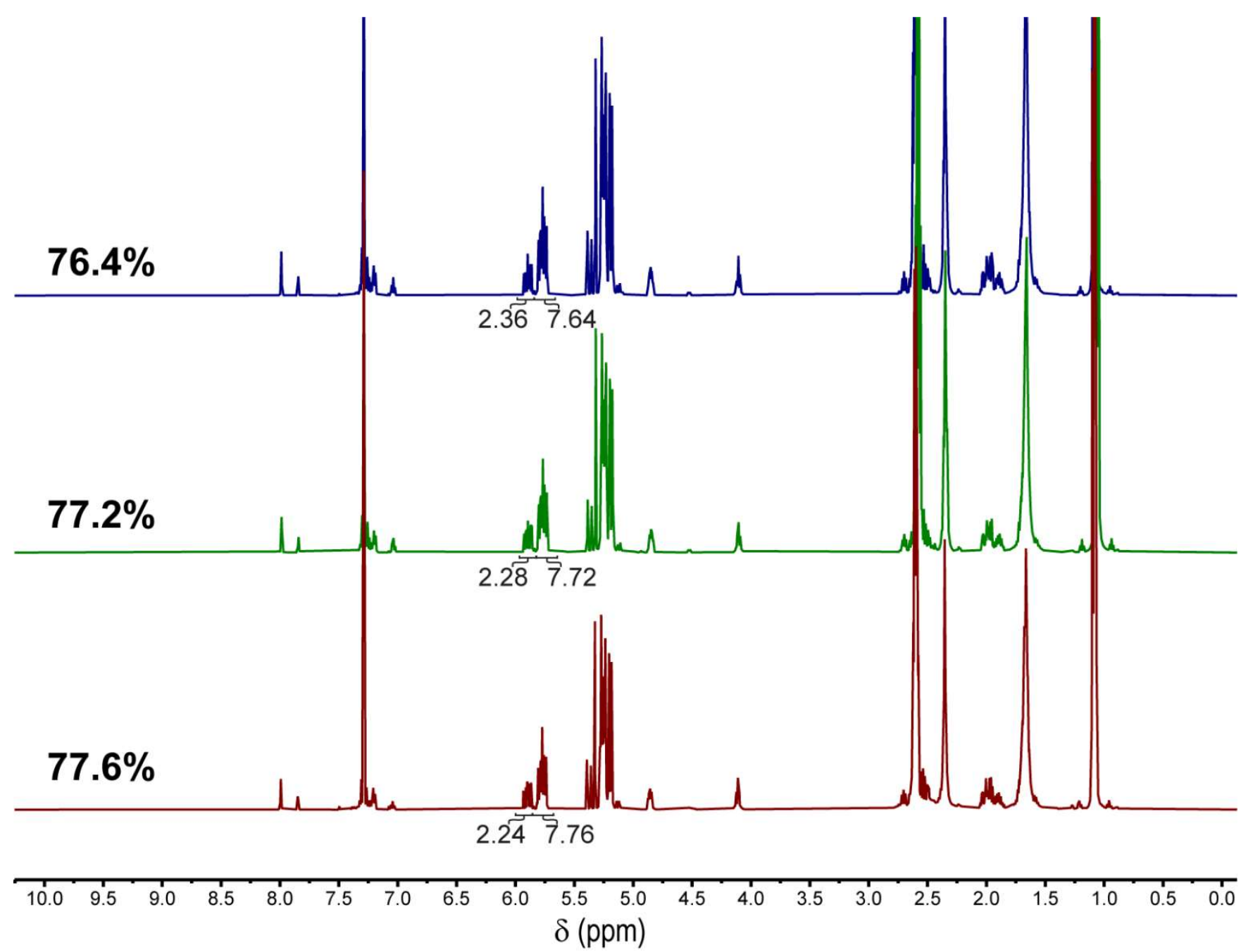

Figure S16. ${ }^{1} \mathrm{H} \mathrm{NMR}\left(500 \mathrm{MHz}, \mathrm{CDCl}_{3}, 23{ }^{\circ} \mathrm{C}\right)$ at the conclusion of the polymerizations of 1 with DPP and 3-phenylpropan-1-ol at $60^{\circ} \mathrm{C}$ with a [M]:[I]:[C] ratio of 25:1:1 in triplicate. 

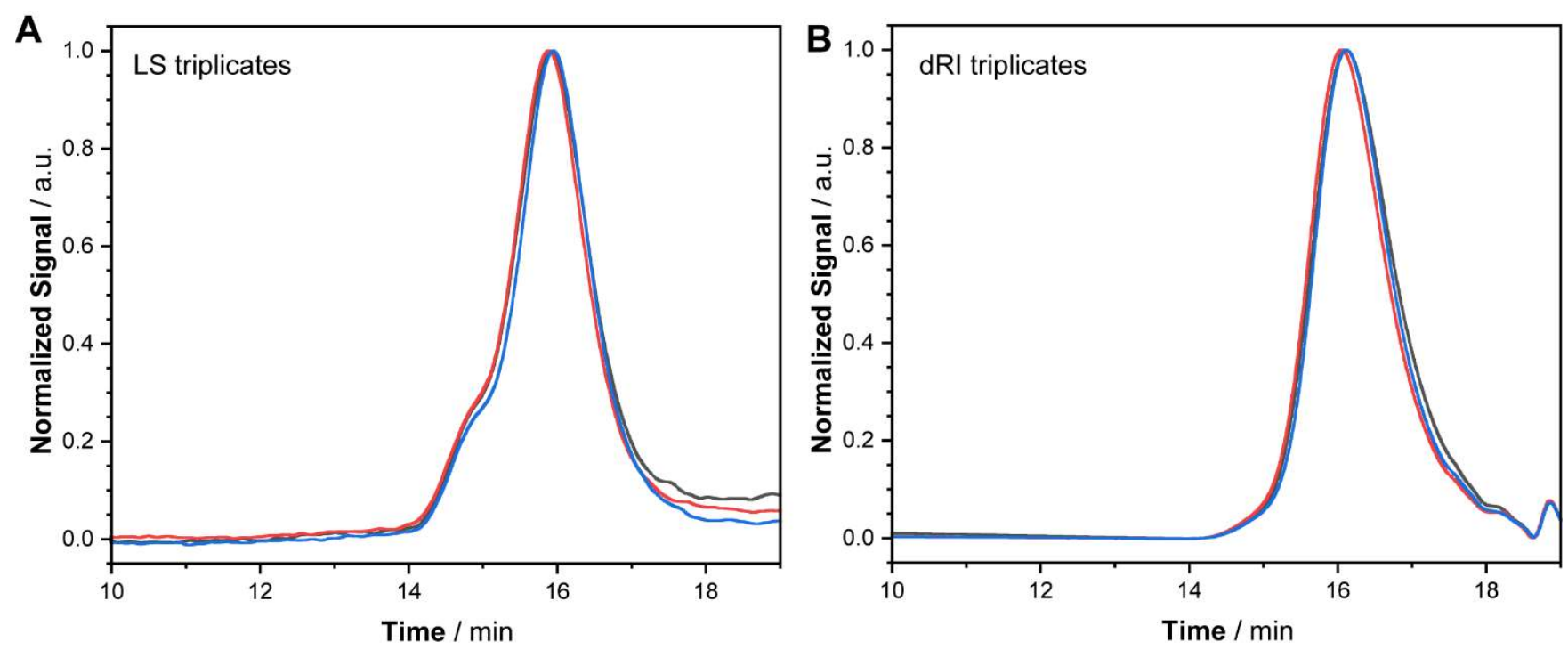

Figure S17. A.-B. Normalized GPC-MALS (A) light scattering (LS) and (B) differential refractive index (dRI) traces of the polymerization of 1 with DPP and 3-phenylpropan-1-ol at $60{ }^{\circ} \mathrm{C}$ with a [M]:[I]:[C] ratio of 25:1:1 in triplicate. 


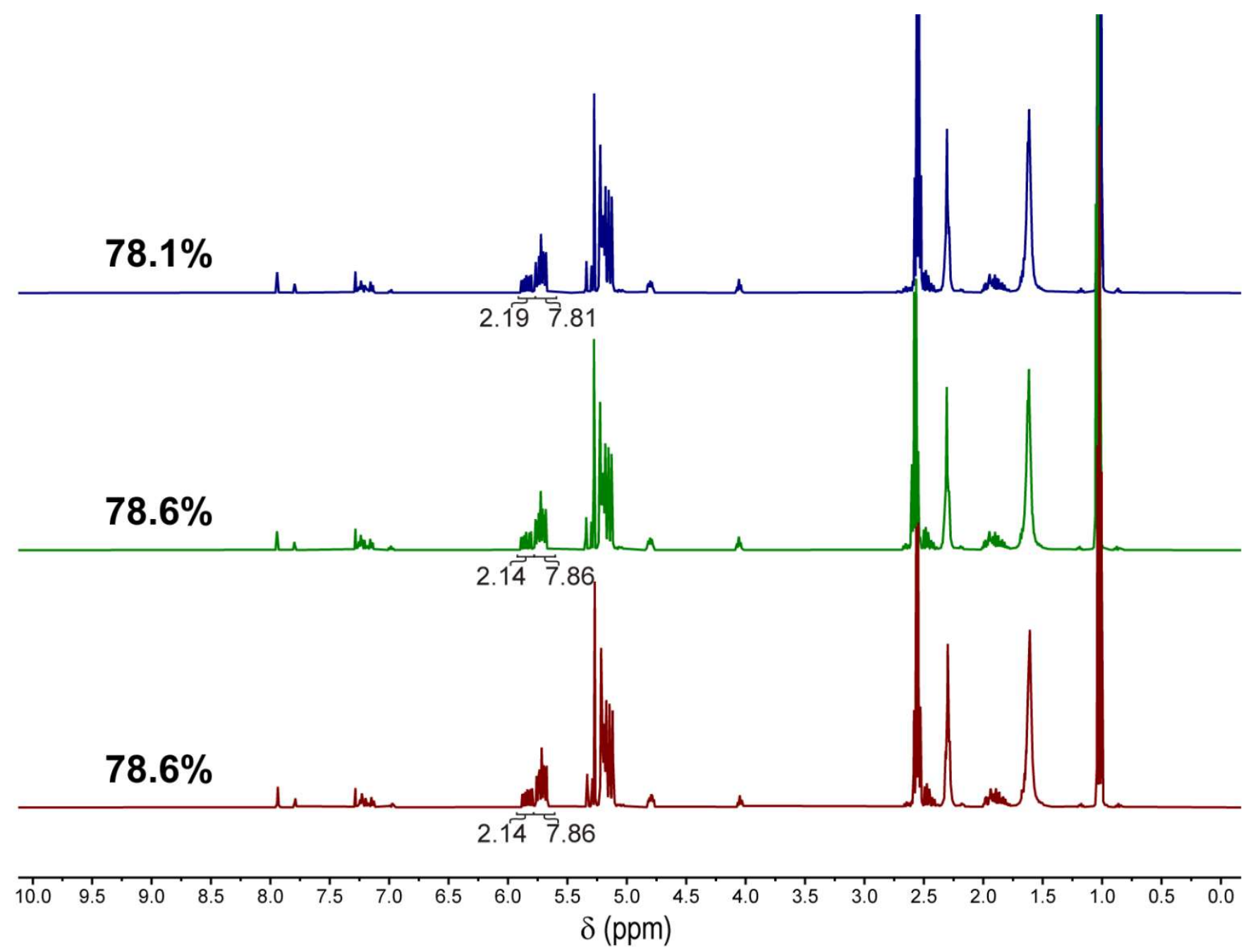

Figure S18. ${ }^{1} \mathrm{H} \mathrm{NMR}\left(500 \mathrm{MHz}, \mathrm{CDCl}_{3}, 23{ }^{\circ} \mathrm{C}\right)$ at the conclusion of the polymerizations of 1 with DPP and 3-phenylpropan-1-ol at $60^{\circ} \mathrm{C}$ with a [M]:[I]:[C] ratio of 50:1:1 in triplicate. 

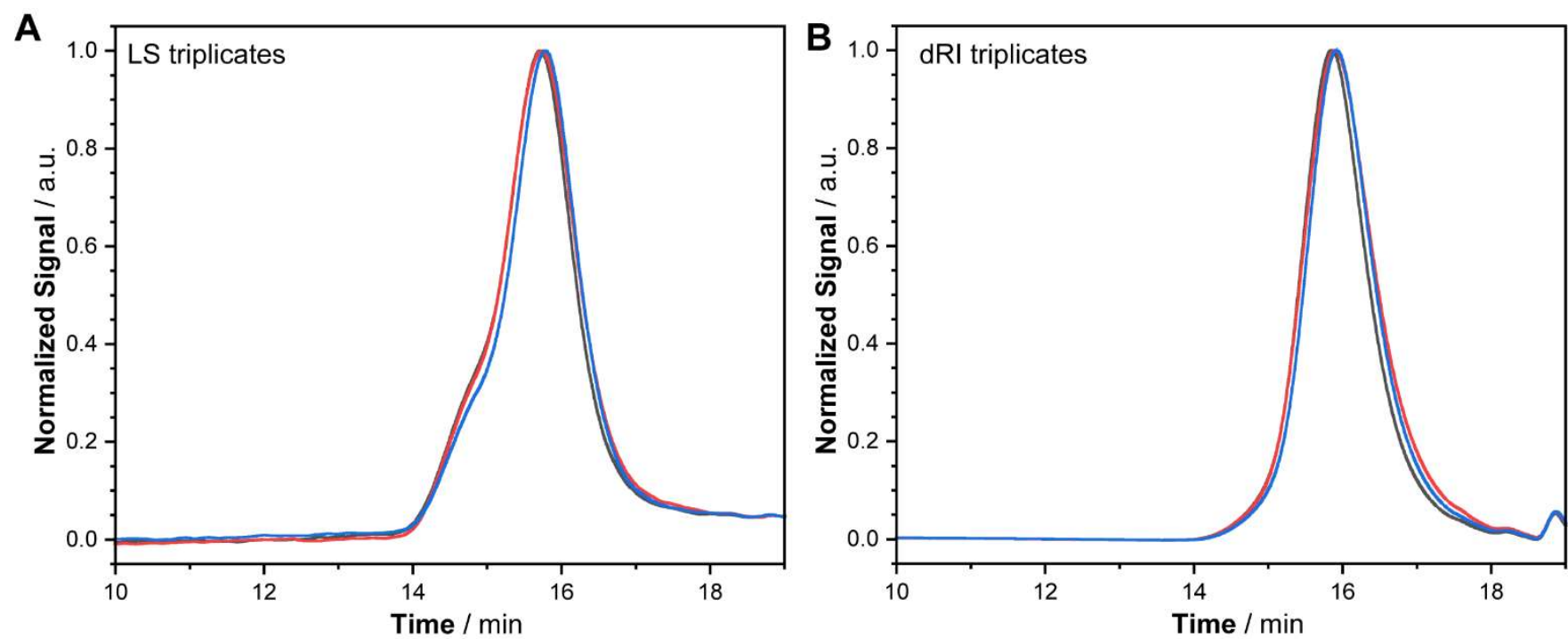

Figure S19. A.-B. Normalized GPC-MALS (A) light scattering (LS) and (B) differential refractive index (dRI) traces of the polymerization of 1 with DPP and 3-phenylpropan-1-ol at $60{ }^{\circ} \mathrm{C}$ with a [M]:[I]:[C] ratio of 50:1:1 in triplicate. 

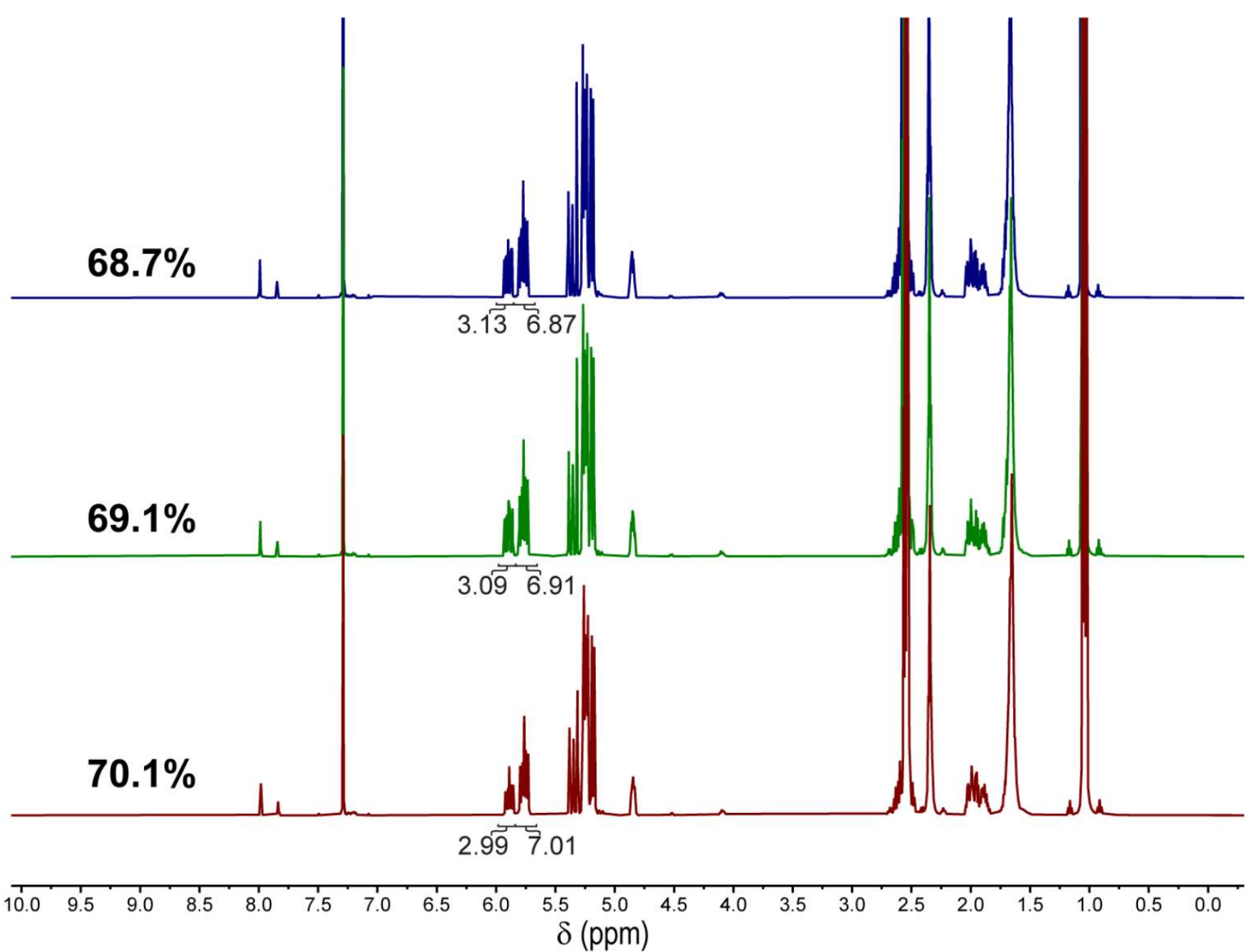

Figure S20. ${ }^{1} \mathrm{H} \mathrm{NMR}\left(500 \mathrm{MHz}, \mathrm{CDCl}_{3}, 23{ }^{\circ} \mathrm{C}\right)$ at the conclusion of the polymerizations of 1 with DPP and 3-phenylpropan-1-ol at $60^{\circ} \mathrm{C}$ with a [M]:[I]:[C] ratio of 250:1:1 in triplicate. 

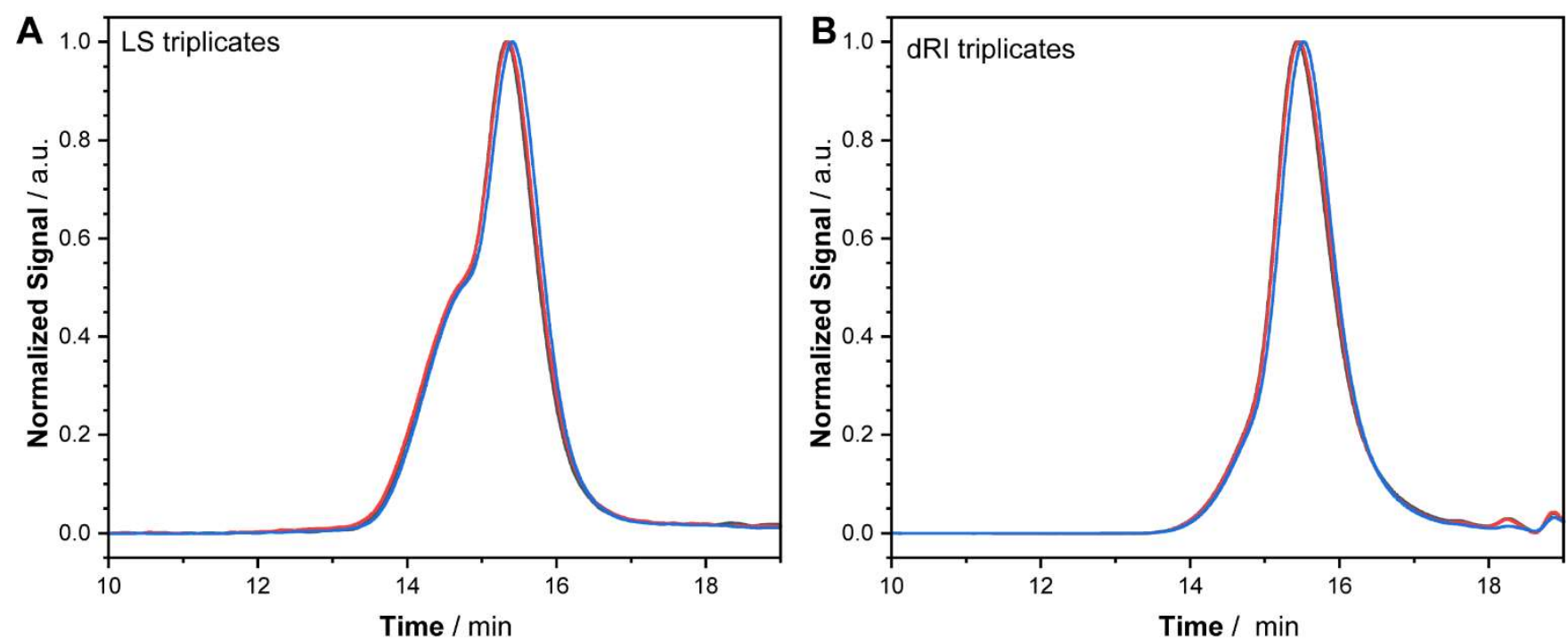

Figure S21. A.-B. Normalized GPC-MALS (A) light scattering (LS) and (B) differential refractive index (dRI) traces of the polymerization of 1 with DPP and 3-phenylpropan-1-ol at $60{ }^{\circ} \mathrm{C}$ with a [M]:[I]:[C] ratio of 250:1:1 in triplicate. 

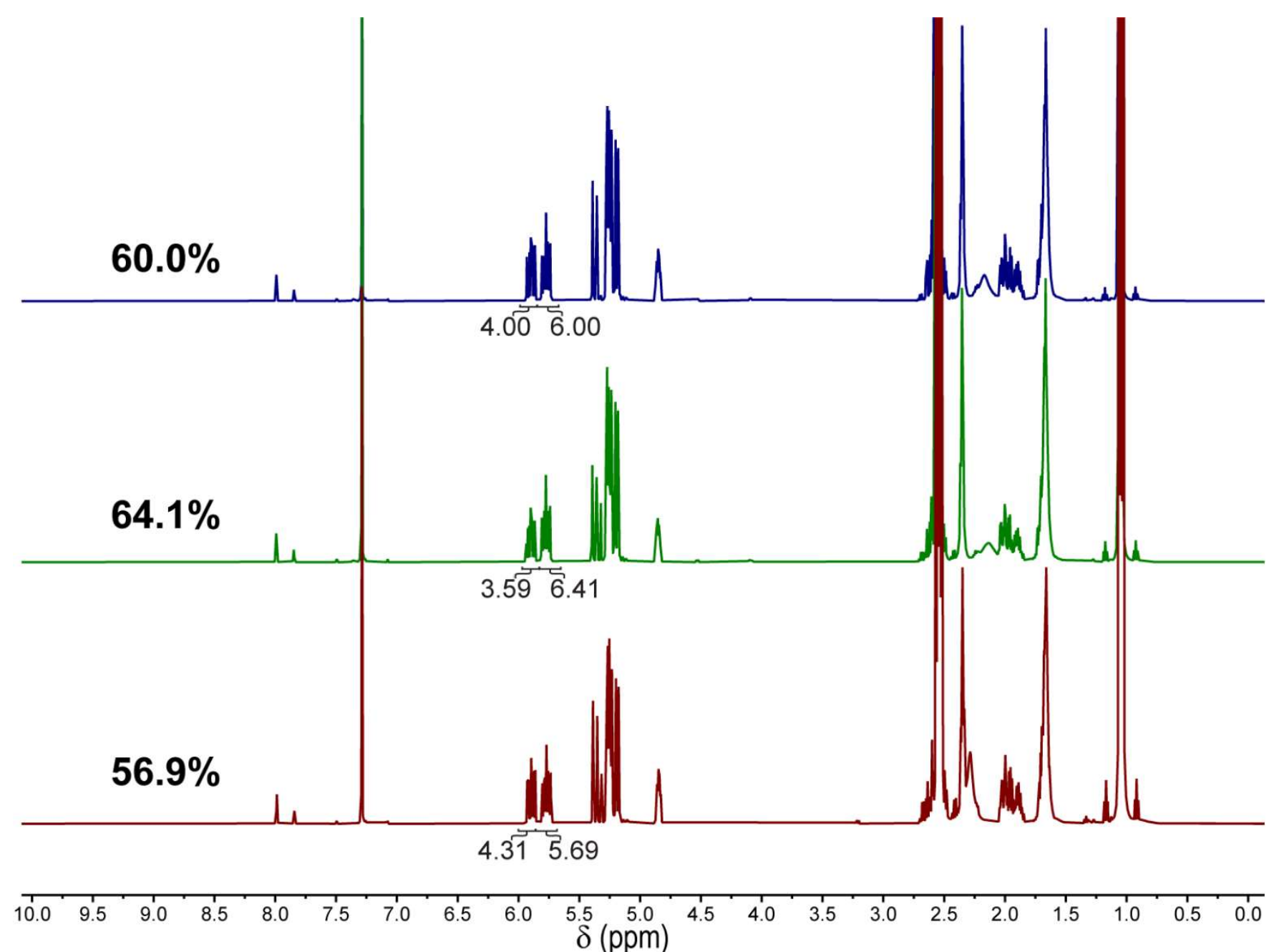

Figure S22. ${ }^{1} \mathrm{H}$ NMR $\left(500 \mathrm{MHz}, \mathrm{CDCl}_{3}, 23{ }^{\circ} \mathrm{C}\right)$ at the conclusion of the polymerizations of 1 with DPP and 3-phenylpropan-1-ol at $60^{\circ} \mathrm{C}$ with a $[\mathrm{M}]:[\mathrm{I}]:[\mathrm{C}]$ ratio of 500:1:2 in triplicate. 

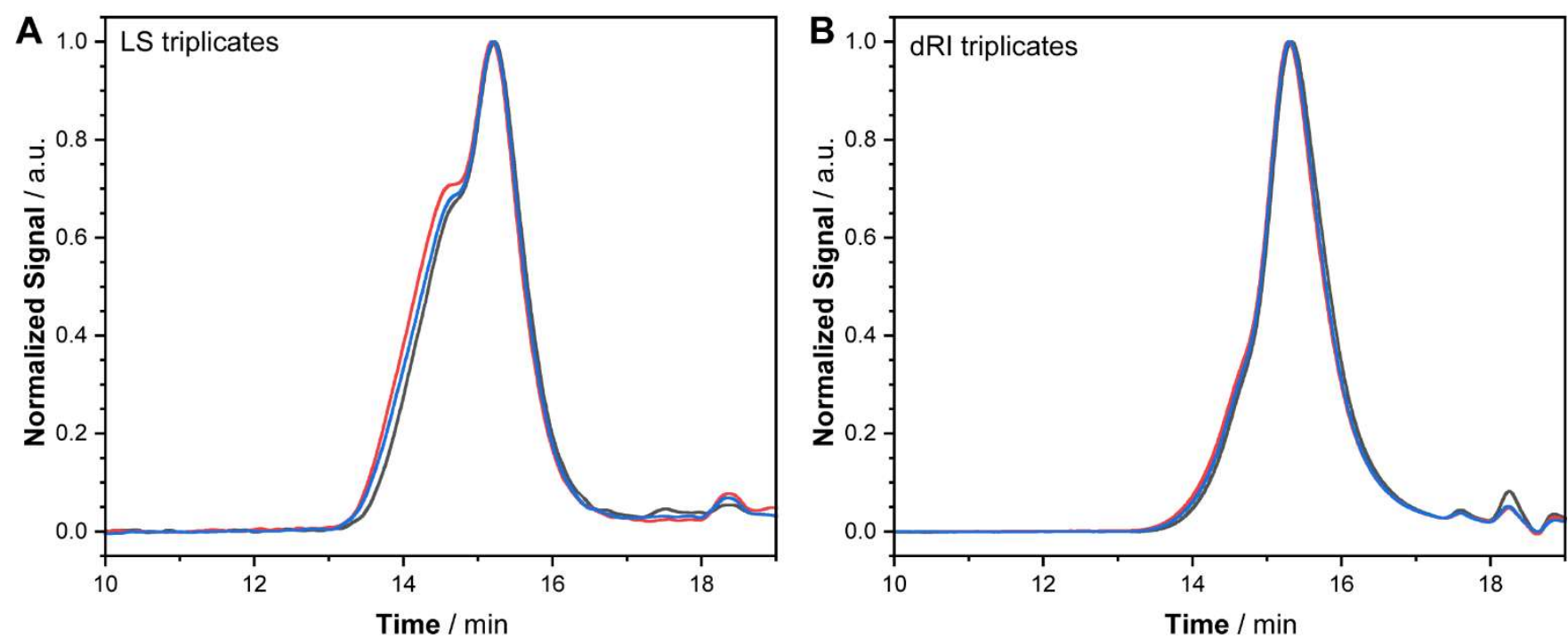

Figure S23. A.-B. Normalized GPC-MALS CA) light scattering (LS) and CB) differential refractive index (dRI) traces of the polymerization of 1 with DPP and 3-phenylpropan-1-ol at $60{ }^{\circ} \mathrm{C}$ with a $[\mathrm{M}]:[\mathrm{I}]:[\mathrm{C}]$ ratio of 500:1:2 in triplicate. 

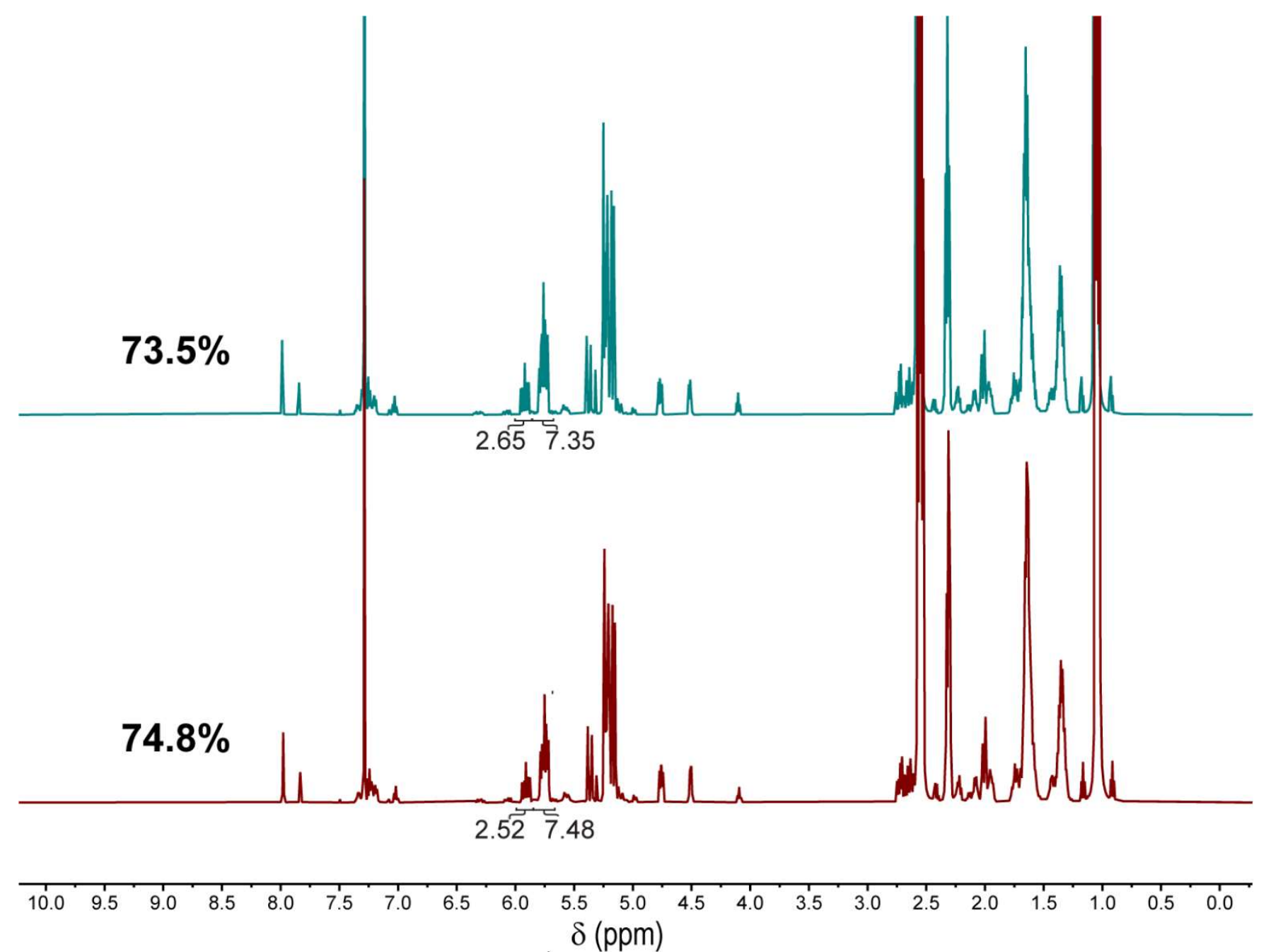

Figure S24. ${ }^{1} \mathrm{H}$ NMR $\left(500 \mathrm{MHz}, \mathrm{CDCl}_{3}, 23^{\circ} \mathrm{C}\right)$ at the conclusion of the polymerizations of 2 with DPP and 3-phenylpropan-1-ol at $60^{\circ} \mathrm{C}$ with a $[\mathrm{M}]:[\mathrm{I}]:[\mathrm{C}]$ ratio of $25: 1: 1$ in duplicate. 

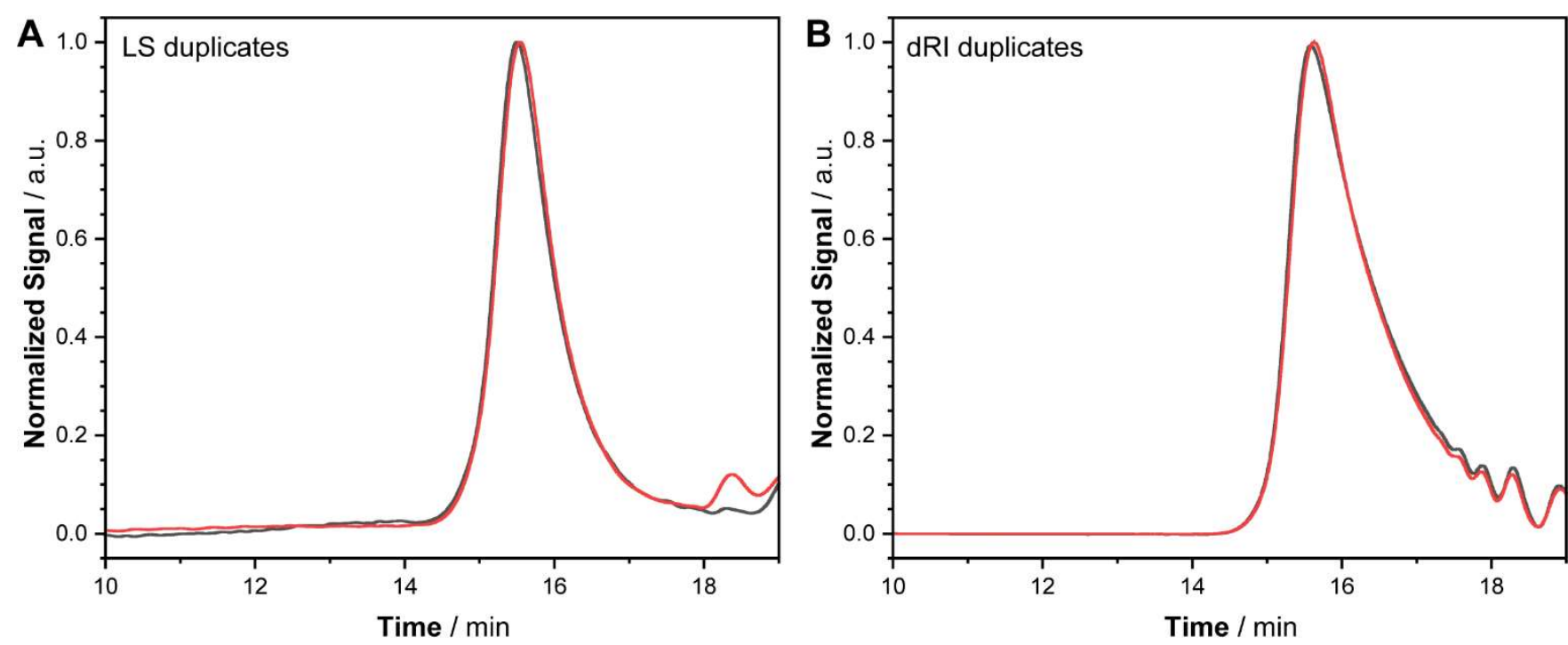

Figure S25. A.-B. Normalized GPC-MALS (A) light scattering (LS) and (B) differential refractive index (dRI) traces of the polymerization of 2 with DPP and 3-phenylpropan-1-ol at $60{ }^{\circ} \mathrm{C}$ with a [M]:[I]:[C] ratio of 25:1:1 in duplicate. 


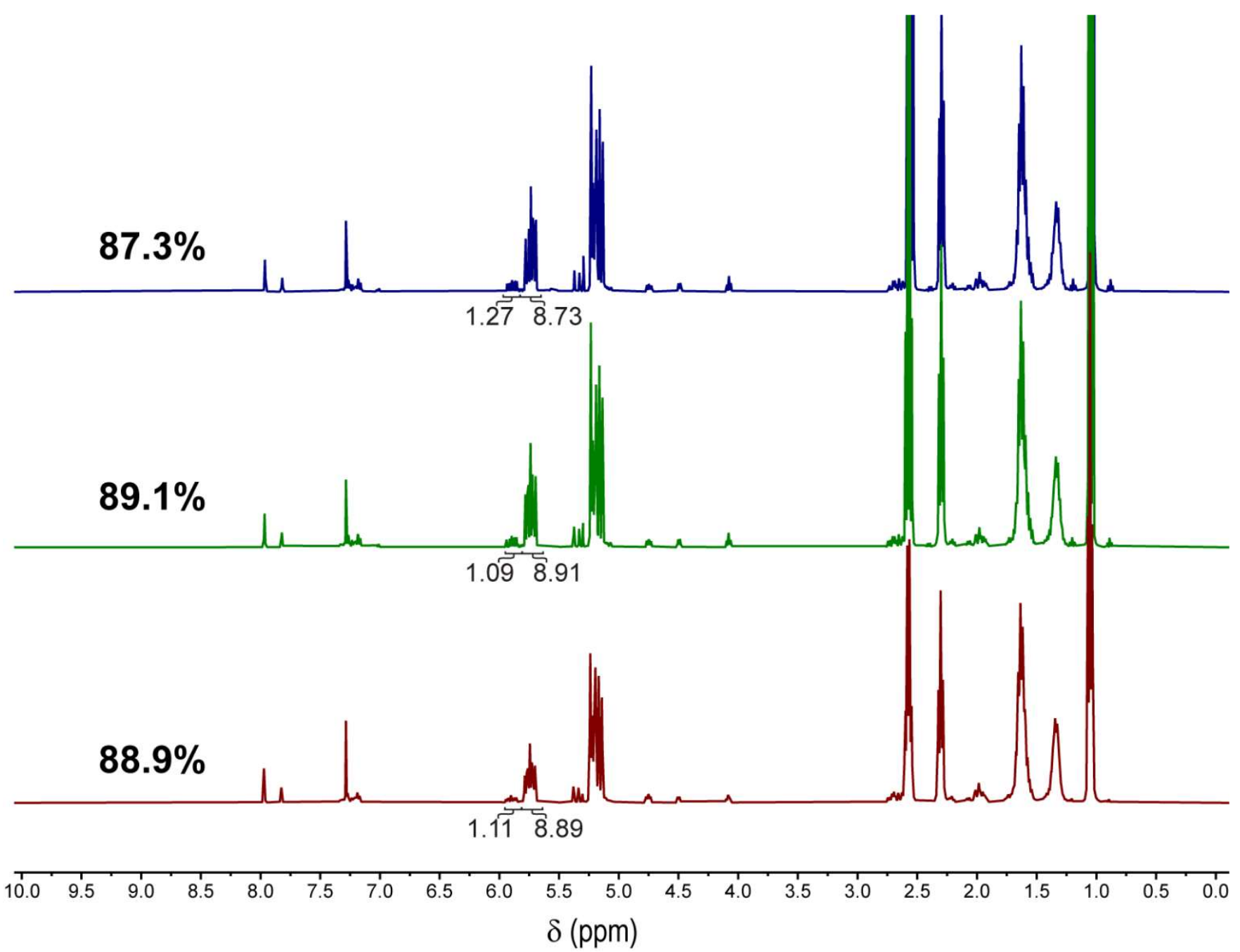

Figure S26. ${ }^{1} \mathrm{H}$ NMR $\left(500 \mathrm{MHz}, \mathrm{CDCl}_{3}, 23{ }^{\circ} \mathrm{C}\right)$ at the conclusion of the polymerizations of 2 with DPP and 3-phenylpropan-1-ol at $60^{\circ} \mathrm{C}$ with a [M]:[I]:[C] ratio of 50:1:1 in triplicate. 

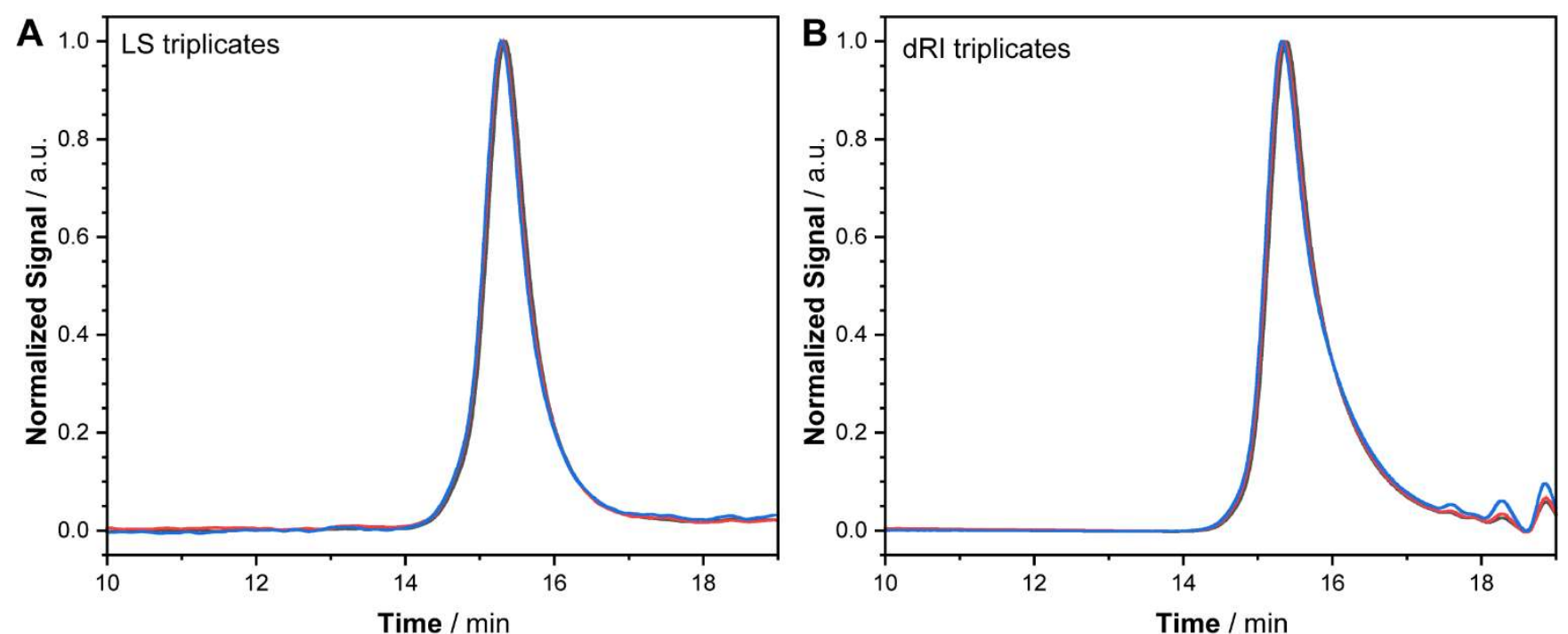

Figure S27. A.-B. Normalized GPC-MALS (A) light scattering (LS) and (B) differential refractive index (dRI) traces of the polymerization of 2 with DPP and 3-phenylpropan-1-ol at $60{ }^{\circ} \mathrm{C}$ with a [M]:[I]:[C] ratio of 50:1:1 in triplicate. 

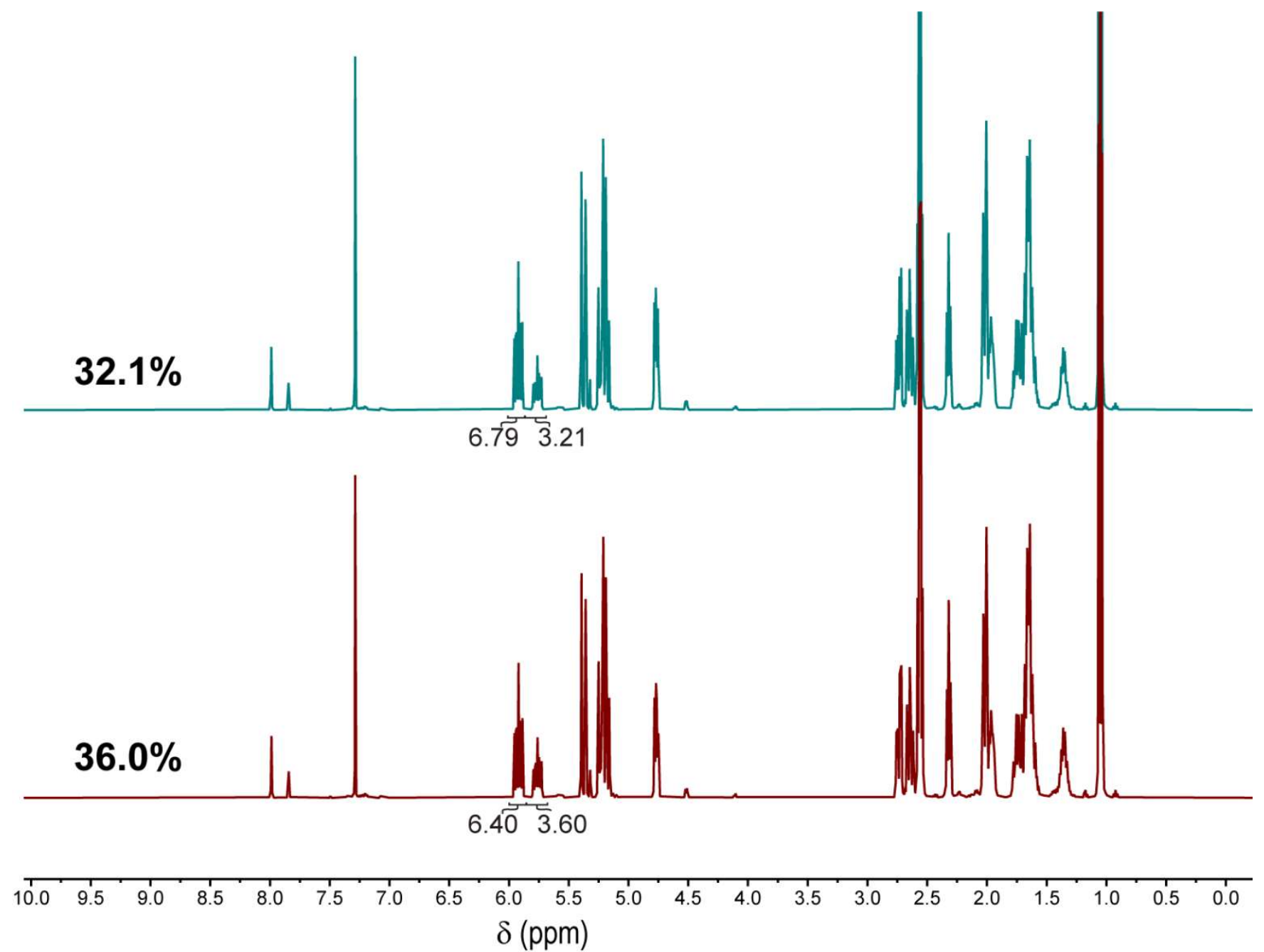

Figure S28. ${ }^{1} \mathrm{H}$ NMR $\left(500 \mathrm{MHz}, \mathrm{CDCl}_{3}, 23{ }^{\circ} \mathrm{C}\right)$ at the conclusion of the polymerizations of 2 with DPP and 3-phenylpropan-1-ol at $60^{\circ} \mathrm{C}$ with a [M]:[I]:[C] ratio of 250:1:1 in duplicate. 

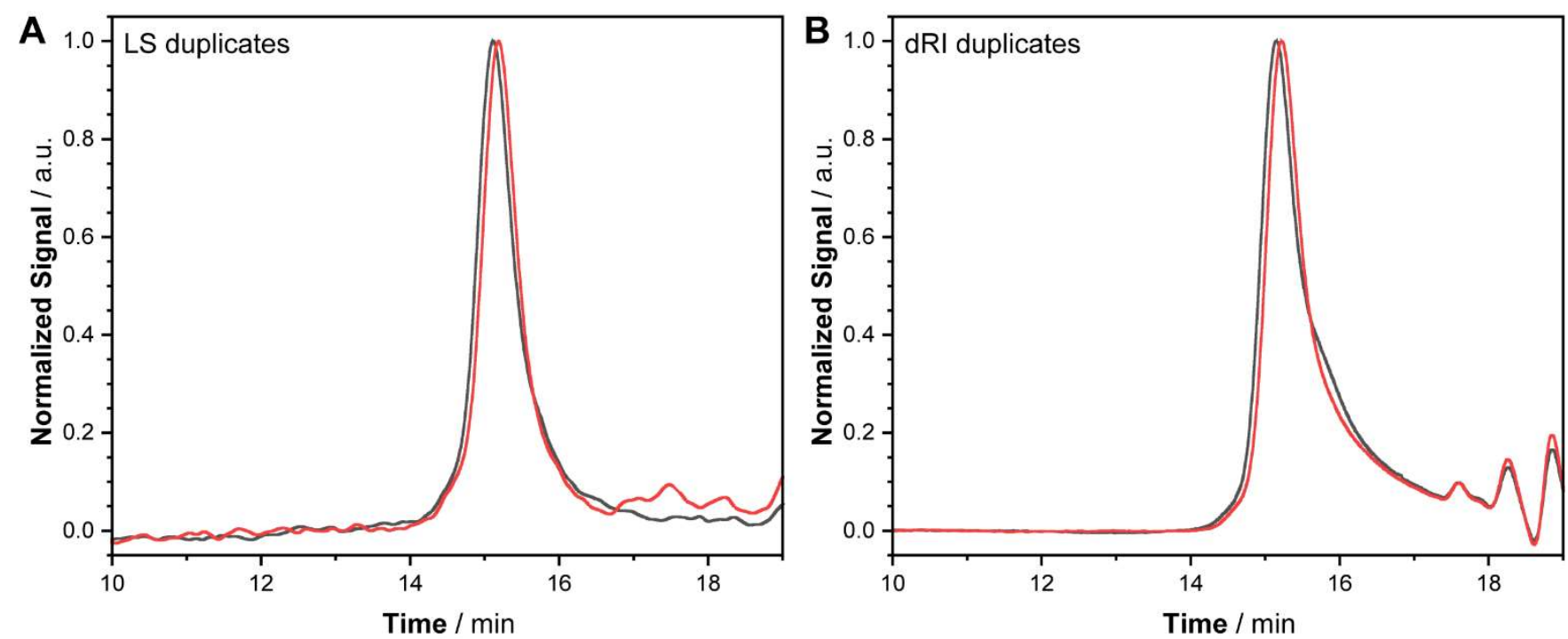

Figure S29. A.-B. Normalized GPC-MALS (A) light scattering (LS) and (B) differential refractive index (dRI) traces of the polymerization of 2 with DPP and 3-phenylpropan-1-ol at $60{ }^{\circ} \mathrm{C}$ with a [M]:[I]:[C] ratio of 250:1:1 in duplicate. 

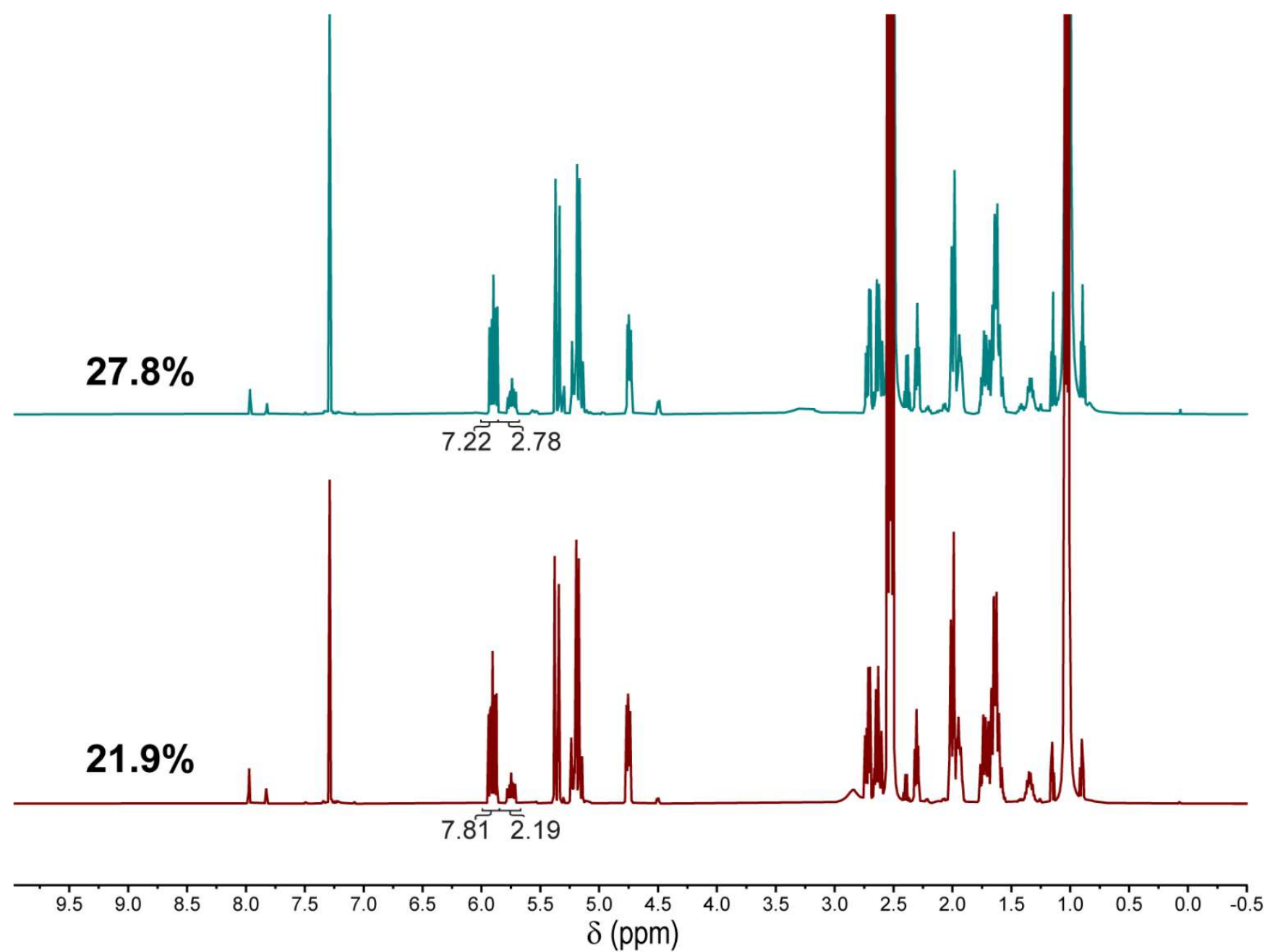

Figure S30. ${ }^{1} \mathrm{H} \mathrm{NMR}\left(500 \mathrm{MHz}, \mathrm{CDCl}_{3}, 23{ }^{\circ} \mathrm{C}\right)$ at the conclusion of the polymerizations of 2 with DPP and 3-phenylpropan-1-ol at $60{ }^{\circ} \mathrm{C}$ with a [M]:[I]:[C] ratio of 500:1:2 in duplicate. 

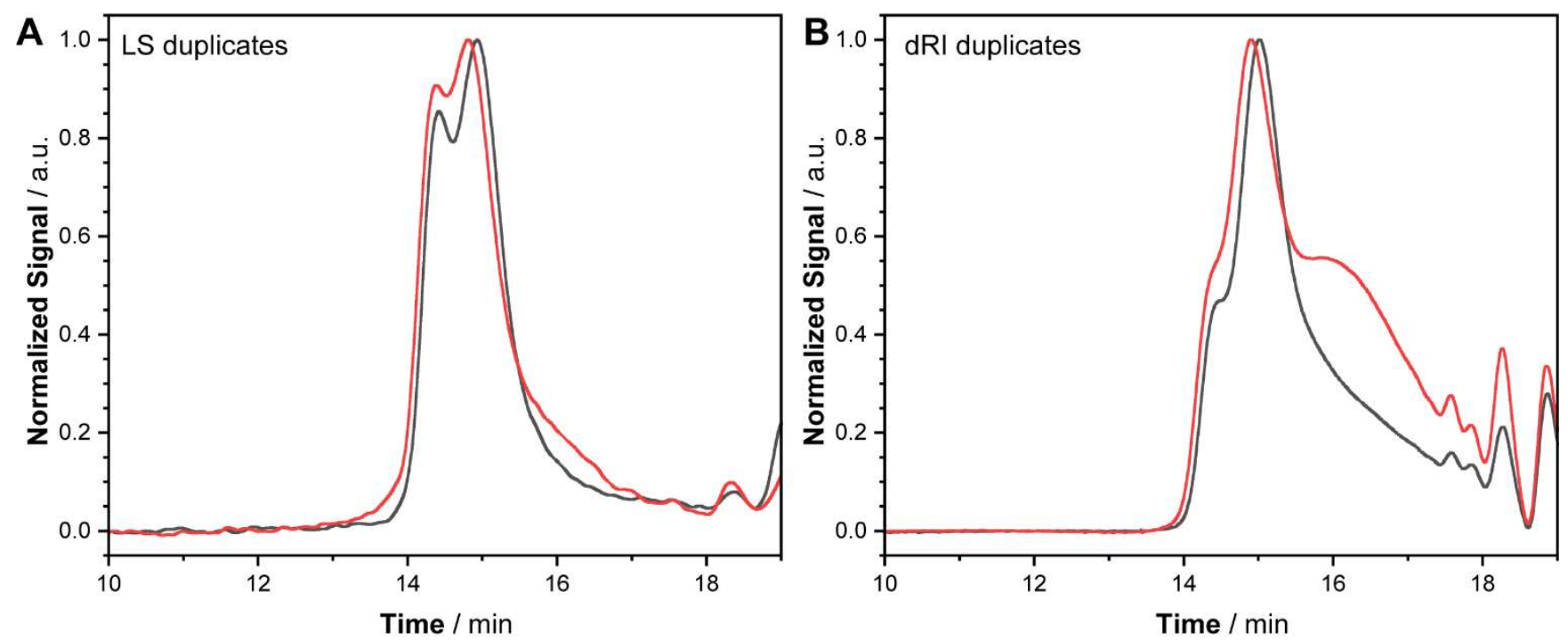

Figure S31. A.-B. Normalized GPC-MALS (A) light scattering (LS) and (B) differential refractive index $(\mathrm{dRI})$ traces of the polymerization of 2 with DPP and 3-phenylpropan-1-ol at $60{ }^{\circ} \mathrm{C}$ with a [M]:[I]:[C] ratio of 500:1:2 in duplicate. 


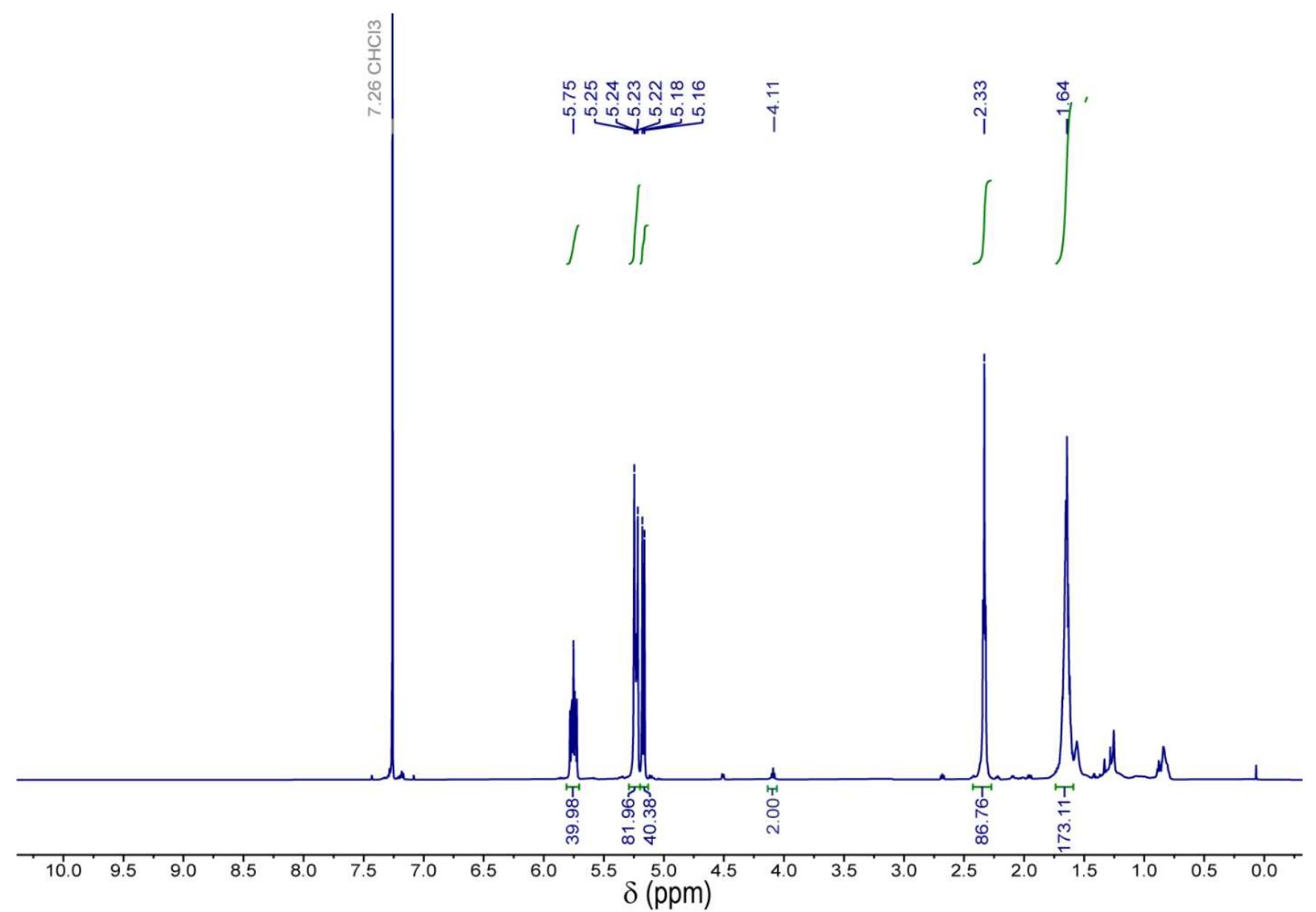

Figure S32. ${ }^{1} \mathrm{H}$ NMR $\left(600 \mathrm{MHz}, \mathrm{CDCl}_{3}, 23{ }^{\circ} \mathrm{C}\right)$ spectrum of polymer $\mathbf{P 1}$ synthesized from 1 with DPP and 3-phenylpropan-1-ol at $60{ }^{\circ} \mathrm{C}$ with a [M]:[I]:[C] ratio of 100:1:1. 


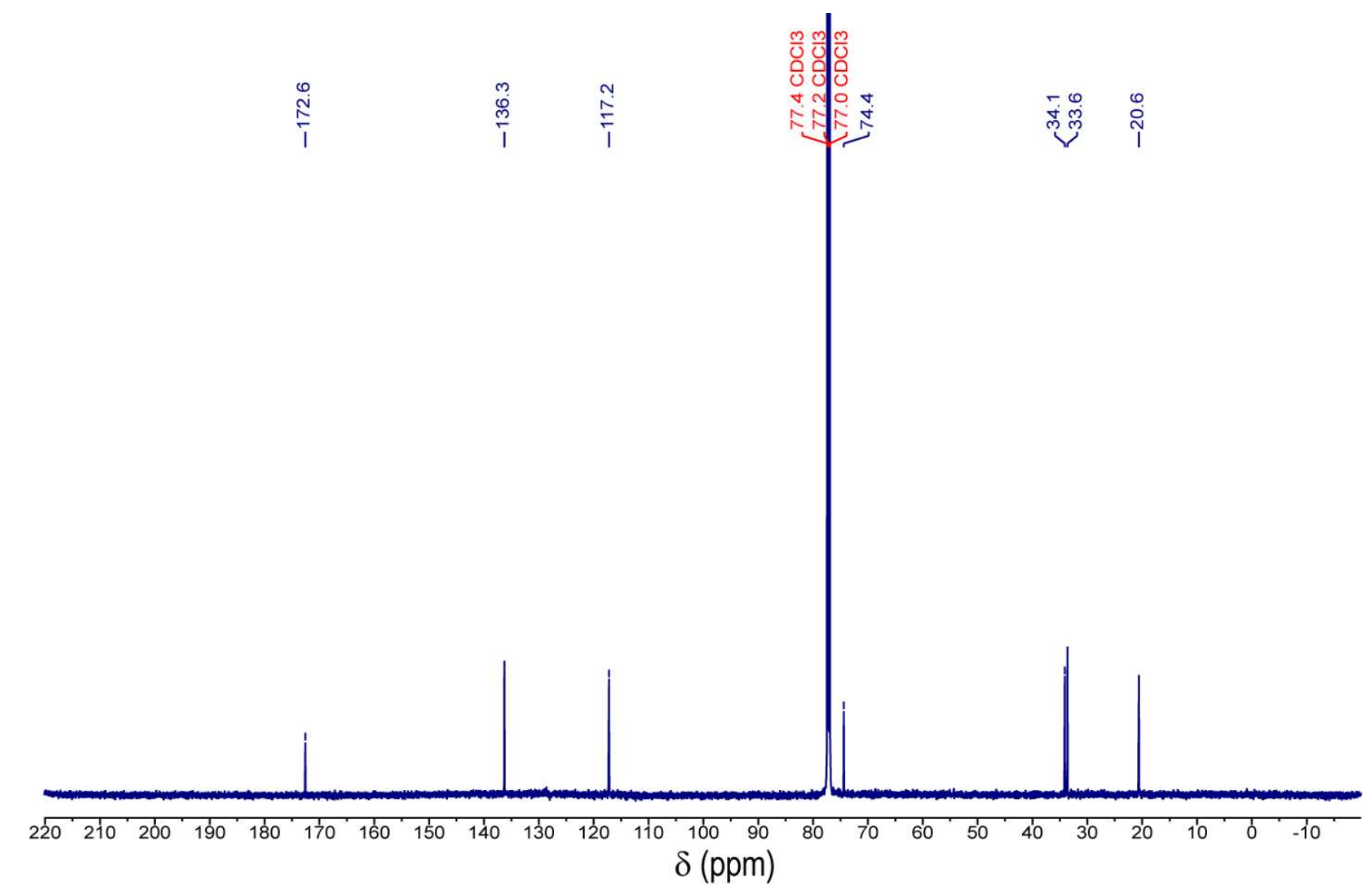

Figure S33. ${ }^{13} \mathrm{C}$ NMR $\left(150 \mathrm{MHz}, \mathrm{CDCl}_{3}, 23{ }^{\circ} \mathrm{C}\right)$ spectrum of polymer $\mathbf{P 1}$ synthesized from 1 with DPP and 3-phenylpropan-1-ol at $60{ }^{\circ} \mathrm{C}$ with a [M]:[I]:[C] ratio of 100:1:1. 


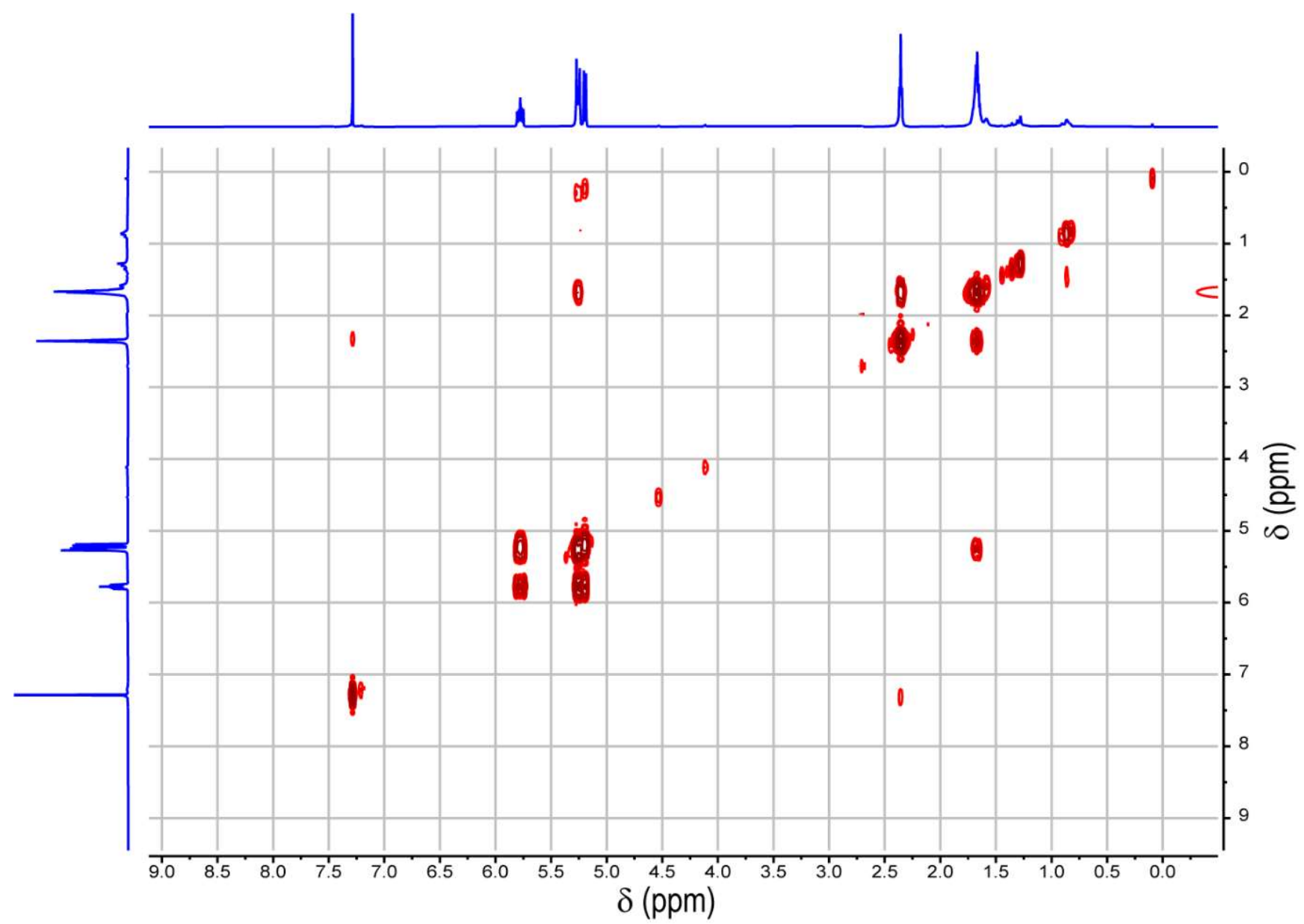

Figure S34. Homonuclear correlation spectroscopy (COSY) NMR (600 $\left.\mathrm{MHz}, \mathrm{CDCl}_{3}, 23{ }^{\circ} \mathrm{C}\right)$ spectrum of polymer P1 synthesized from 1 with DPP and 3-phenylpropan-1-ol at $60^{\circ} \mathrm{C}$ with a [M]:[I]:[C] ratio of 100:1:1. 


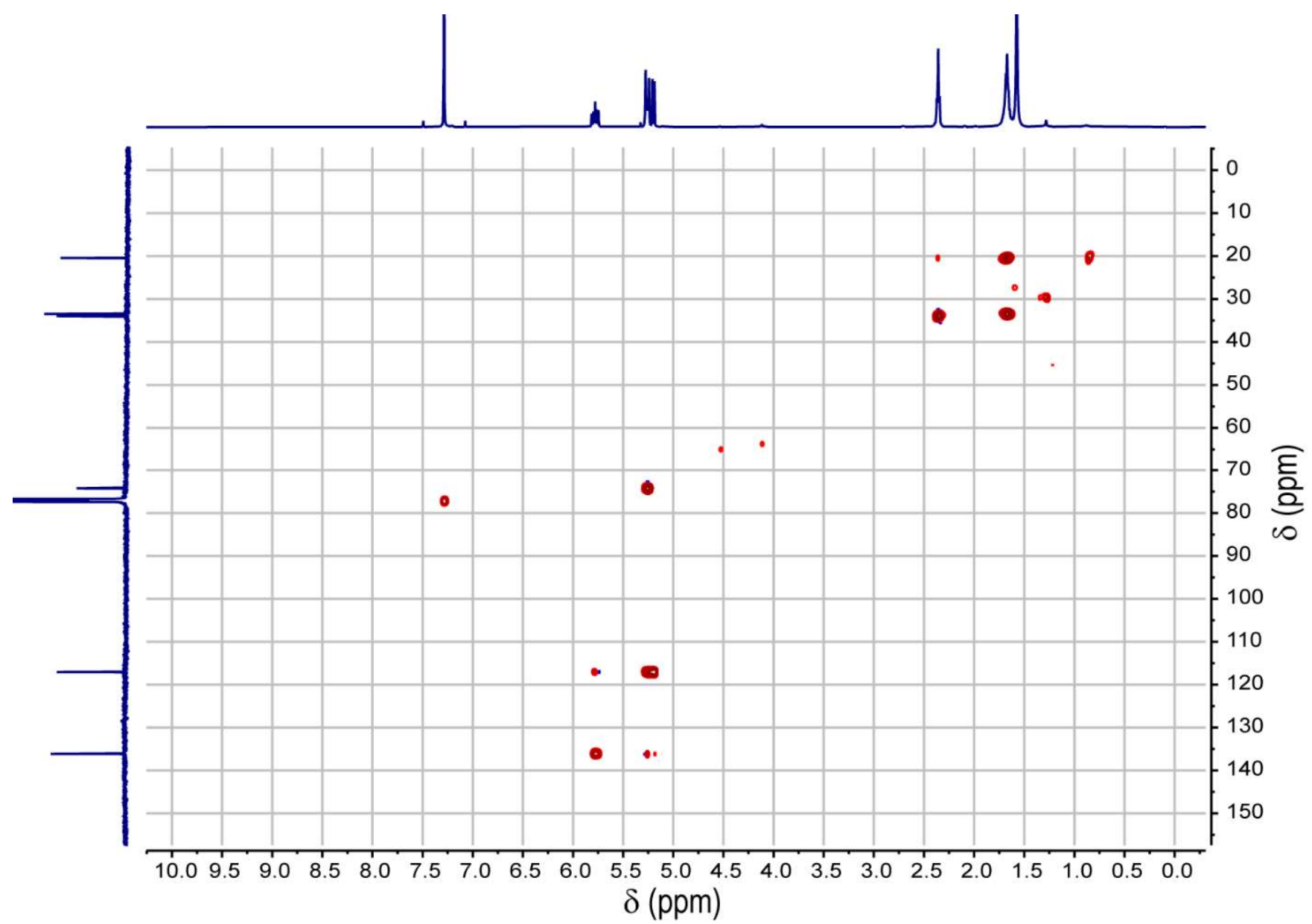

Figure S35. Heteronuclear single quantum coherence (HSQC) $\mathrm{NMR}\left(600 \mathrm{MHz}, \mathrm{CDCl}_{3}, 23{ }^{\circ} \mathrm{C}\right)$ spectrum of polymer P1 synthesized from 1 with DPP and 3-phenylpropan-1-ol at $60^{\circ} \mathrm{C}$ with a [M]:[I]:[C] ratio of 100:1:1. 


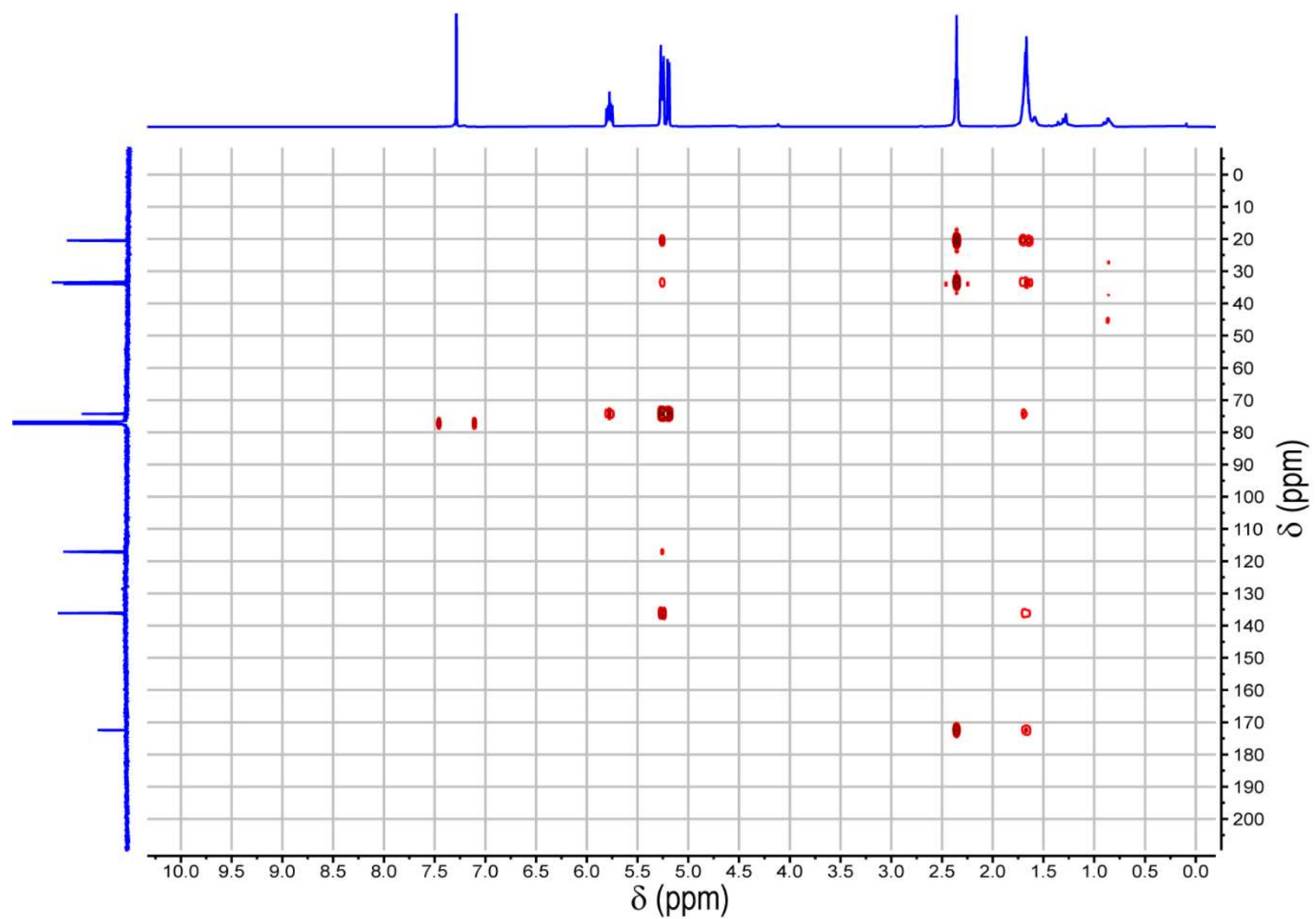

Figure S36. Heteronuclear multiple bond correlation (HMBC) NMR (600 $\left.\mathrm{MHz}, \mathrm{CDCl}_{3}, 23{ }^{\circ} \mathrm{C}\right)$ spectrum of polymer P1 synthesized from 1 with DPP and 3-phenylpropan-1-ol at $60{ }^{\circ} \mathrm{C}$ with a [M]:[I]:[C] ratio of 100:1:1. 

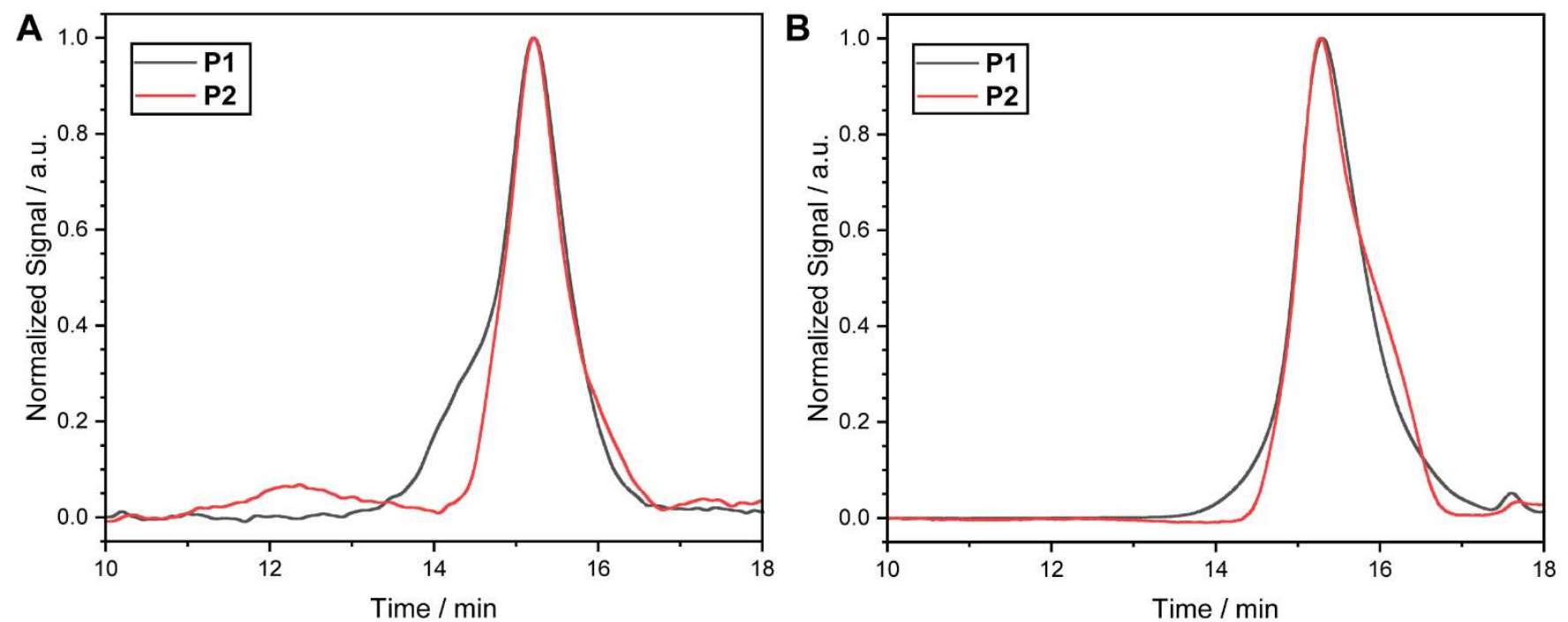

Figure S37. A.-B. Normalized GPC-MALS (A) light scattering (LS) and (B) differential refractive index $(\mathrm{dRI})$ traces of purified P1 $\left(d \mathrm{n} / d \mathrm{c}=0.0771 \mathrm{~mL} / \mathrm{g}, M_{\mathrm{n}}=5.52 \mathrm{~kg}^{\circ} \mathrm{mol}^{-1}, \mathrm{DP}=42, \mathrm{Ð}=1.24\right)$ and P2 $(d \mathrm{n} / d \mathrm{c}$ $\left.=0.0775 \mathrm{~mL} / \mathrm{g}, M_{\mathrm{n}}=4.91 \mathrm{~kg} \cdot \mathrm{mol}^{-1}, \mathrm{DP}=34, \mathrm{D}=1.15\right)$. 


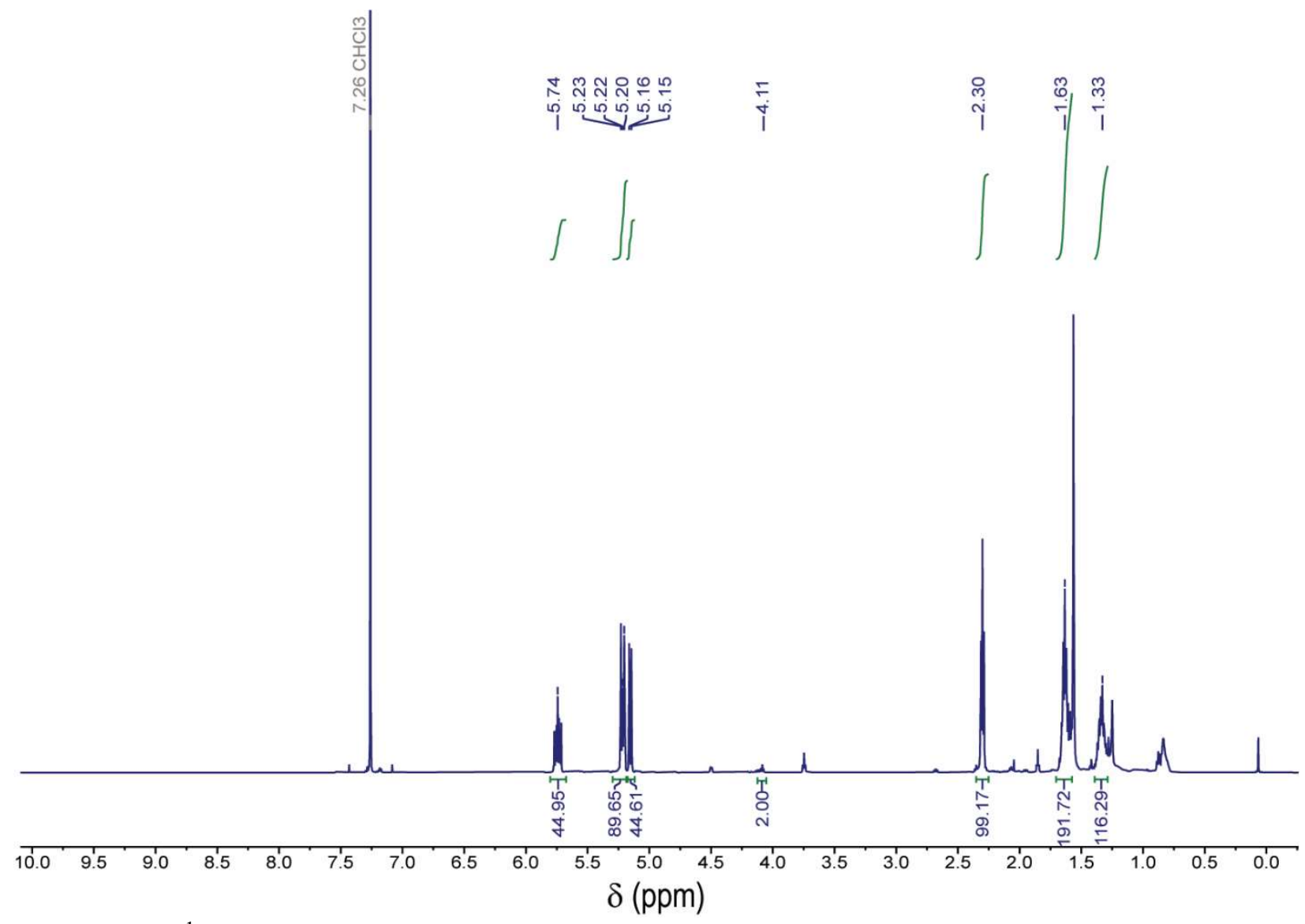

Figure S38. ${ }^{1} \mathrm{H}$ NMR $\left(600 \mathrm{MHz}, \mathrm{CDCl}_{3}, 23^{\circ} \mathrm{C}\right)$ spectrum of polymer $\mathbf{P 2}$ synthesized from 2 with DPP and 3-phenylpropan-1-ol at $60{ }^{\circ} \mathrm{C}$ with a [M]:[I]:[C] ratio of 100:1:1. 


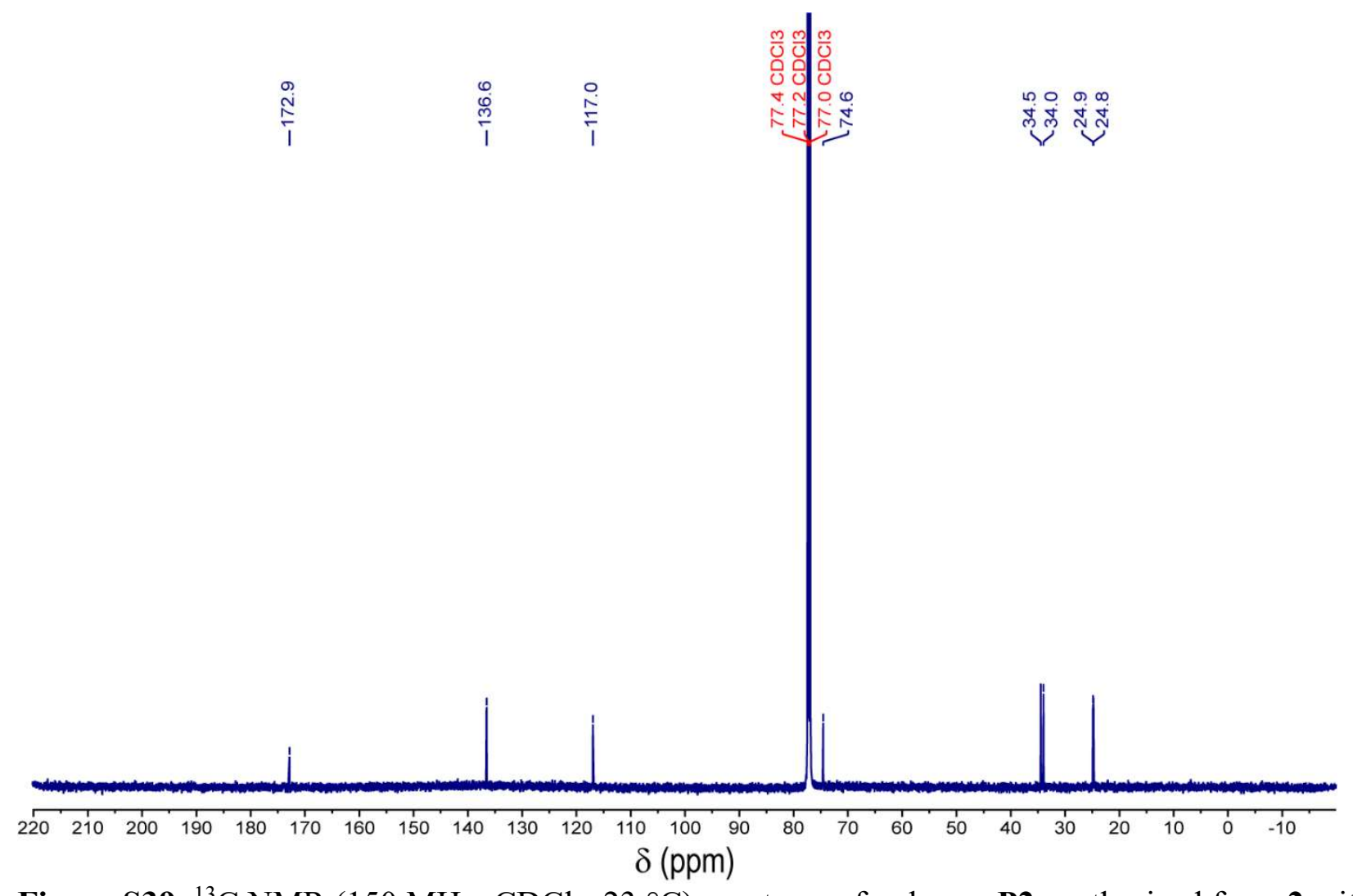

Figure S39. ${ }^{13} \mathrm{C}$ NMR $\left(150 \mathrm{MHz}, \mathrm{CDCl}_{3}, 23{ }^{\circ} \mathrm{C}\right)$ spectrum of polymer $\mathbf{P 2}$ synthesized from 2 with DPP and 3-phenylpropan-1-ol at $60{ }^{\circ} \mathrm{C}$ with a [M]:[I]:[C] ratio of 100:1:1. 


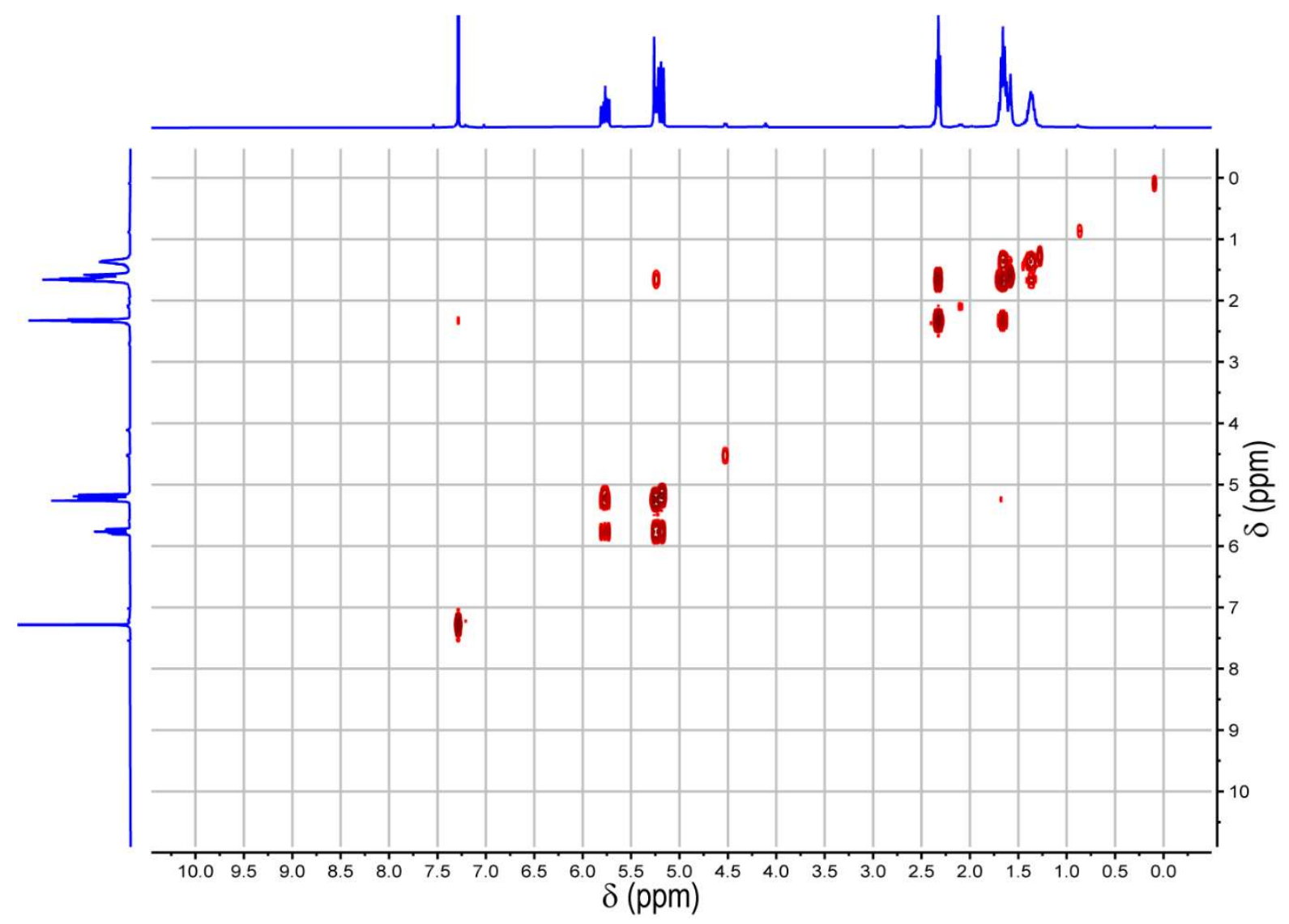

Figure S40. COSY NMR $\left(600 \mathrm{MHz}, \mathrm{CDCl}_{3}, 23{ }^{\circ} \mathrm{C}\right)$ spectrum of polymer $\mathbf{P 2}$ synthesized from 2 with DPP and 3-phenylpropan-1-ol at $60^{\circ} \mathrm{C}$ with a [M]:[I]:[C] ratio of 100:1:1. 


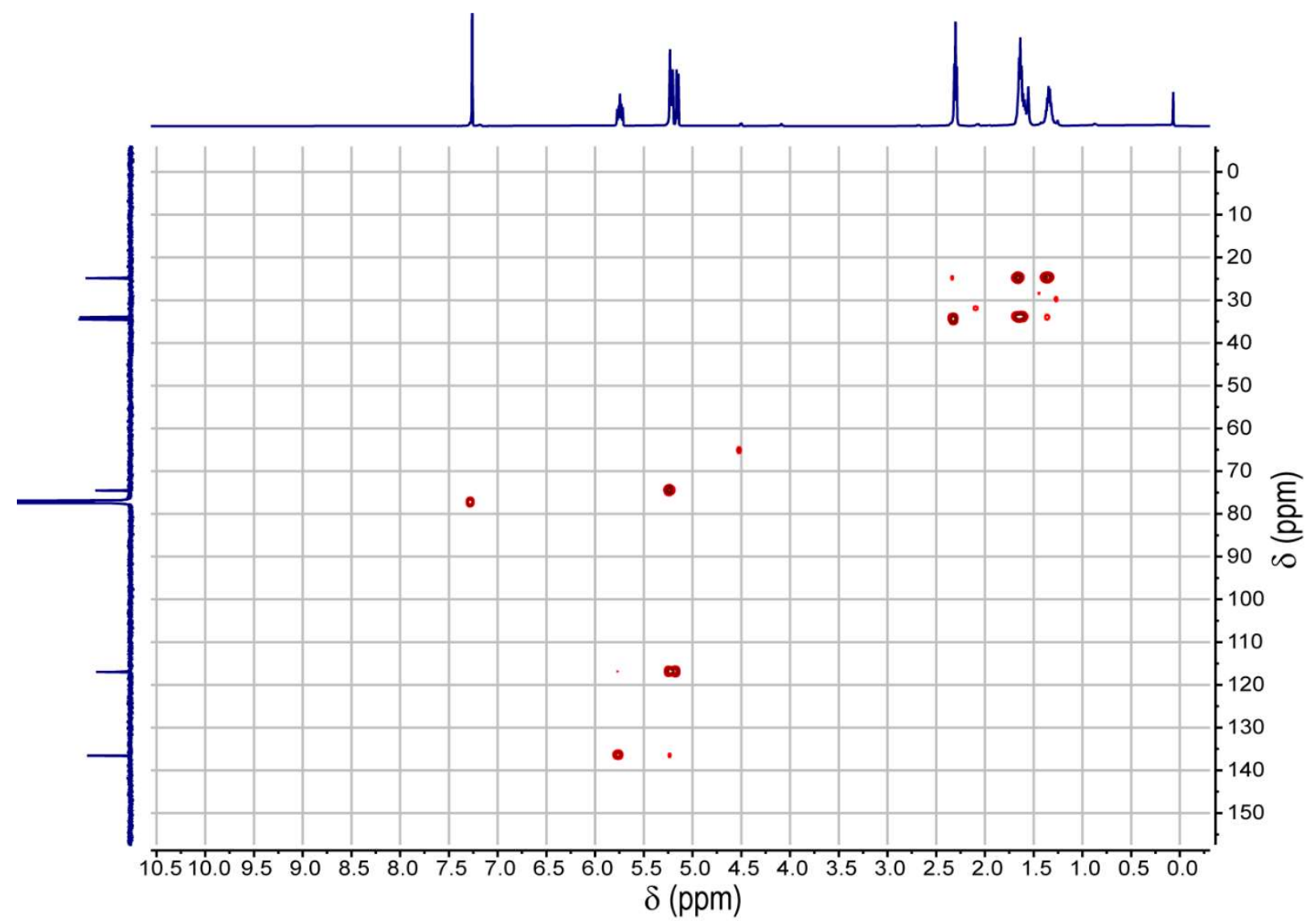

Figure S41. HSQC NMR (600 MHz, $\left.\mathrm{CDCl}_{3}, 23{ }^{\circ} \mathrm{C}\right)$ spectrum of polymer $\mathbf{P 2}$ synthesized from 2 with DPP and 3-phenylpropan-1-ol at $60^{\circ} \mathrm{C}$ with a [M]:[I]:[C] ratio of 100:1:1. 


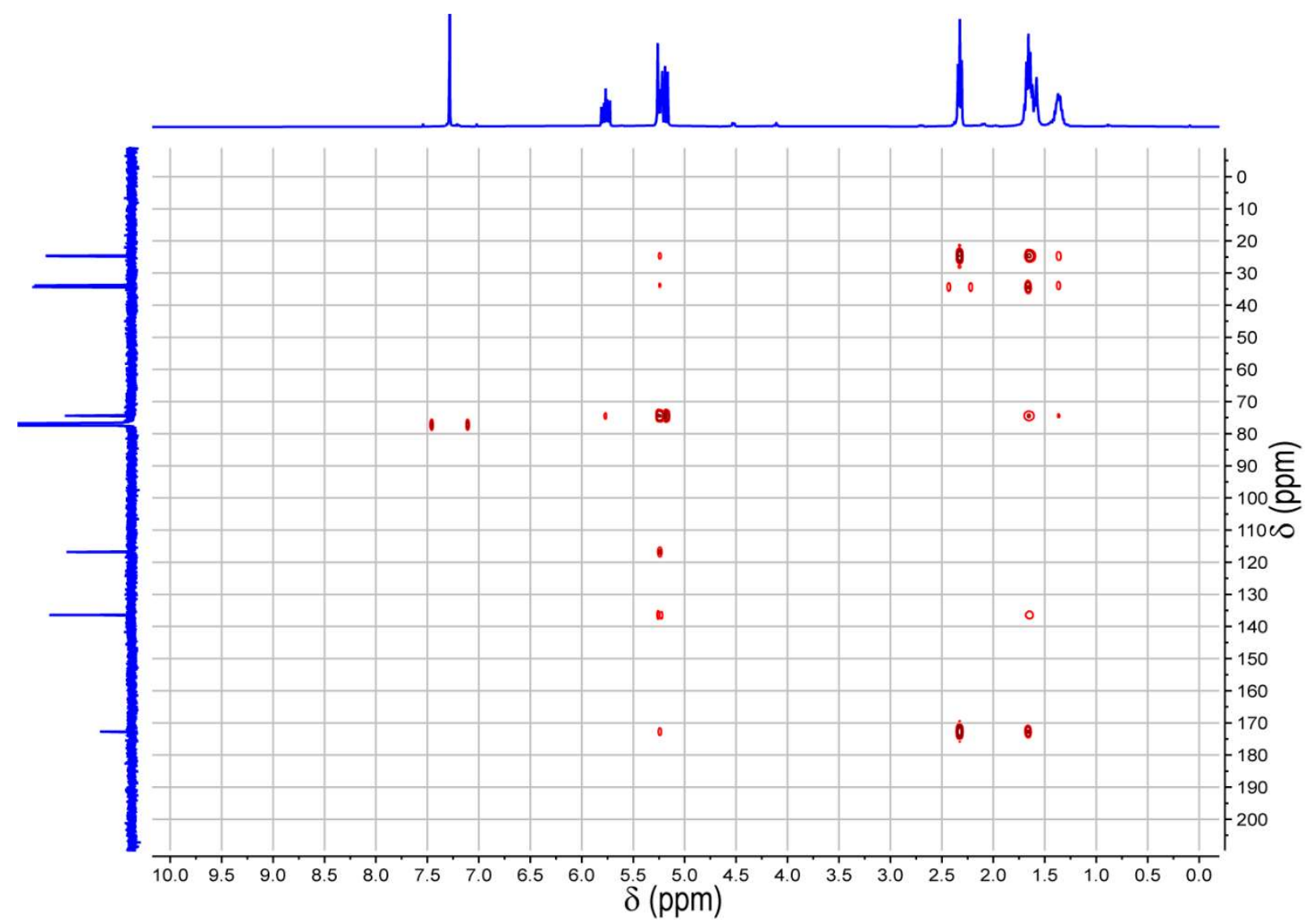

Figure S42. HMBC NMR $\left(600 \mathrm{MHz}, \mathrm{CDCl}_{3}, 23^{\circ} \mathrm{C}\right)$ spectrum of polymer $\mathbf{P} 2$ synthesized from 2 with DPP and 3-phenylpropan-1-ol at $60^{\circ} \mathrm{C}$ with a [M]:[I]:[C] ratio of 100:1:1. 


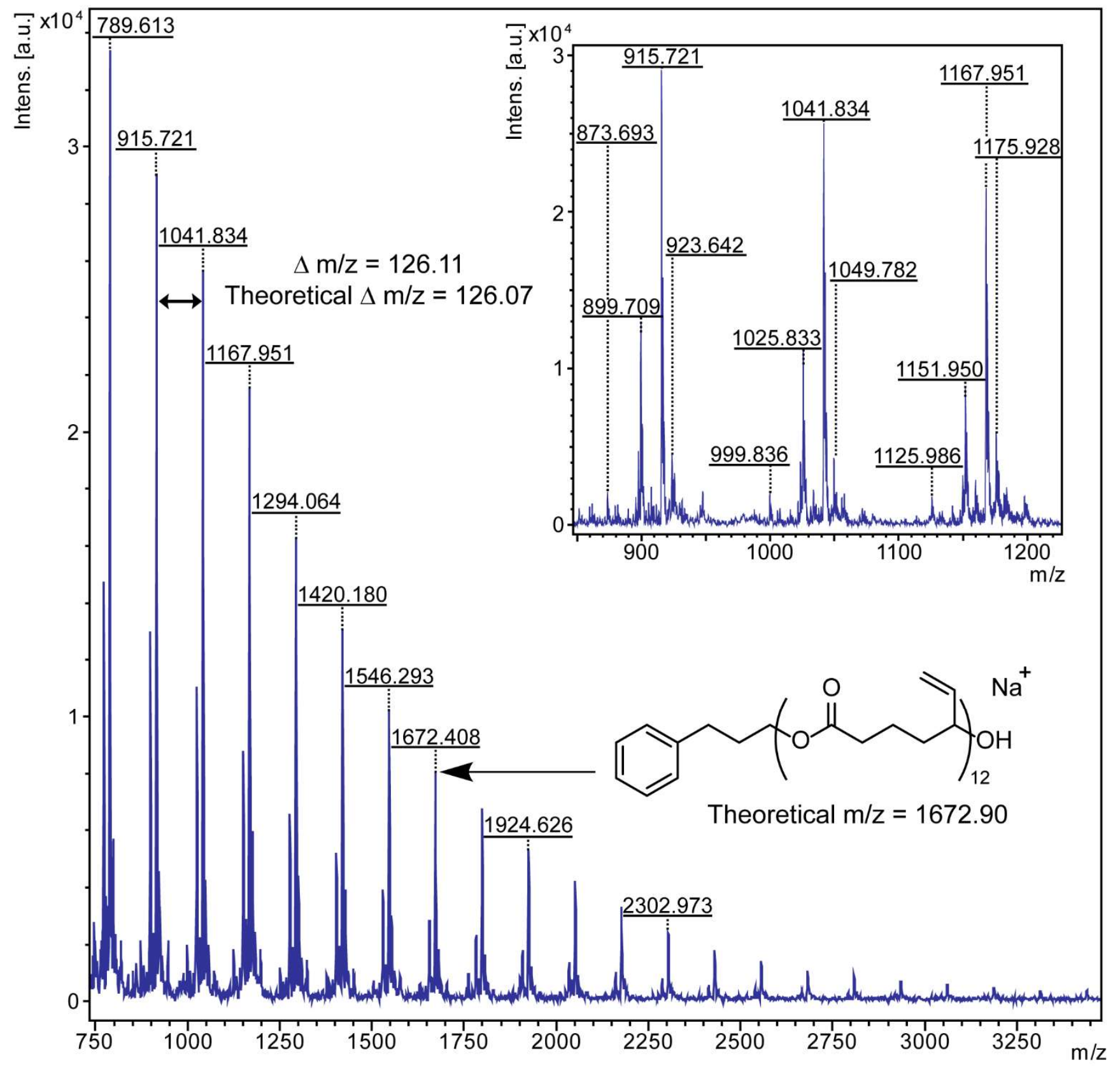

Figure S43. MALDI-TOF spectrum of the homopolymer P1 synthesized using a [M]:[C]:[I] ratio of 25:1:1. 


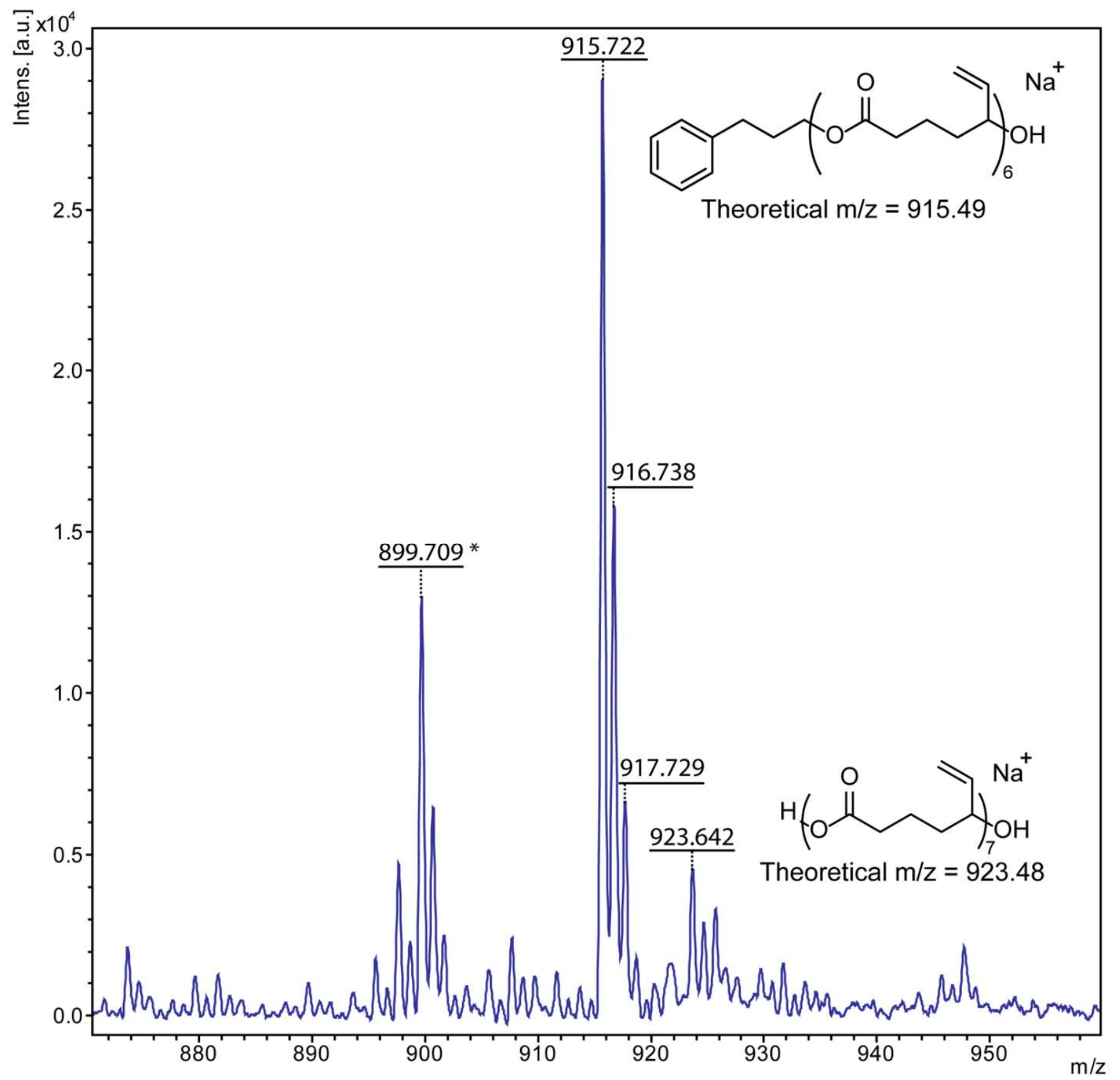

Figure S44. MALDI-TOF analysis of homopolymer P1 synthesized using a [M]:[C]:[I] ratio of 25:1:1 with the respective $\mathrm{m} / \mathrm{z}$ peaks labeled with their respective molecules. ${ }^{*} \mathrm{~m} / \mathrm{z}$ of this peak series could not be assigned to any possible combination of ionizing agents $\left(\mathrm{H}^{+}, \mathrm{Na}^{+}\right.$, or $\left.\mathrm{K}^{+}\right)$and end groups $\left(\mathrm{PhC}_{3} \mathrm{H}_{6} \mathrm{O} / \mathrm{OH}\right.$ or $\mathrm{HO} / \mathrm{OH}$ for linear chains, or no end-groups for cyclics). 


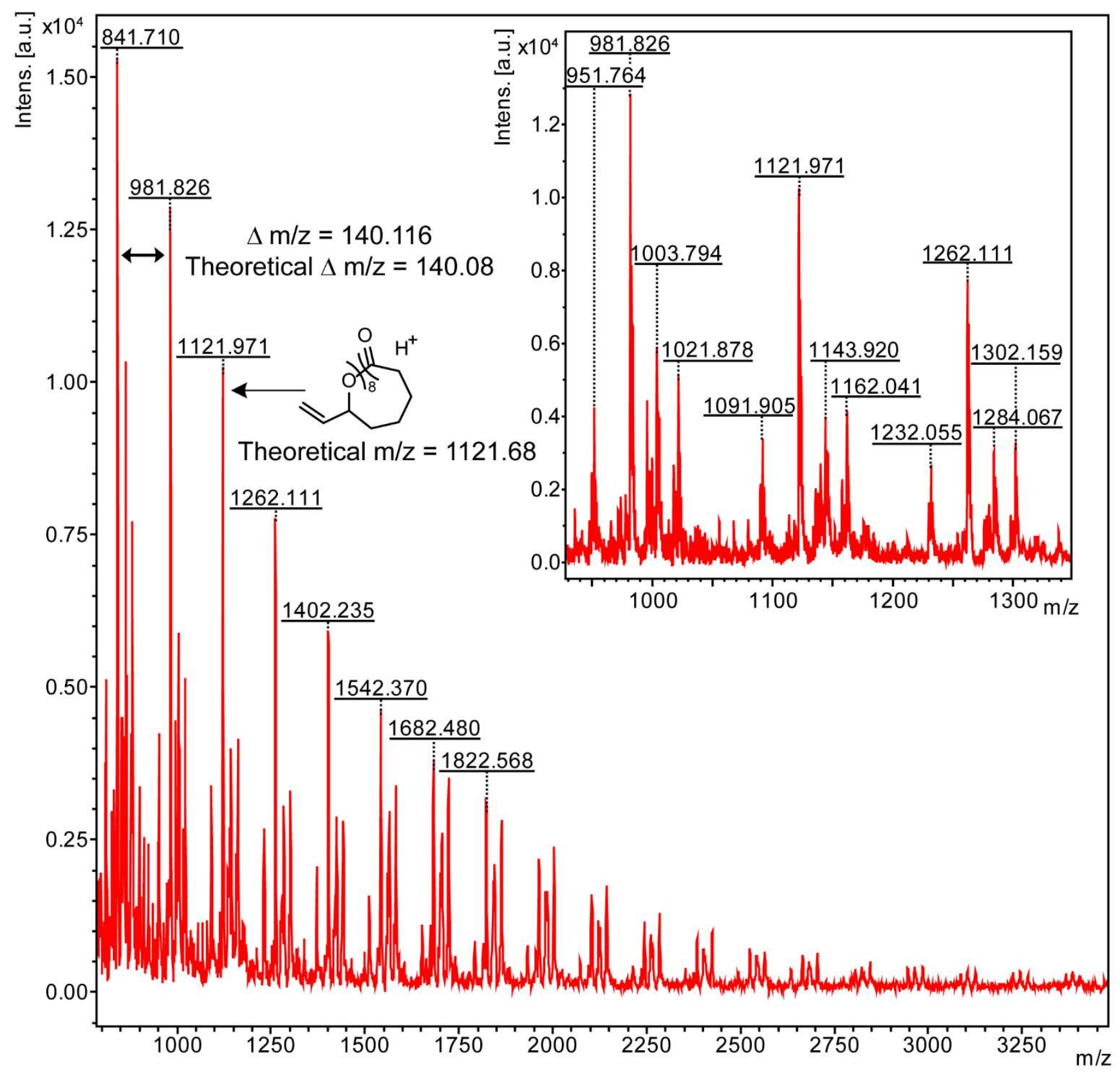

Figure S45. MALDI-TOF spectrum of the homopolymer P2 synthesized using a [M]:[C]:[I] ratio of 25:1:1. 


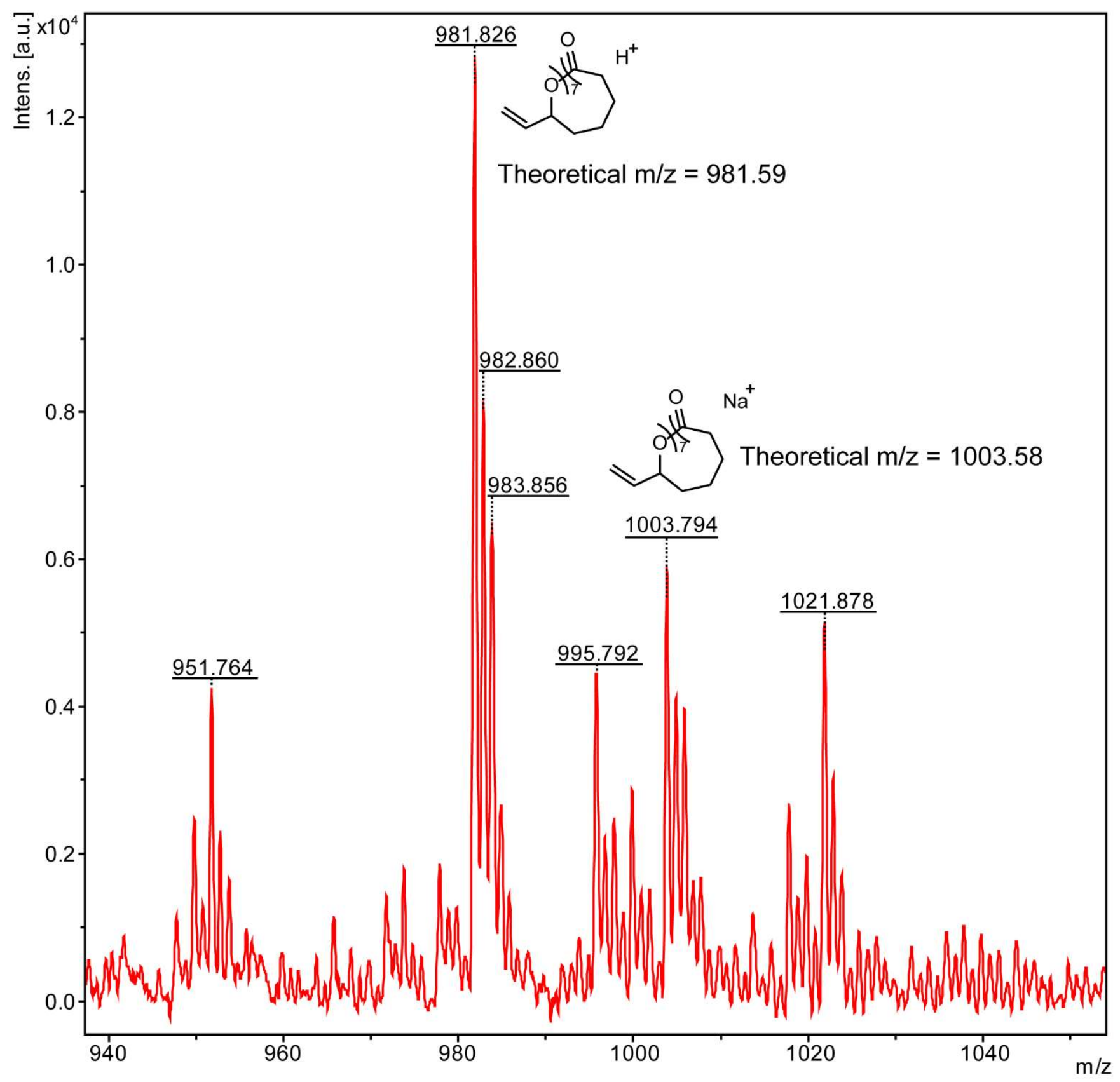

Figure S46. MALDI-TOF analysis of homopolymer P2 synthesized using a [M]:[C]:[I] ratio of 25:1:1 with the respective $\mathrm{m} / \mathrm{z}$ peaks labeled with their respective molecules. 


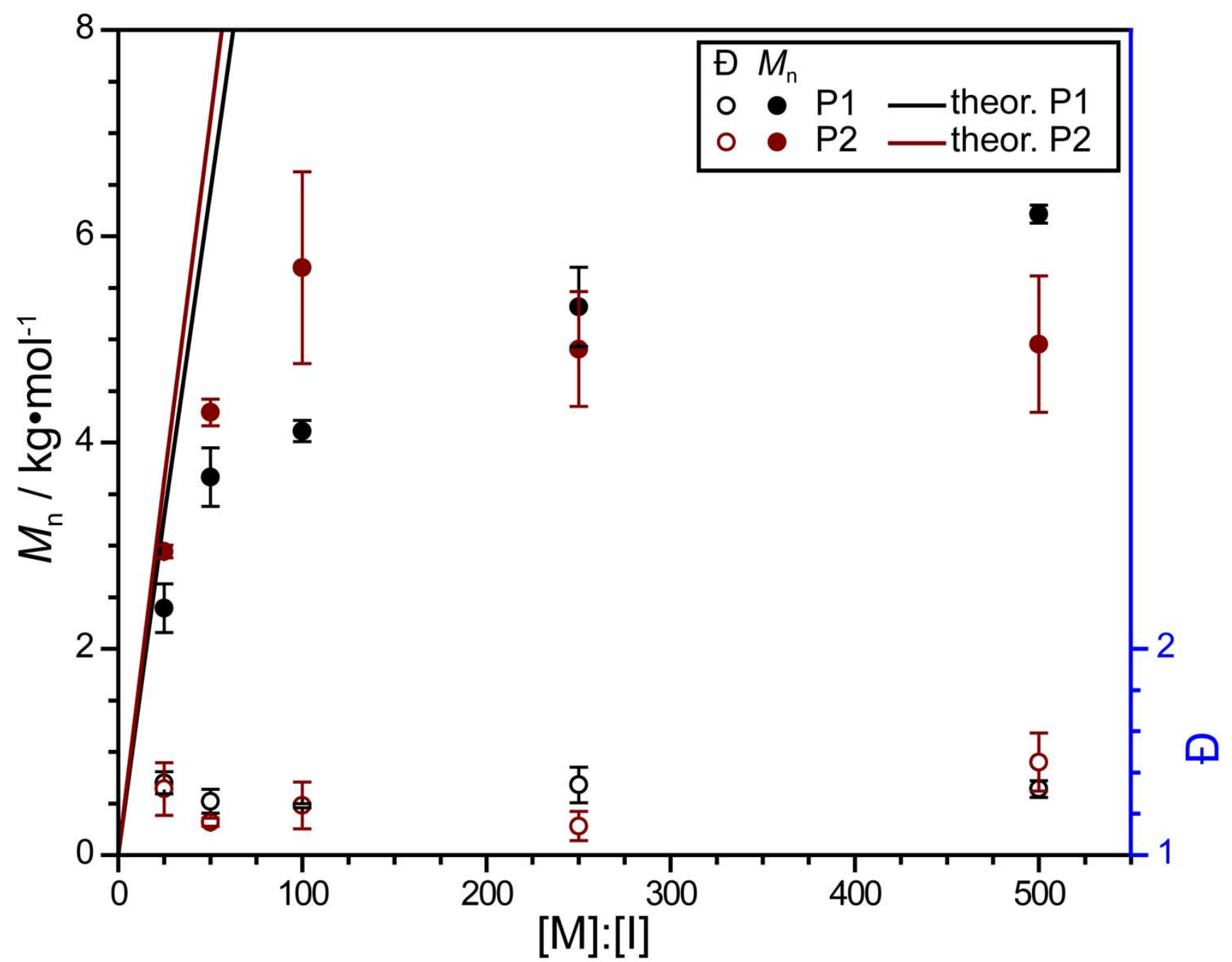

Figure S47. $M_{\mathrm{n}}$ of $\mathbf{P 1}$ and $\mathbf{P 2}$ vs $[\mathbf{M}]$ :[I] for $\mathrm{M}=1$ and 2, respectively. Data plotted here correspond to entries 6-15 in Supplementary Table S1. 


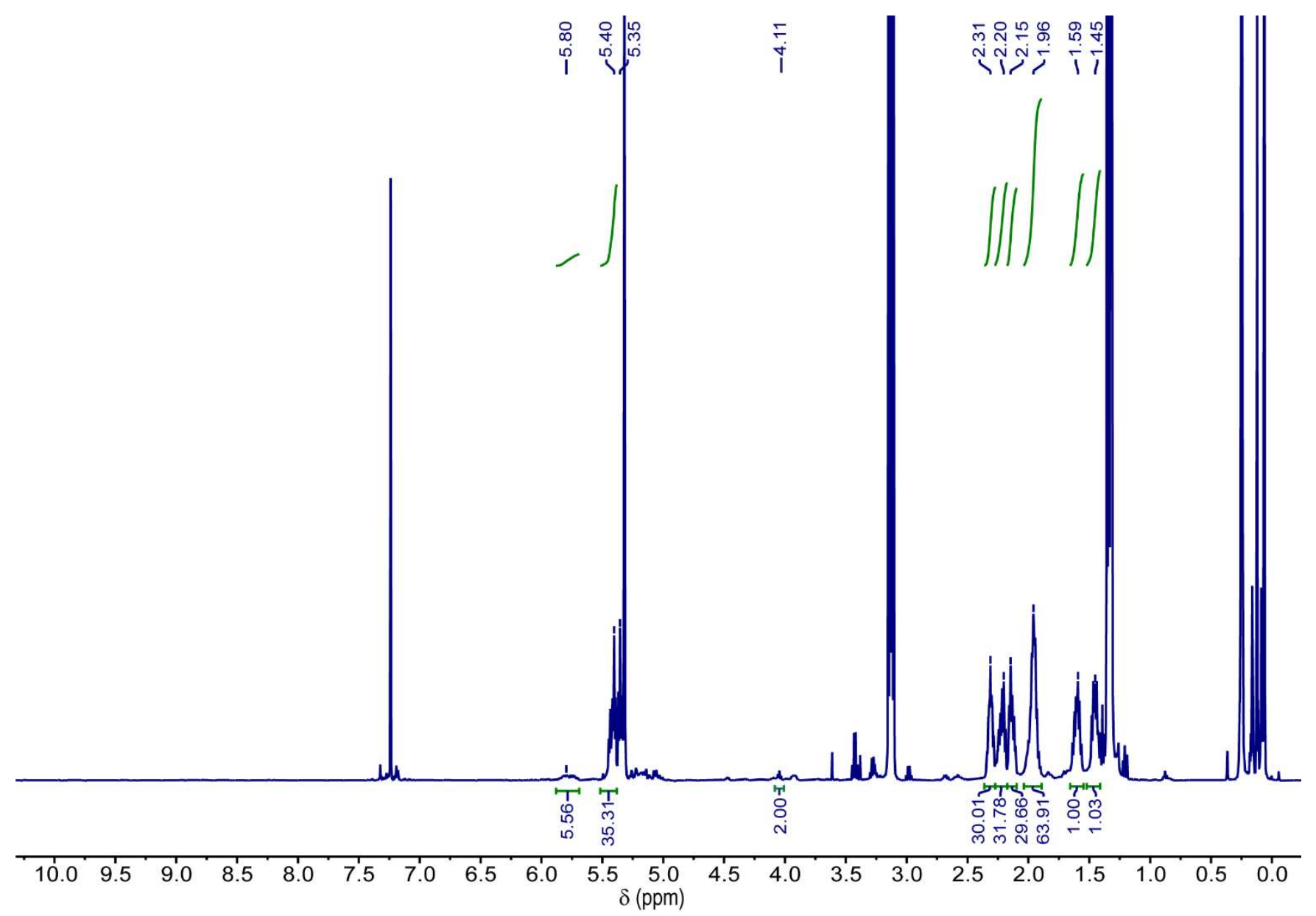

Figure S48. ${ }^{1} \mathrm{H}$ NMR $\left(600 \mathrm{MHz}, \mathrm{CD}_{2} \mathrm{Cl}_{2}, 23{ }^{\circ} \mathrm{C}\right)$ spectrum of $\mathbf{P 1}$. 


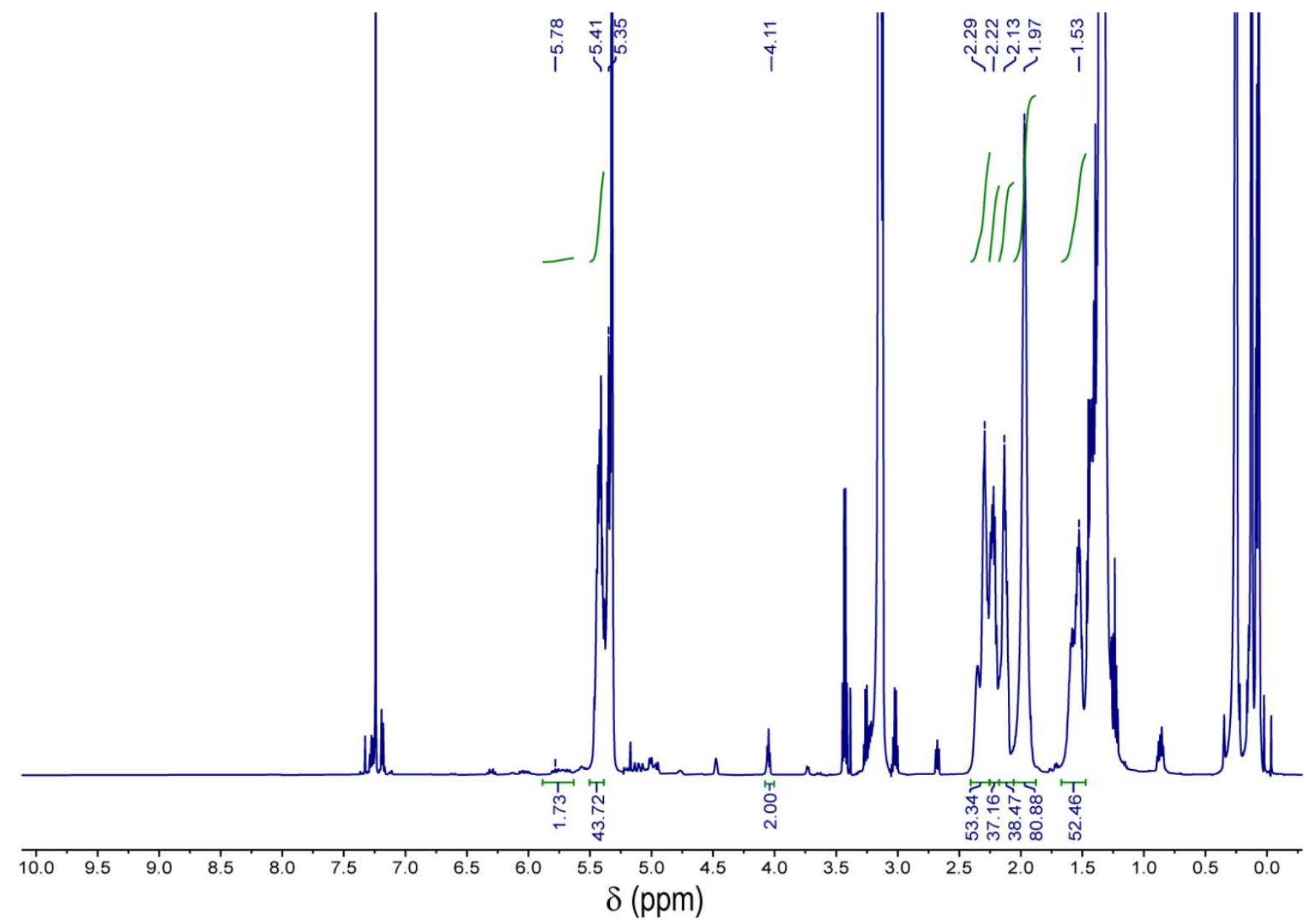

Figure S49. ${ }^{1} \mathrm{H} \mathrm{NMR}\left(600 \mathrm{MHz}, \mathrm{CD}_{2} \mathrm{Cl}_{2}, 23{ }^{\circ} \mathrm{C}\right)$ spectrum of $\mathbf{P 2}$. 


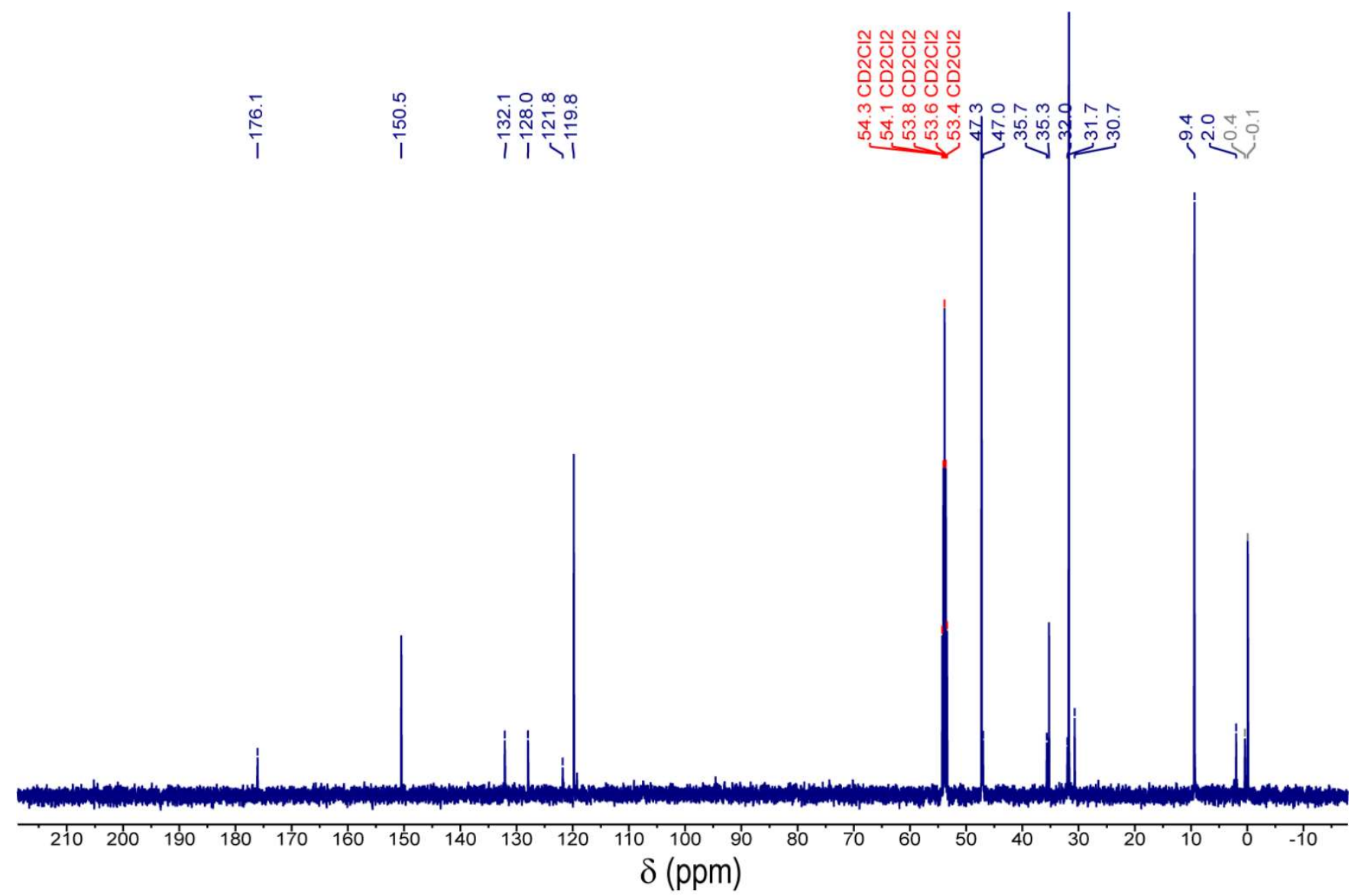

Figure S50. ${ }^{13} \mathrm{C}$ NMR $\left(150 \mathrm{MHz}, \mathrm{CD}_{2} \mathrm{Cl}_{2}, 23{ }^{\circ} \mathrm{C}\right)$ spectrum of P1'. 


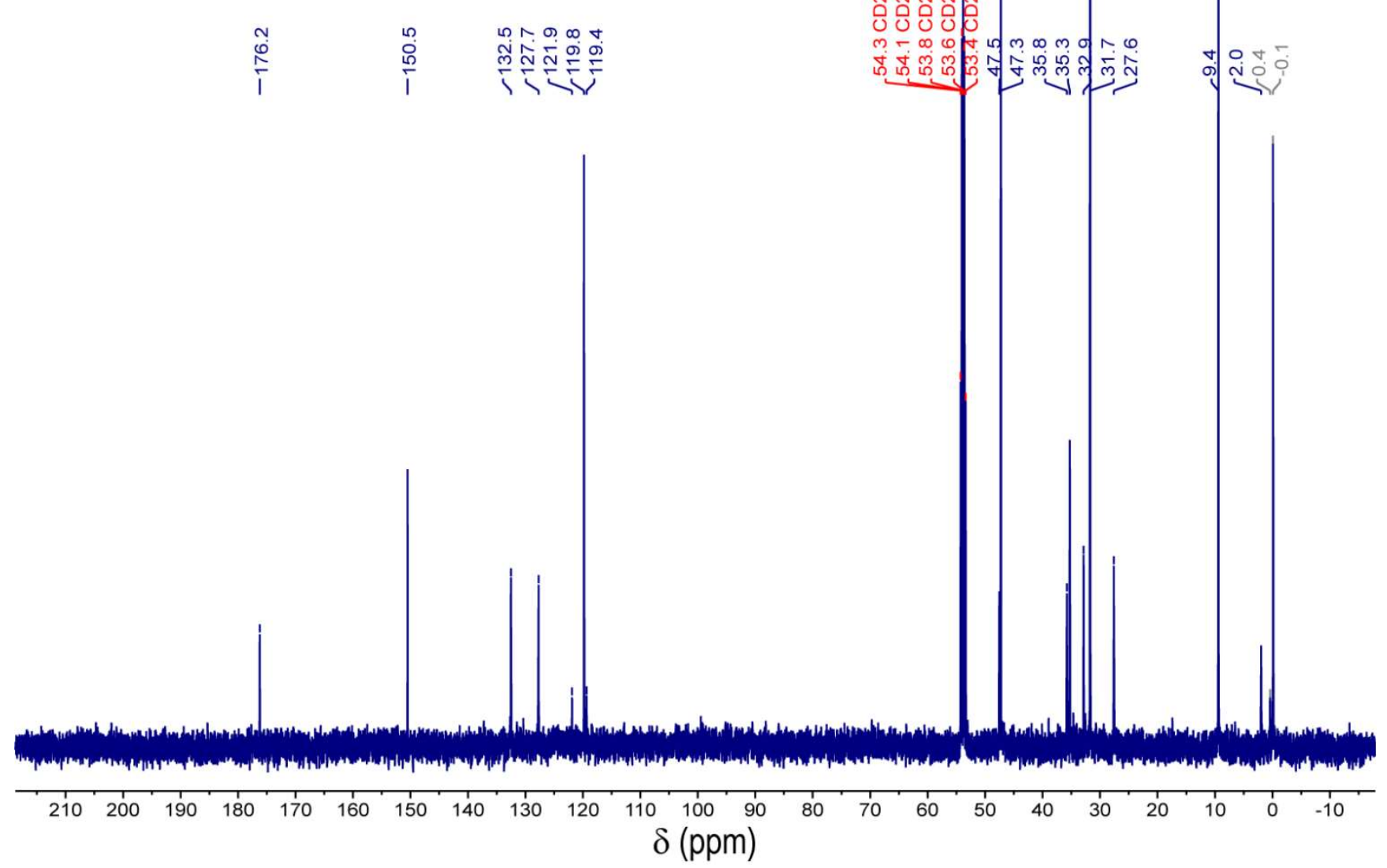

Figure S51. ${ }^{13} \mathrm{C}$ NMR $\left(150 \mathrm{MHz}, \mathrm{CD}_{2} \mathrm{Cl}_{2}, 23{ }^{\circ} \mathrm{C}\right)$ spectrum of $\mathbf{P 2}$. 

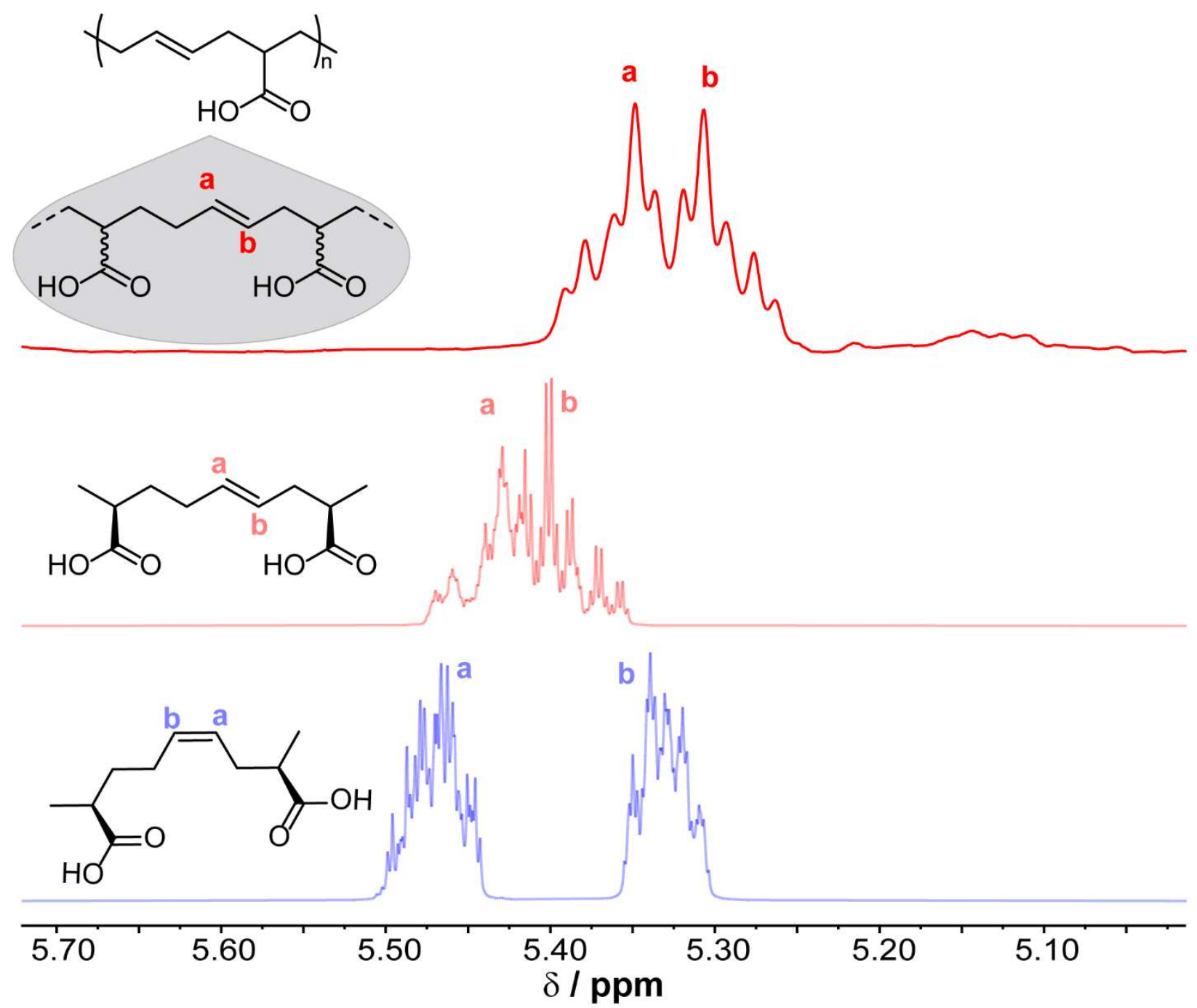

Figure S52. Observed ${ }^{1} \mathrm{H}$ NMR $\left(500 \mathrm{MHz}\right.$, DMSO- $\left.d_{6}, 23{ }^{\circ} \mathrm{C}\right)$ of the alkene backbone resonances of P1" (top) and predicted ${ }^{1} \mathrm{H}$ NMR spectra $\left(500 \mathrm{MHz}\right.$, DMSO- $\left.d_{6}\right)$ of $E$ - and $Z$-alkene small molecule analogues (bottom two) using MestreNova ${ }^{1} \mathrm{H}$ NMR Predict. 


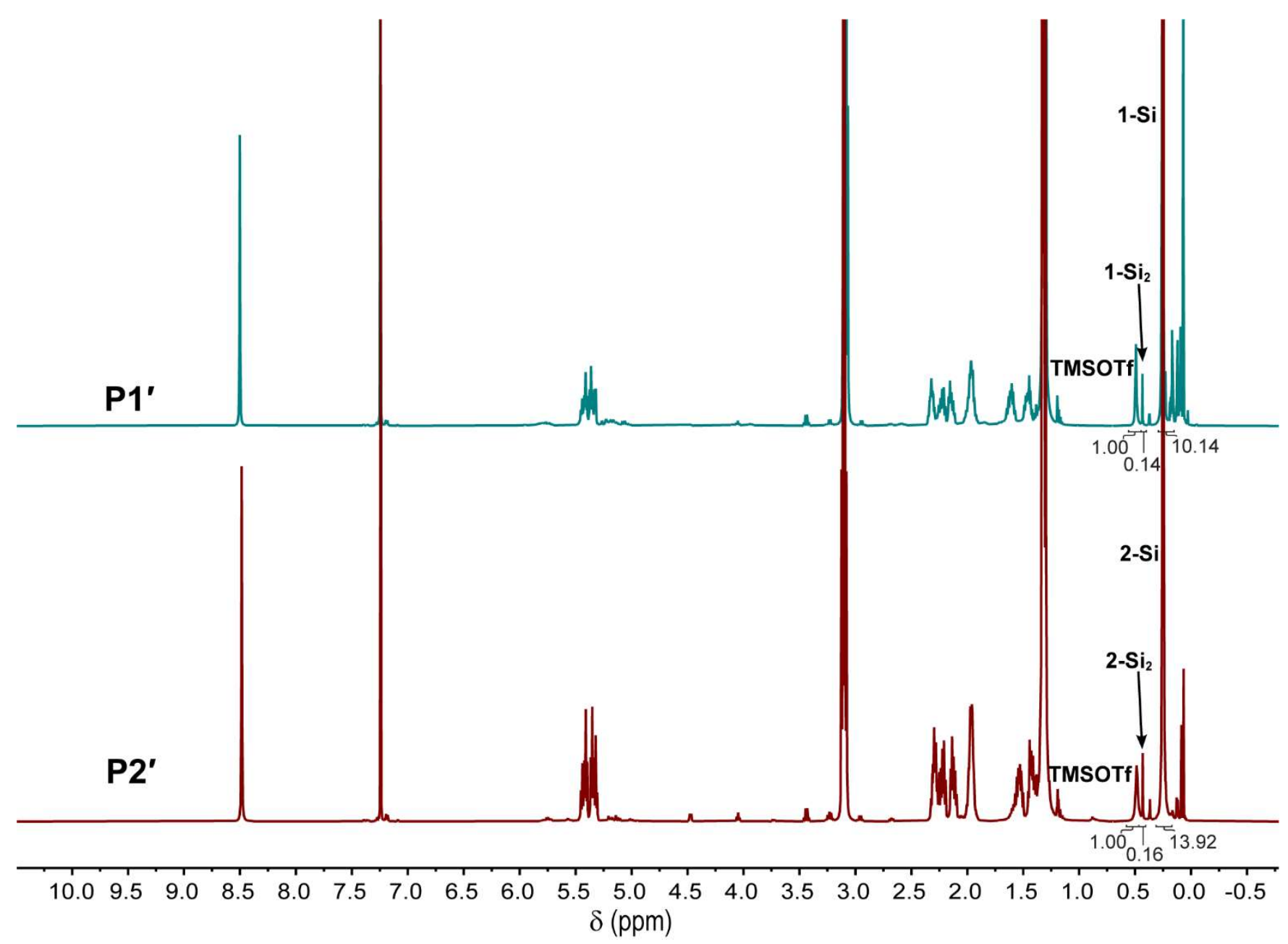

Figure S53. Representative ${ }^{1} \mathrm{H}$ NMR $\left(600 \mathrm{MHz}, \mathrm{CD}_{2} \mathrm{Cl}_{2}, 23{ }^{\circ} \mathrm{C}\right)$ spectrum of $\mathbf{P 1}$ ' and $\mathbf{P 2}$ ' with trimethylsilyl groups labeled, where 1-Si and 2-Si are the intermediate TMS-ester intermediates formed during Ireland-Claisen rearrangement and $\mathbf{1 - S \mathbf { i } _ { 2 }}$ and $\mathbf{2 - S \mathbf { S i } _ { 2 }}$ are the twice-silylated ester intermediates formed. 

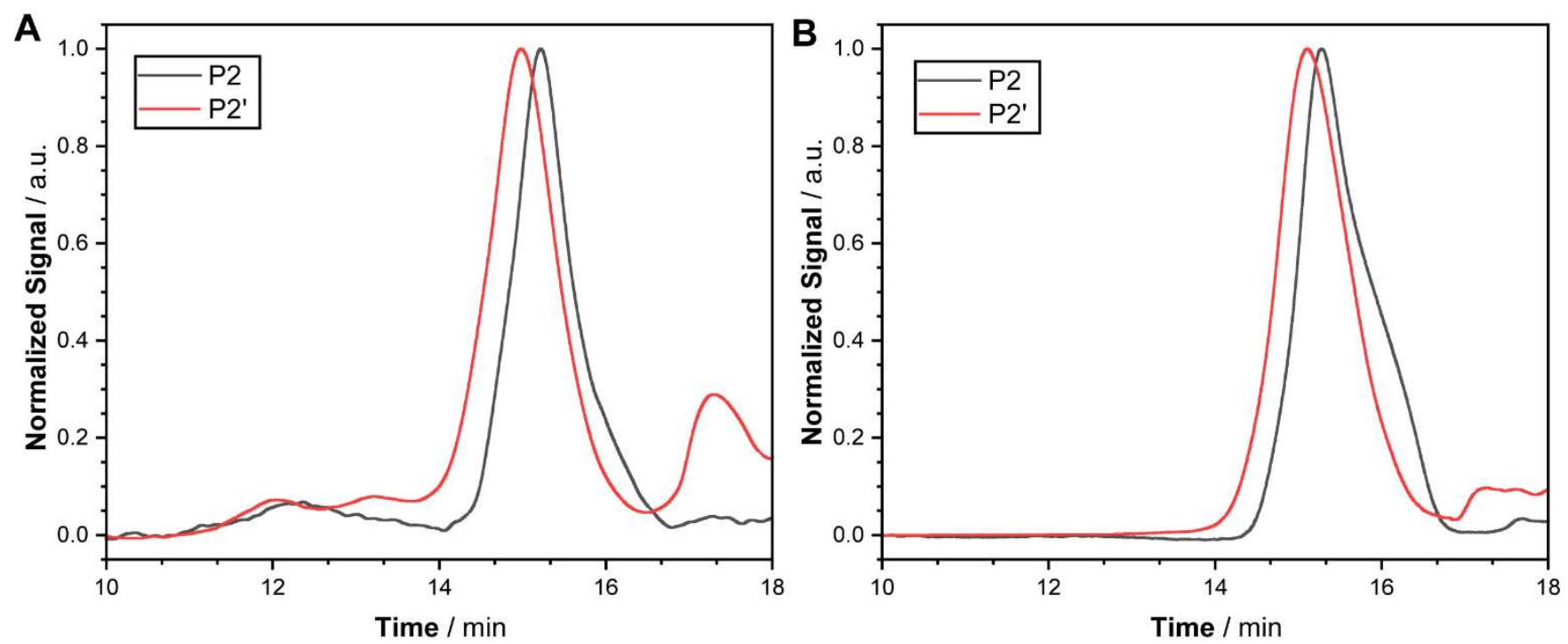

Figure S54. A.-B. Normalized GPC-MALS (A) light scattering (LS) and (B) differential refractive index $(\mathrm{dRI})$ traces of $\mathbf{P 2}\left(M_{\mathrm{n}}=4.91 \mathrm{~kg} \bullet \mathrm{mol}^{-1}, \mathrm{DP}=34, \mathrm{Ð}=1.15\right)$ and crude $\mathbf{P 2} \mathbf{2}^{\prime}\left(M_{\mathrm{n}}=8.63 \mathrm{~kg} \bullet \mathrm{mol}^{-1}, \mathrm{DP}=39\right.$, $\mathrm{Ð}=1.16) . \mathrm{dn} / \mathrm{dc}=0.0775 \mathrm{~mL} / \mathrm{g}$ for $\mathbf{P} 2$ and $\mathrm{dn} / \mathrm{dc}=0.0609 \mathrm{~mL} / \mathrm{g}$ for $\mathbf{P 2}{ }^{\prime}$. 


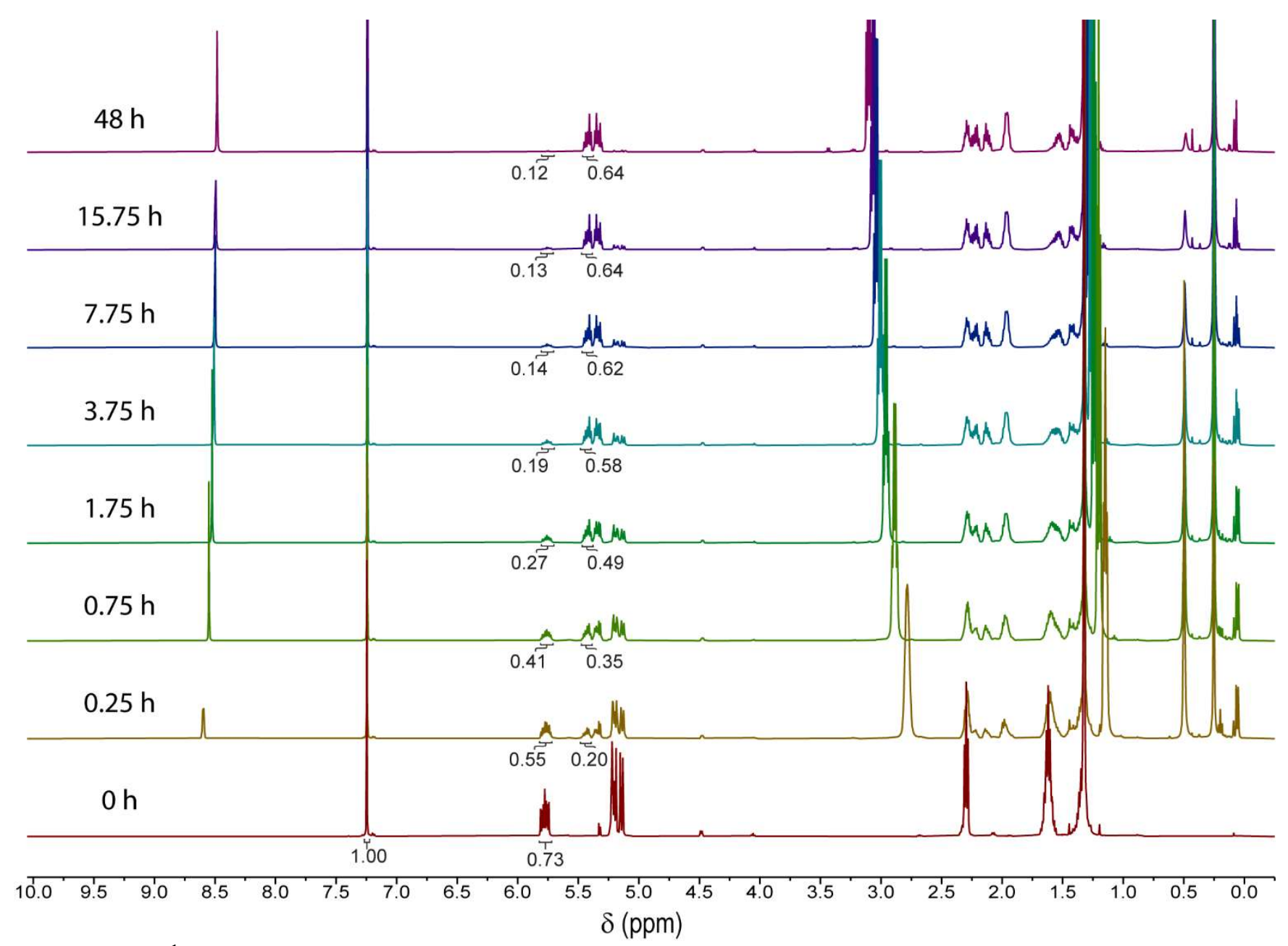

Figure S55. ${ }^{1} \mathrm{H}$ NMR $\left(600 \mathrm{MHz}, \mathrm{CD}_{2} \mathrm{Cl}_{2}, 23^{\circ} \mathrm{C}\right)$ at various times throughout the rearrangement of $\mathbf{P 1}$ to P1' with 1.20 equiv triethylamine and 1.15 equiv TMSOTf. 


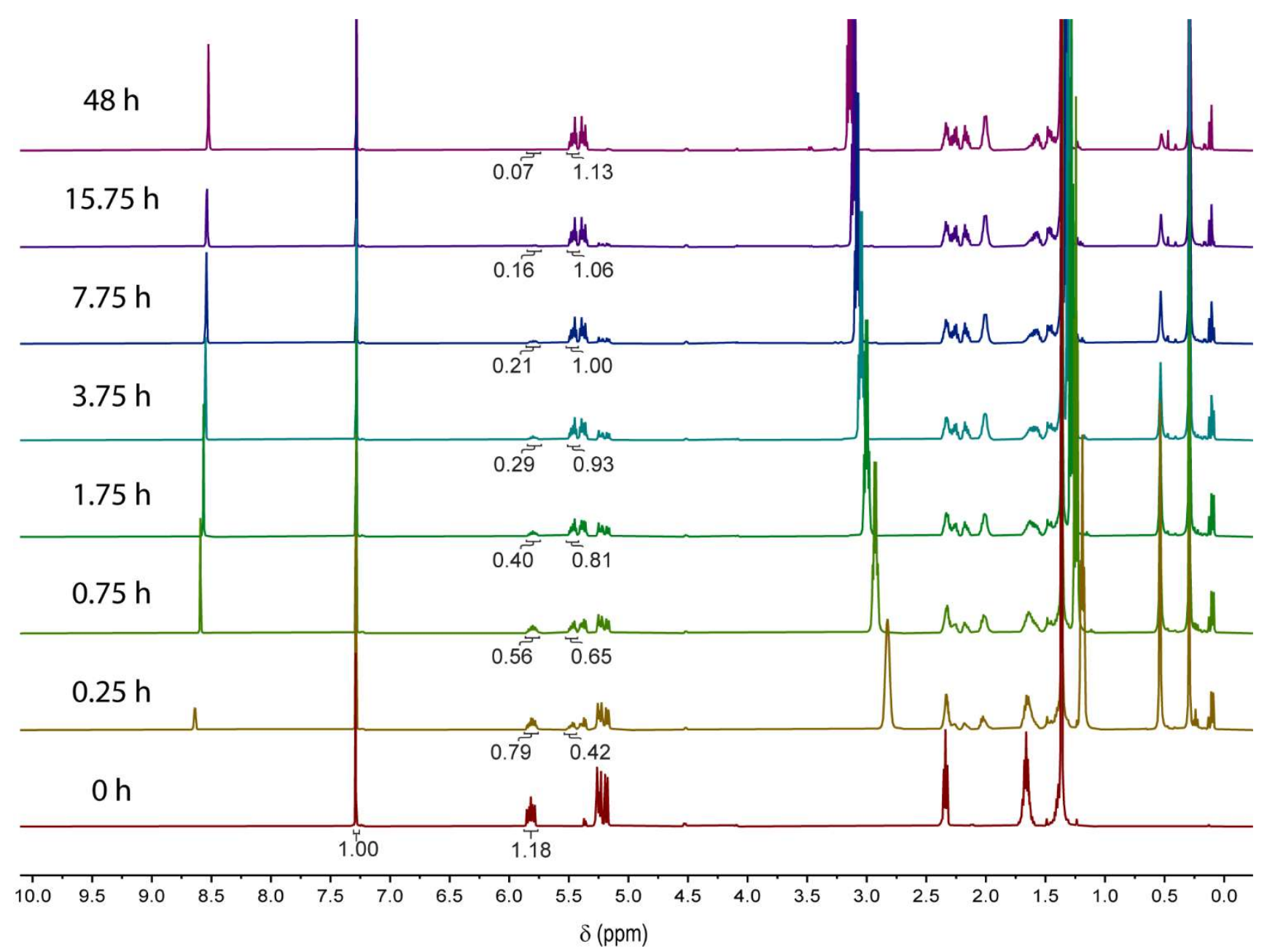

Figure S56. ${ }^{1} \mathrm{H}$ NMR $\left(600 \mathrm{MHz}, \mathrm{CD}_{2} \mathrm{Cl}_{2}, 23^{\circ} \mathrm{C}\right)$ at various times throughout the rearrangement of $\mathbf{P 2}$ to P2' with 1.20 equiv triethylamine and 1.15 equiv TMSOTf. 


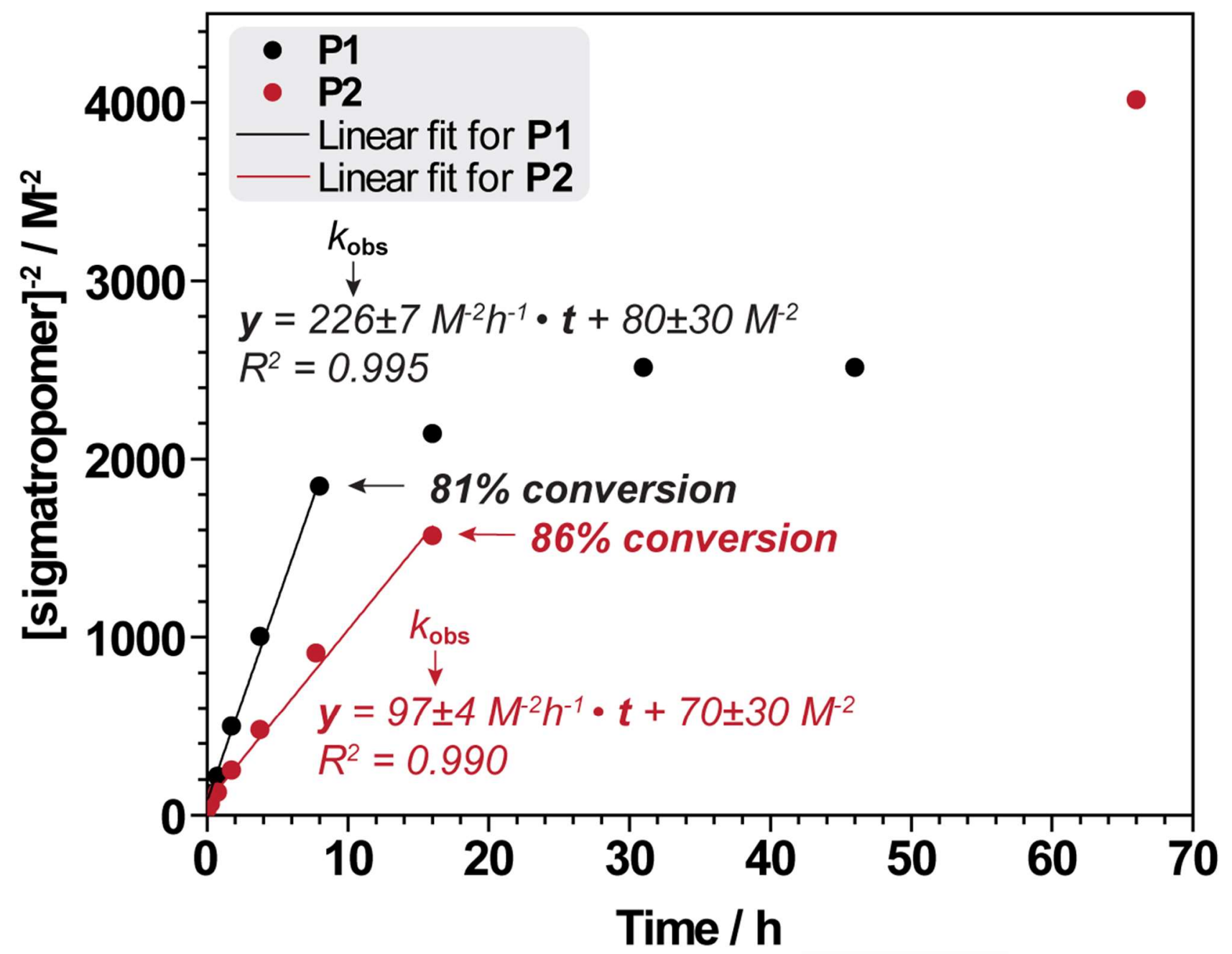

Figure S57. Kinetic plots for the rearrangement of $\mathbf{P 1}$ to $\mathbf{P 1} \mathbf{1}^{\prime}$ and $\mathbf{P 2}$ to $\mathbf{P 2}{ }^{\prime}$ using TMSOTf and triethylamine at $20{ }^{\circ} \mathrm{C}$ over 48 hours. See discussion of kinetics data analysis in the Supplementary Information section "Kinetic Analysis of the Ireland-Claisen Rearrangement of P1 and P2 to P1' and P2"' on page $\mathrm{S} 10$. 


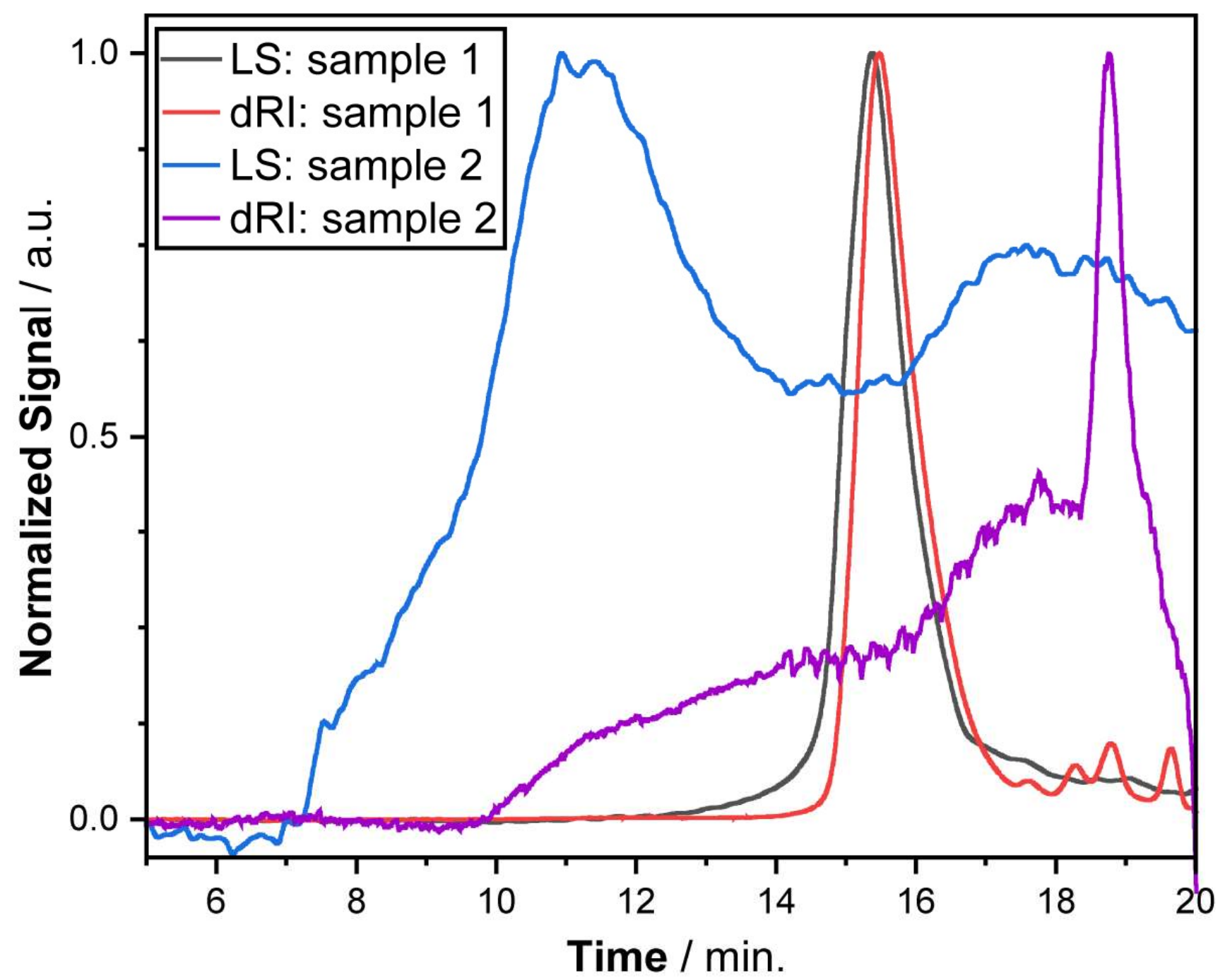

Figure S58. Normalized GPC-MALS light scattering (LS) and differential refractive index (dRI) traces of the rearranged and isolated material P1" showing variability in the GPC traces due to solubility and cross-linking in the material. 


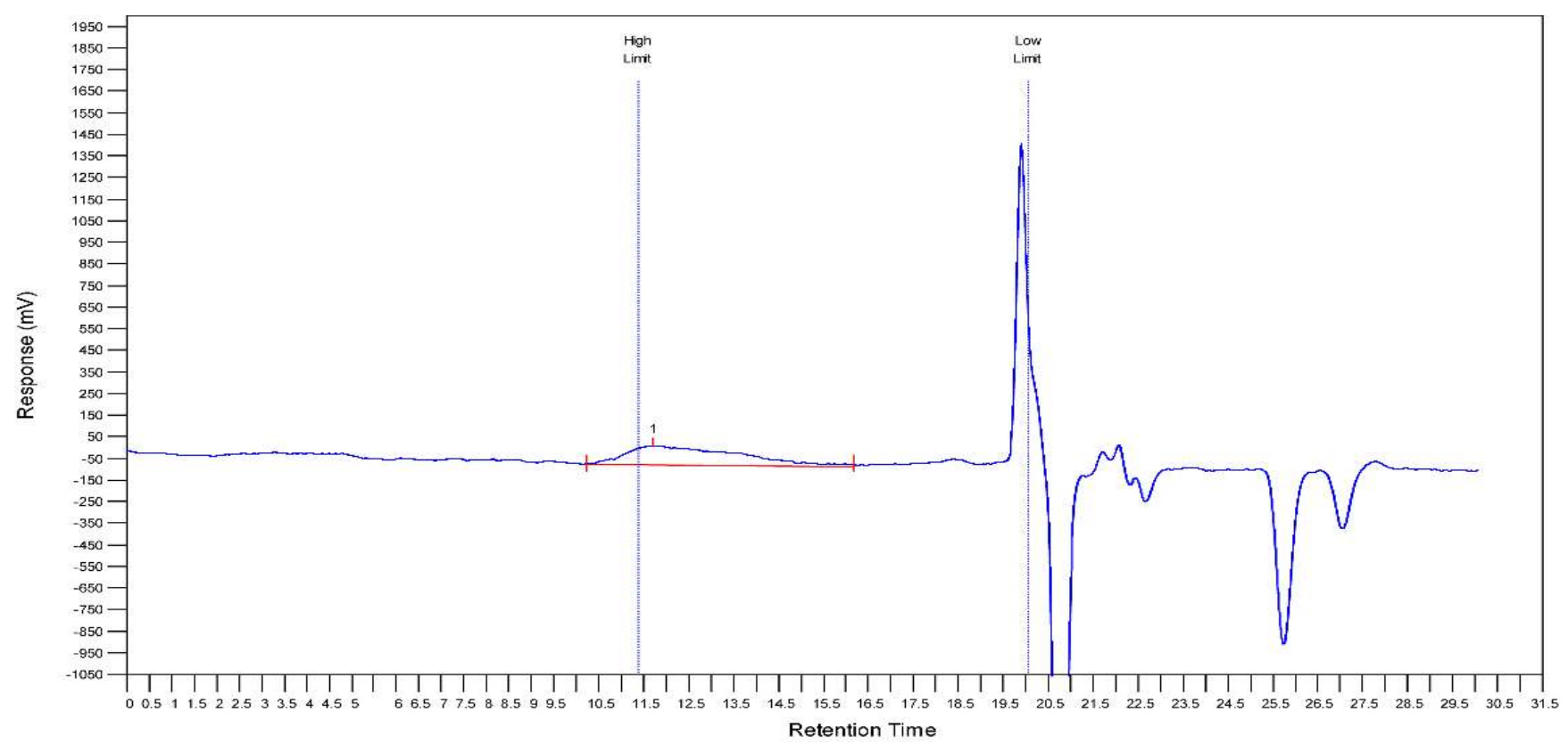

Figure S59. GPC differential refractive index (dRI) trace taken in DMF with $0.1 \mathrm{wt} \% \mathrm{LiBr}$ of the rearranged and isolated material P1" showing a broad peak due to low solubility of the polymer. 


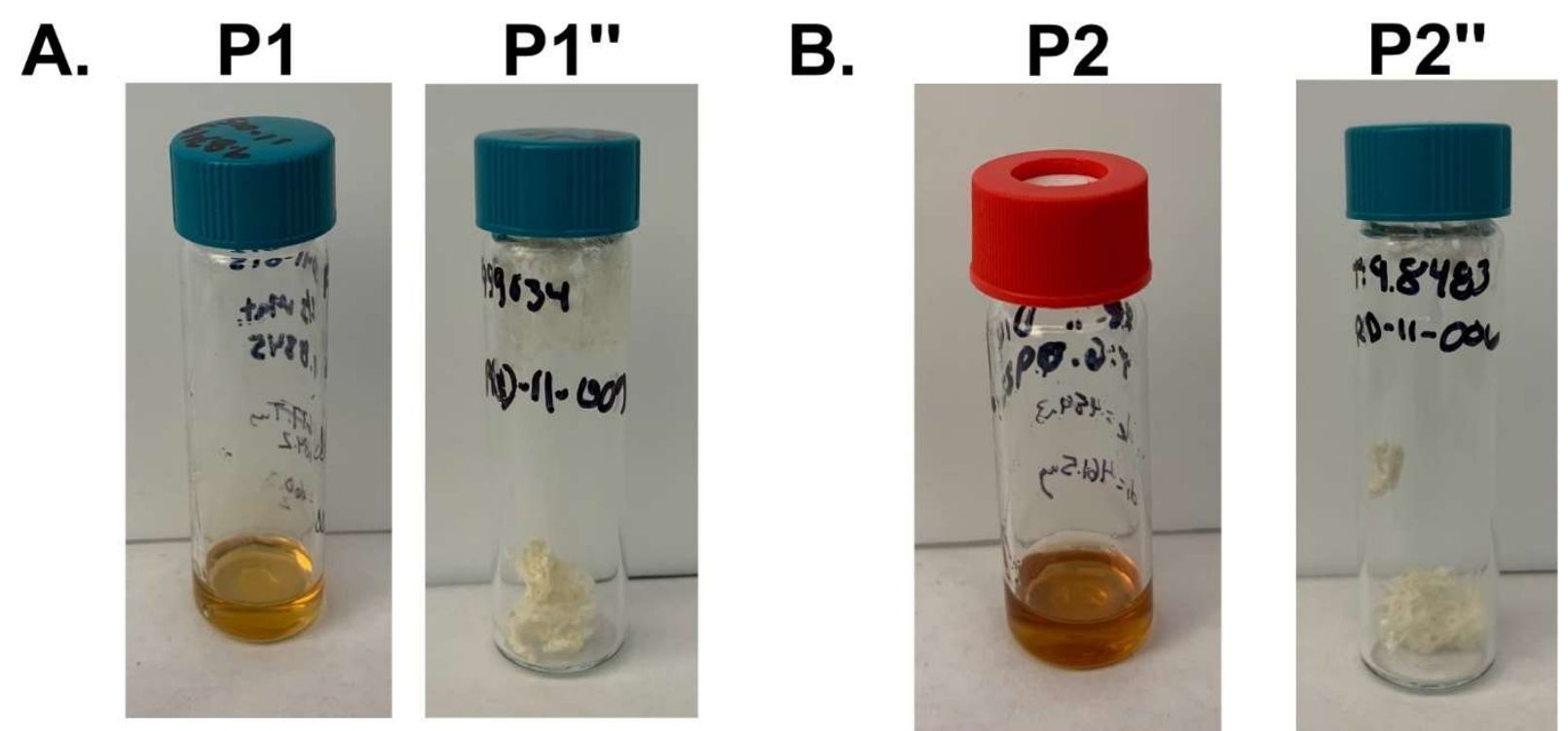

Figure S60. Pictures taken of the isolated pure materials A. P1 and P1" and B. P2 and P2". 


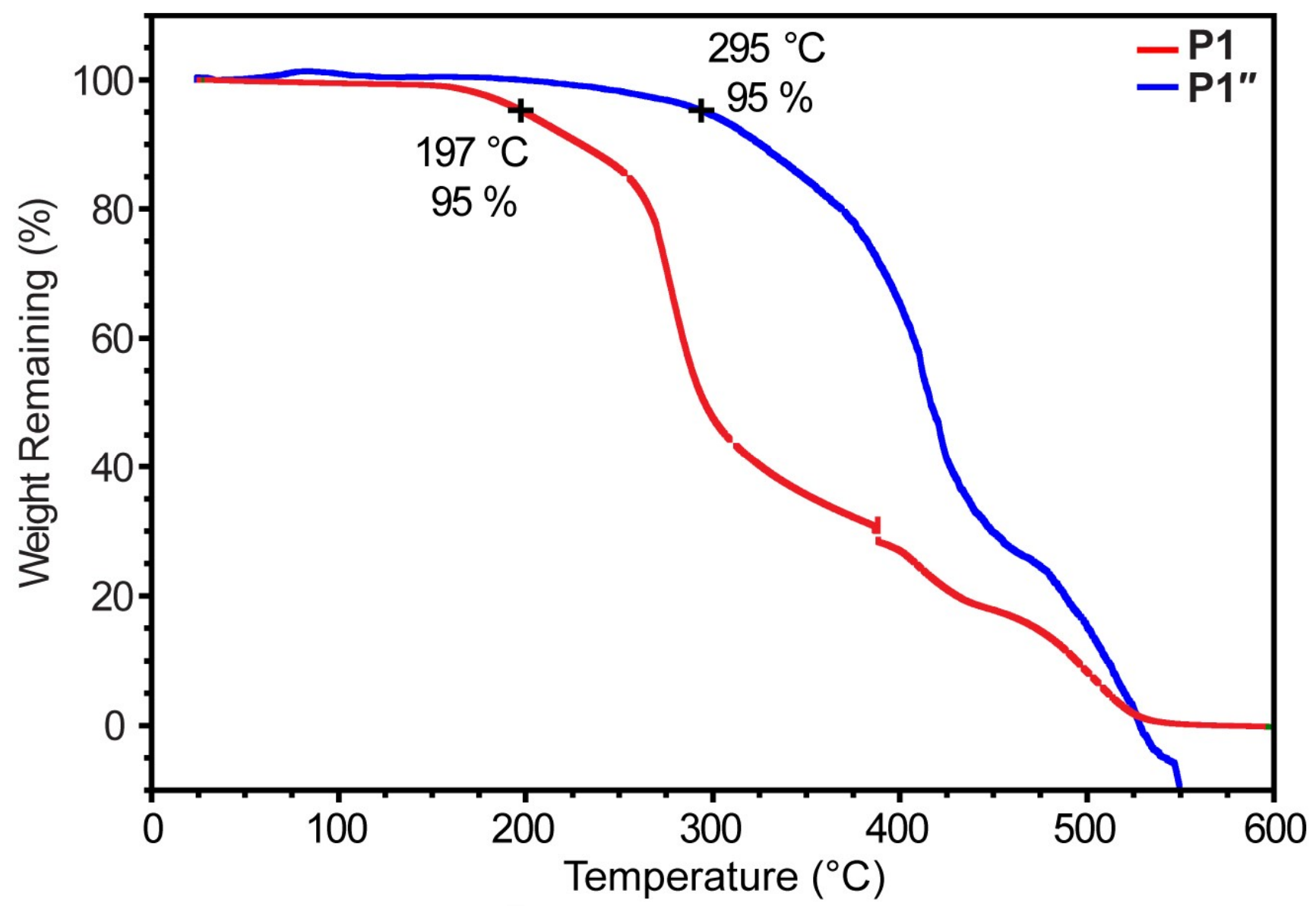

Figure S61. TGA traces for P1 and P1". 


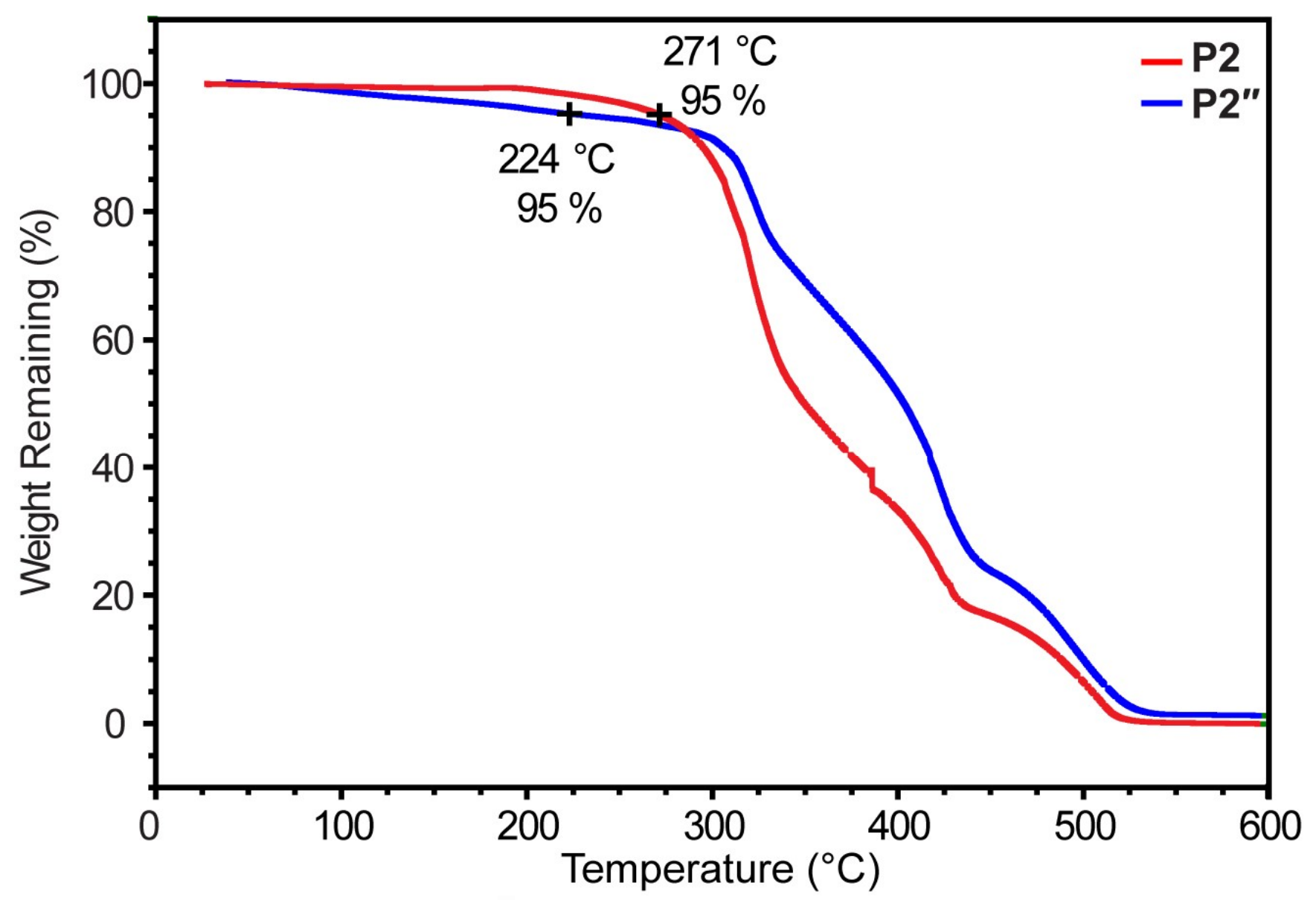

Figure S62. TGA traces for $\mathbf{P 2}$ and $\mathbf{P 2}$ ". 


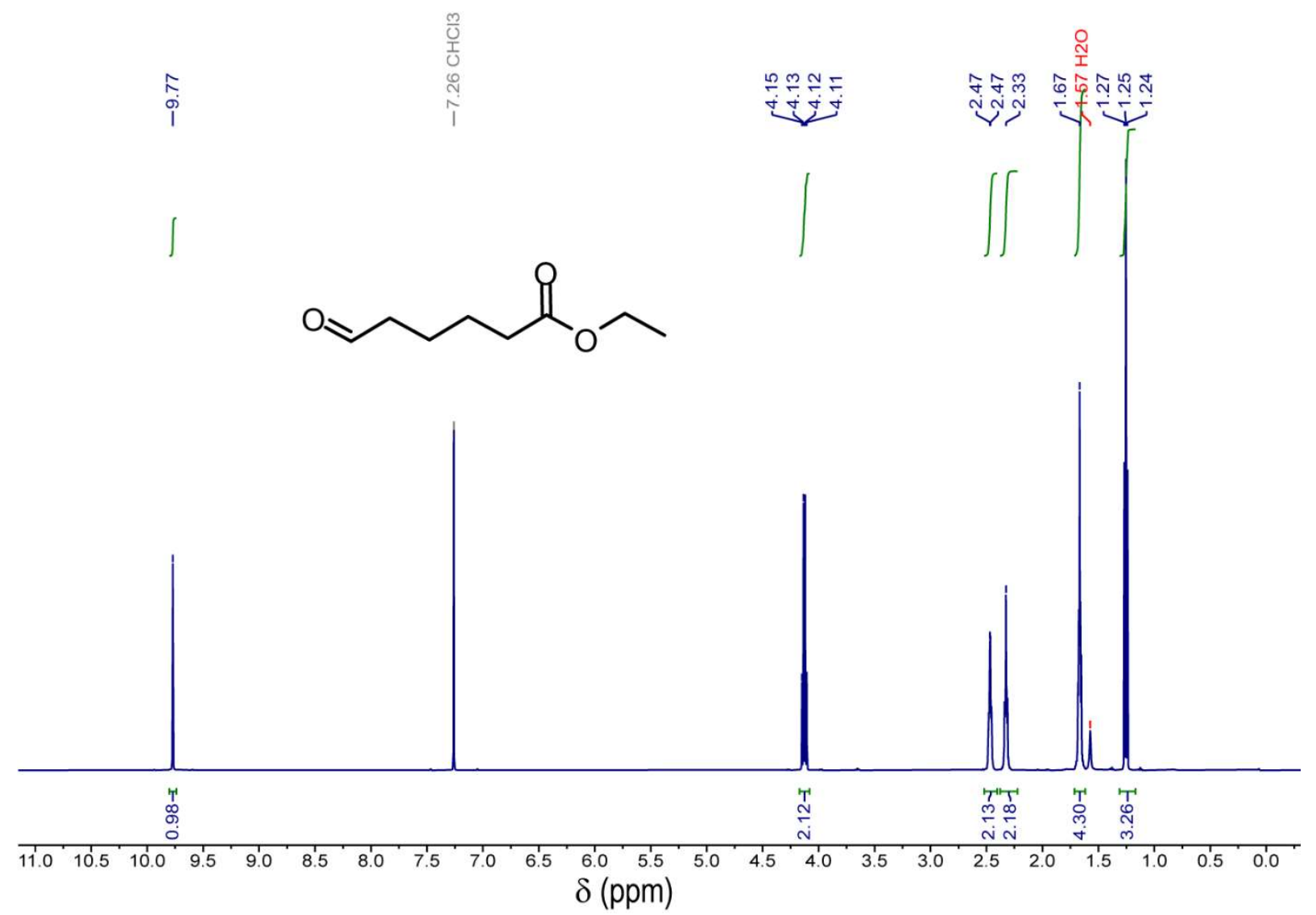

Figure S63. ${ }^{1} \mathrm{H}$ NMR $\left(500 \mathrm{MHz}, \mathrm{CDCl}_{3}, 23{ }^{\circ} \mathrm{C}\right)$ spectrum of compound $\mathbf{S 2}$. 


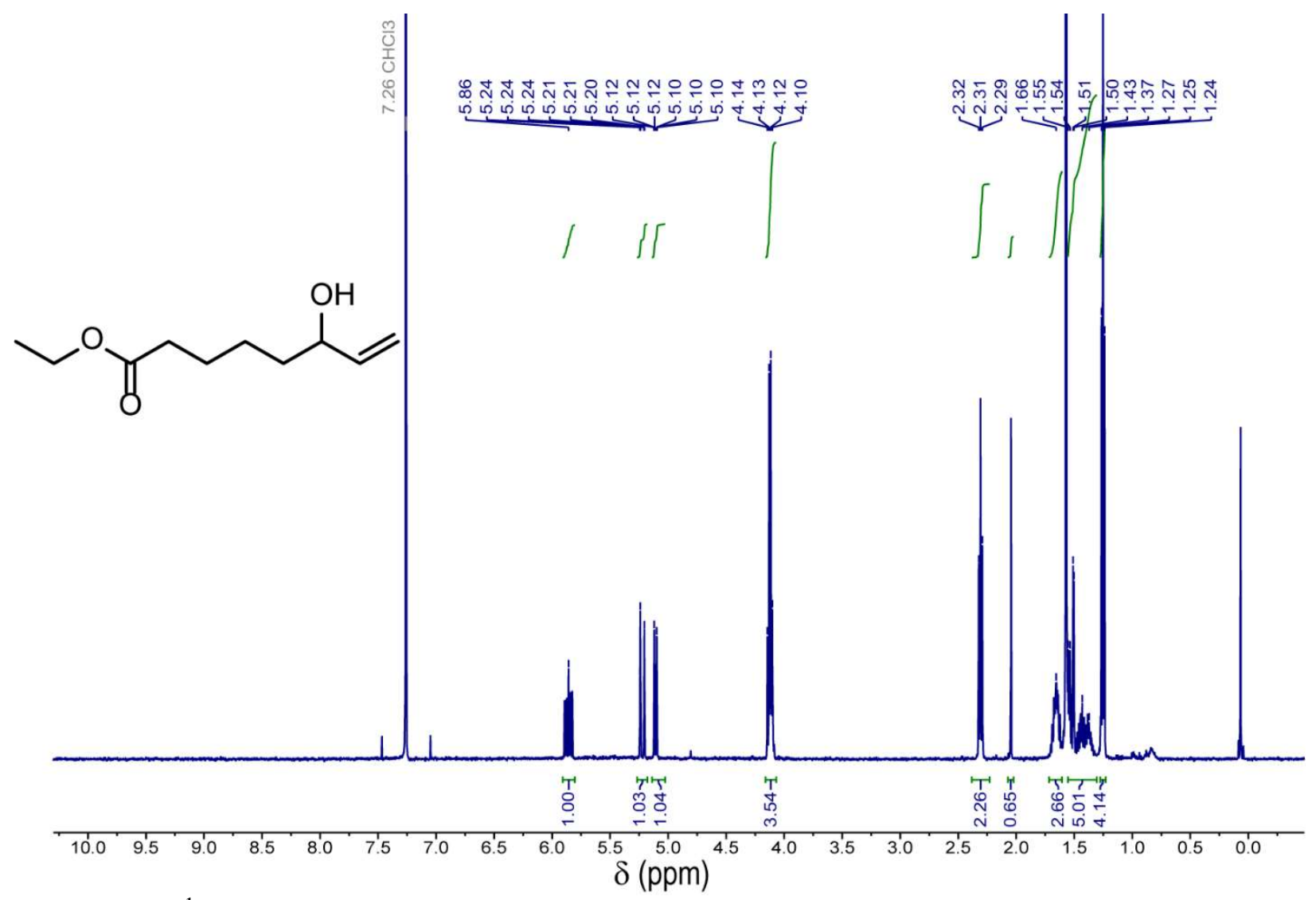

Figure S64. ${ }^{1} \mathrm{H} \mathrm{NMR}\left(500 \mathrm{MHz}, \mathrm{CDCl}_{3}, 23{ }^{\circ} \mathrm{C}\right)$ spectrum of compound $\mathbf{S 3}$. 


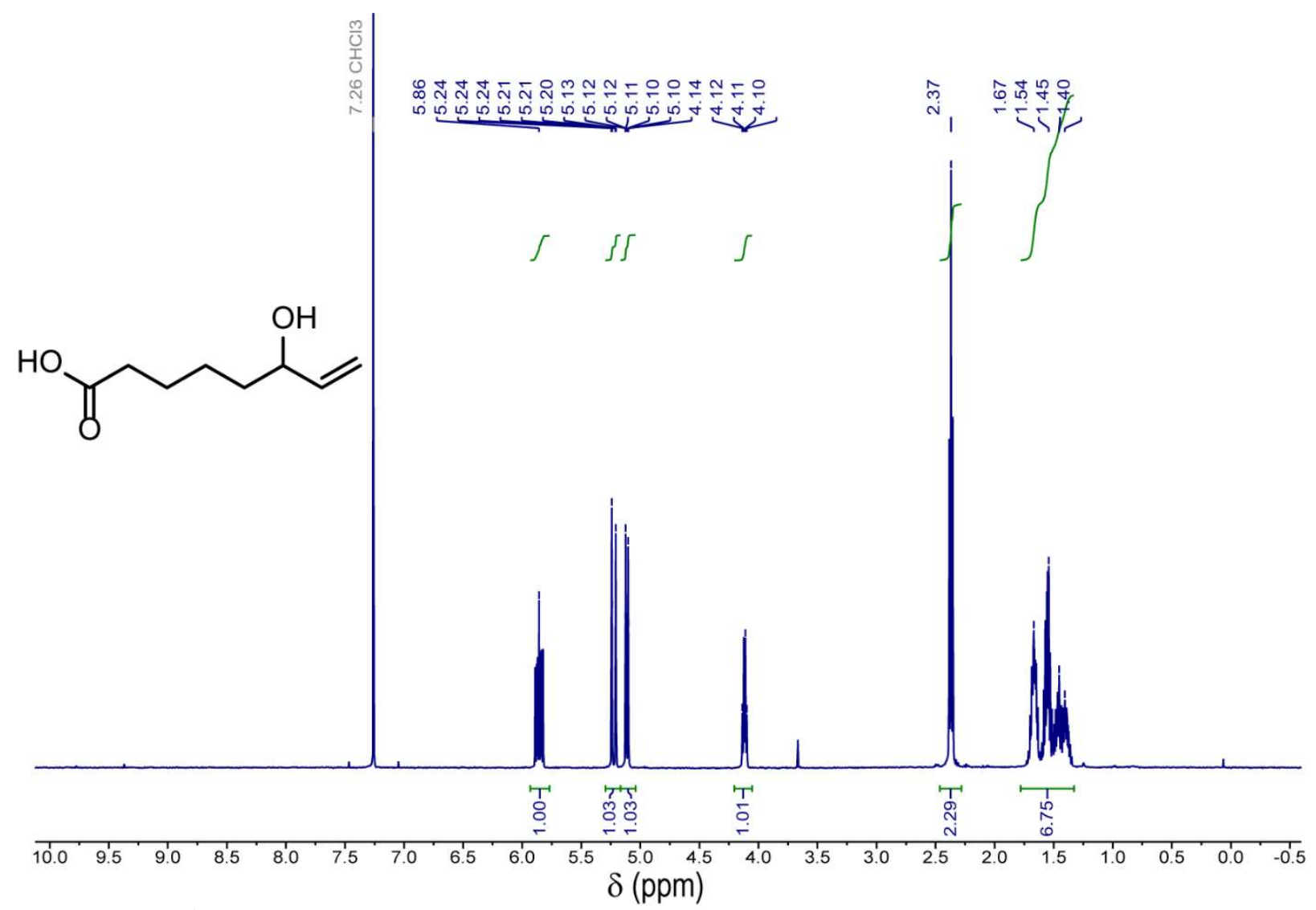

Figure S65. ${ }^{1} \mathrm{H} \mathrm{NMR}\left(500 \mathrm{MHz}, \mathrm{CDCl}_{3}, 23^{\circ} \mathrm{C}\right)$ spectrum of monomer $\mathbf{S 4}$. 


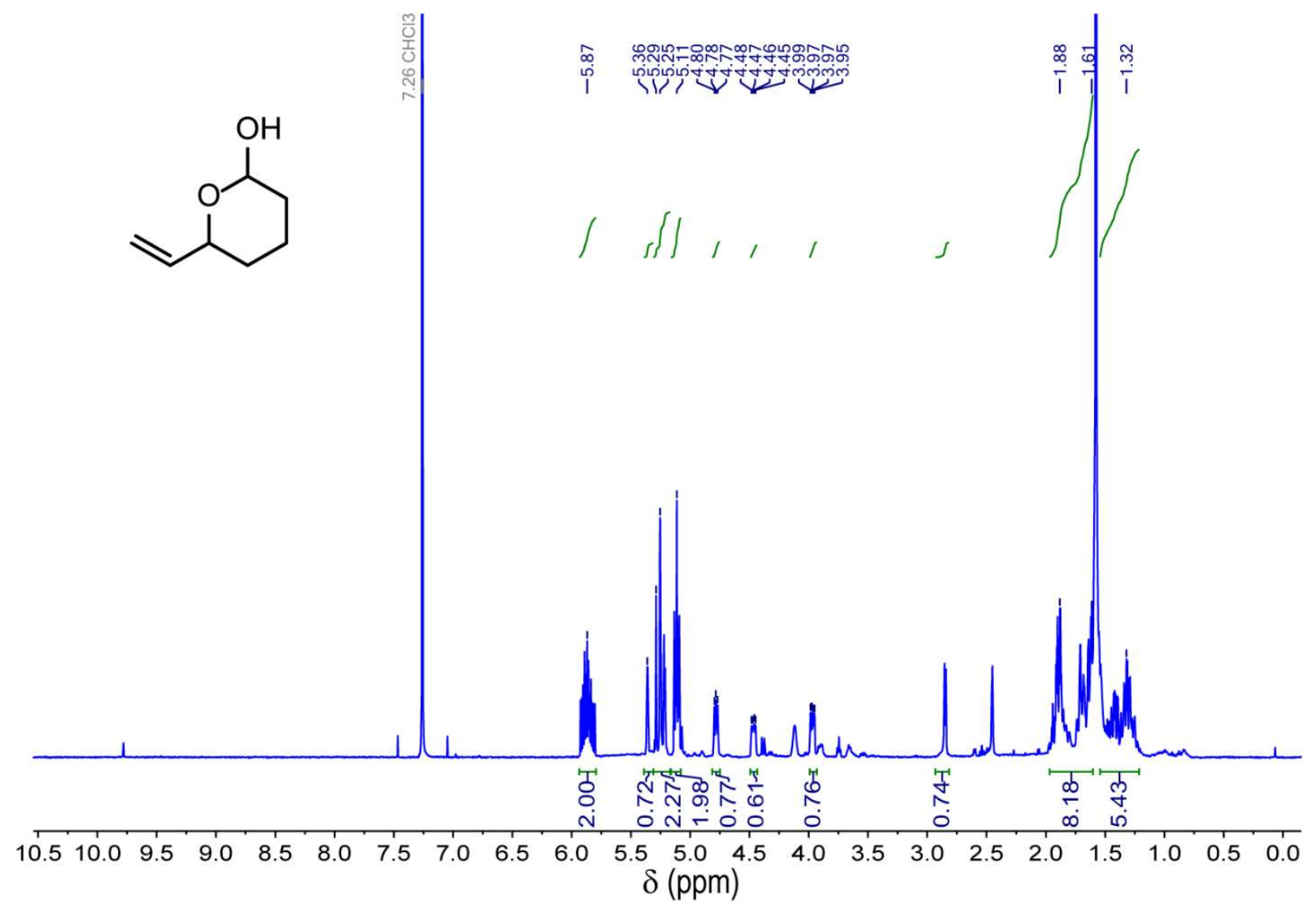

Figure S66. ${ }^{1} \mathrm{H}$ NMR $\left(500 \mathrm{MHz}, \mathrm{CDCl}_{3}, 23{ }^{\circ} \mathrm{C}\right)$ spectrum of monomer S6. 


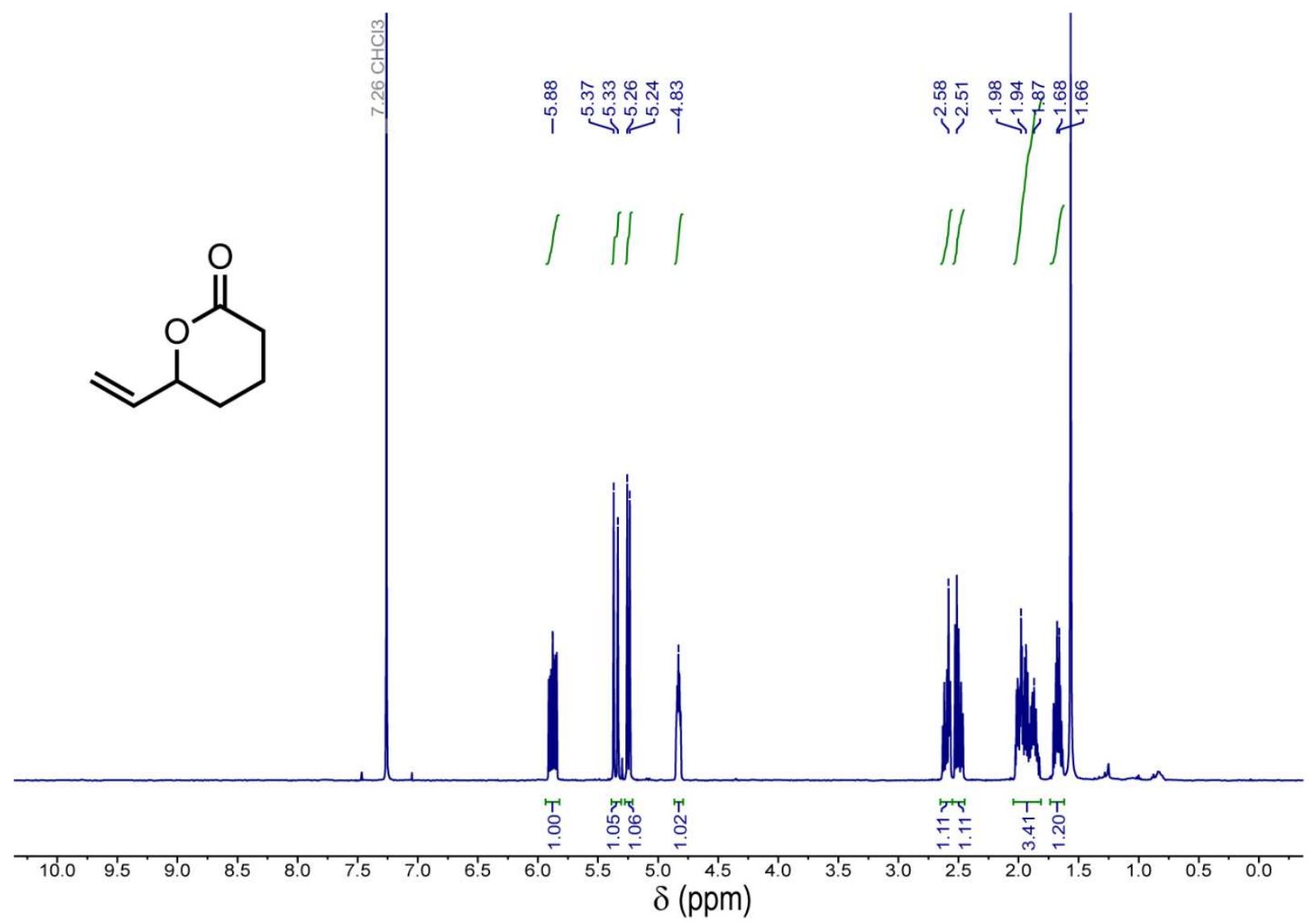

Figure S67. ${ }^{1} \mathrm{H} \mathrm{NMR}\left(500 \mathrm{MHz}, \mathrm{CDCl}_{3}, 23{ }^{\circ} \mathrm{C}\right)$ spectrum of monomer 1. 


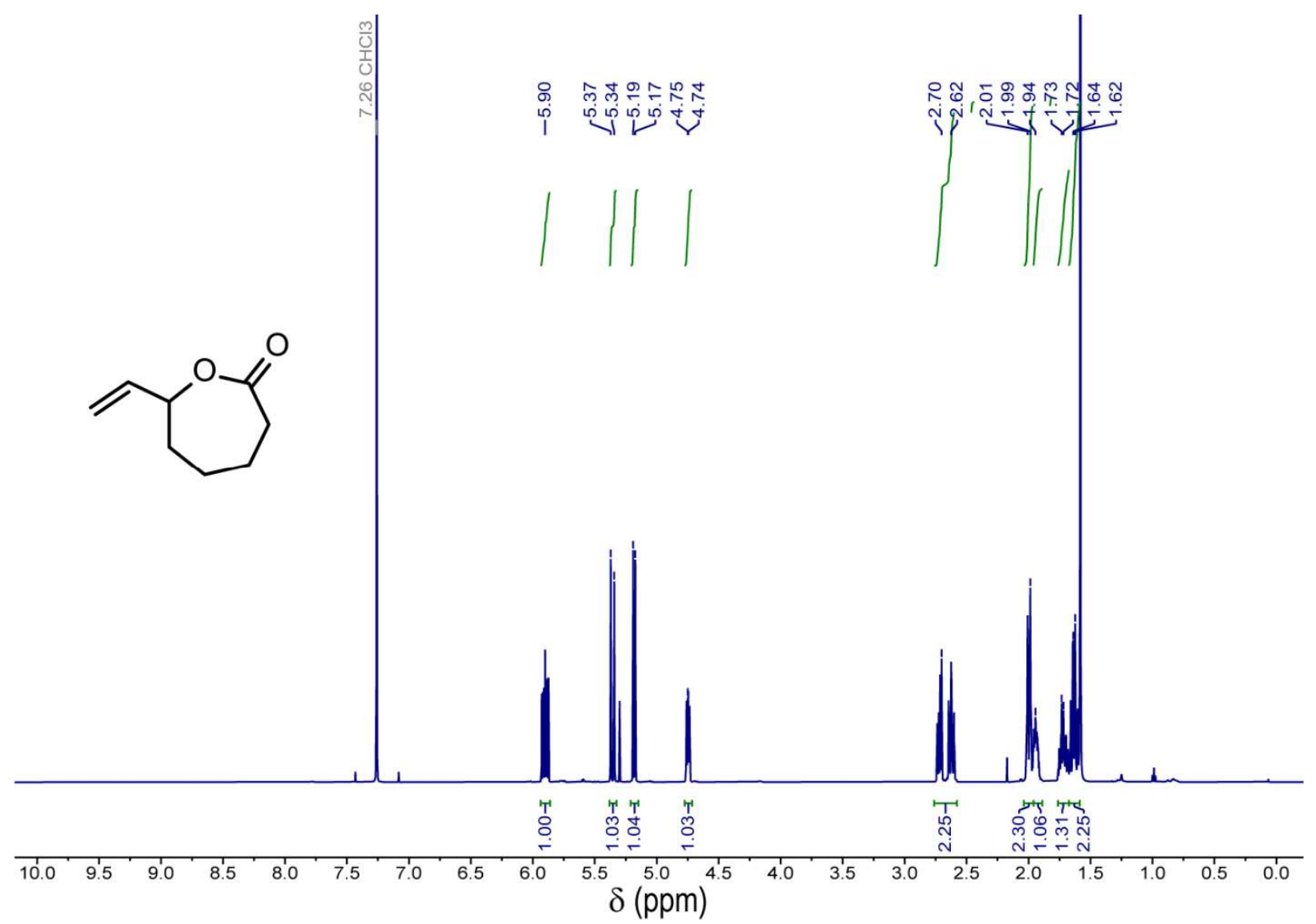

Figure S68. ${ }^{1} \mathrm{H} \mathrm{NMR}\left(500 \mathrm{MHz}, \mathrm{CDCl}_{3}, 23{ }^{\circ} \mathrm{C}\right)$ spectrum of monomer 2 


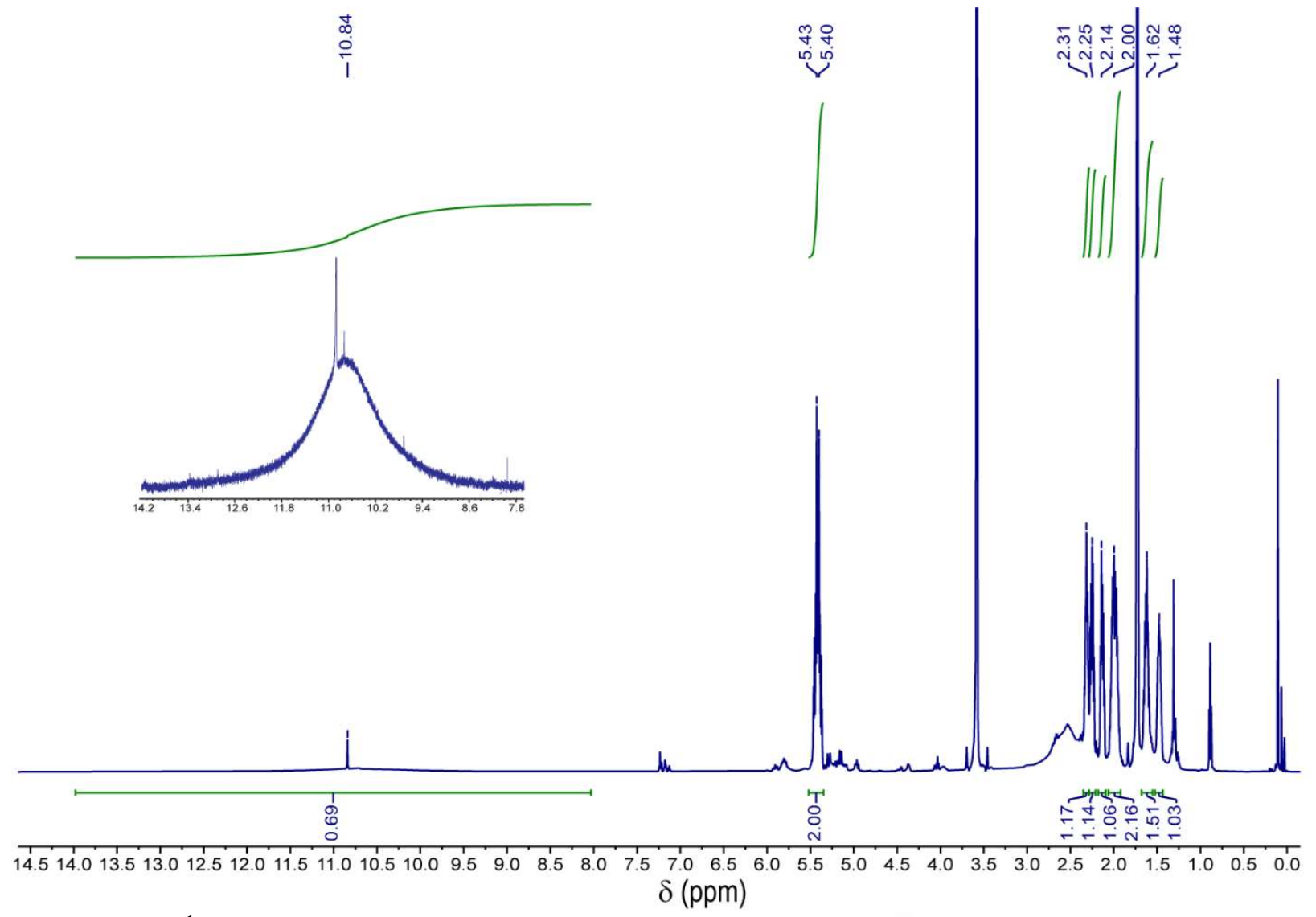

Figure S69. ${ }^{1} \mathrm{H}$ NMR $\left(600 \mathrm{MHz}, \mathrm{THF}-d_{8}, 23{ }^{\circ} \mathrm{C}\right)$ spectrum of P1" synthesized from P1 with the region from $14.2-7.8 \mathrm{ppm}$ magnified to show the presence of the carboxylic acid proton. 


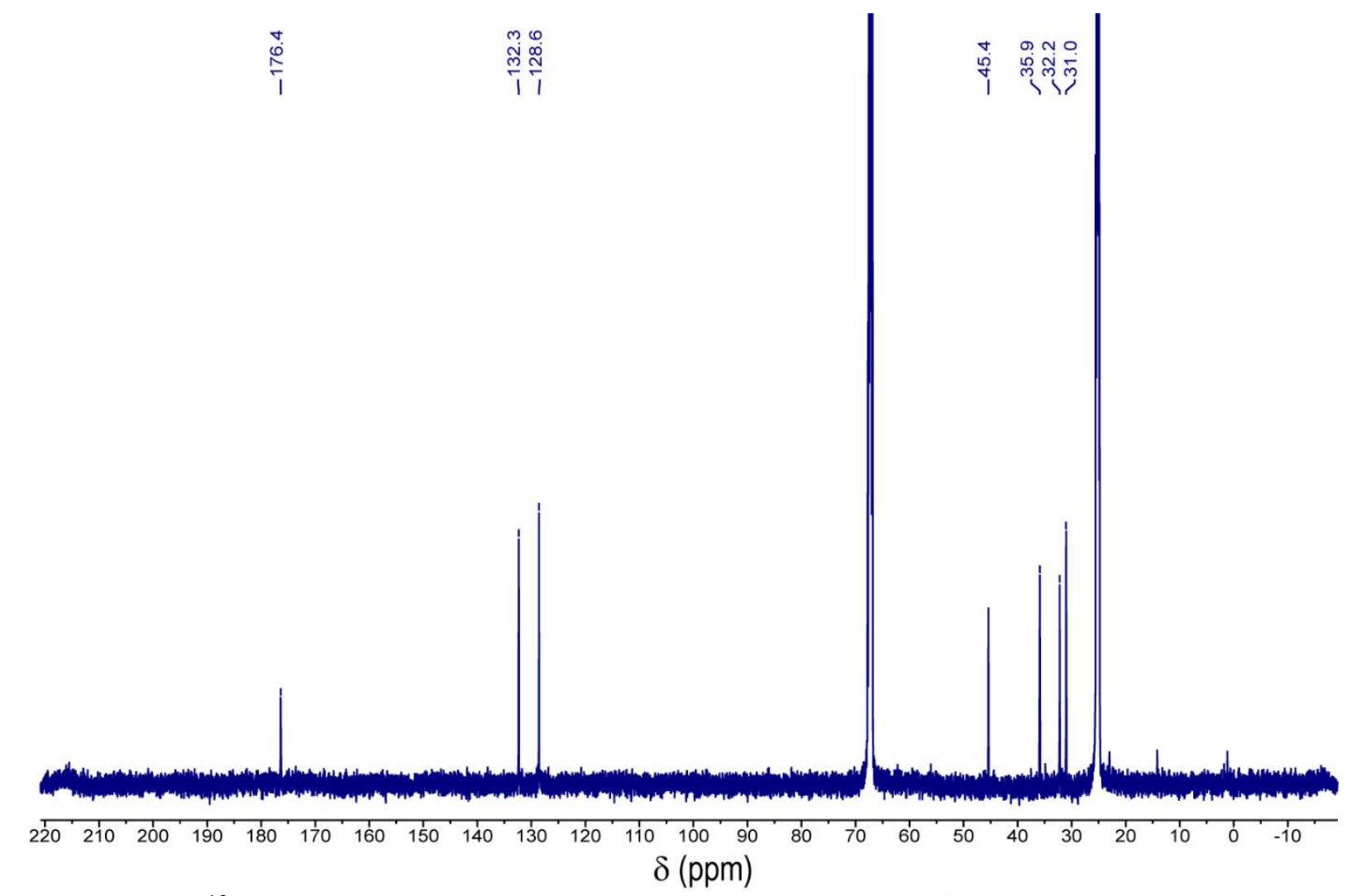

Figure S70. ${ }^{13} \mathrm{C}$ NMR $\left(150 \mathrm{MHz}\right.$, THF- $\left.d 8,23{ }^{\circ} \mathrm{C}\right)$ spectrum of P1" synthesized from P1. 


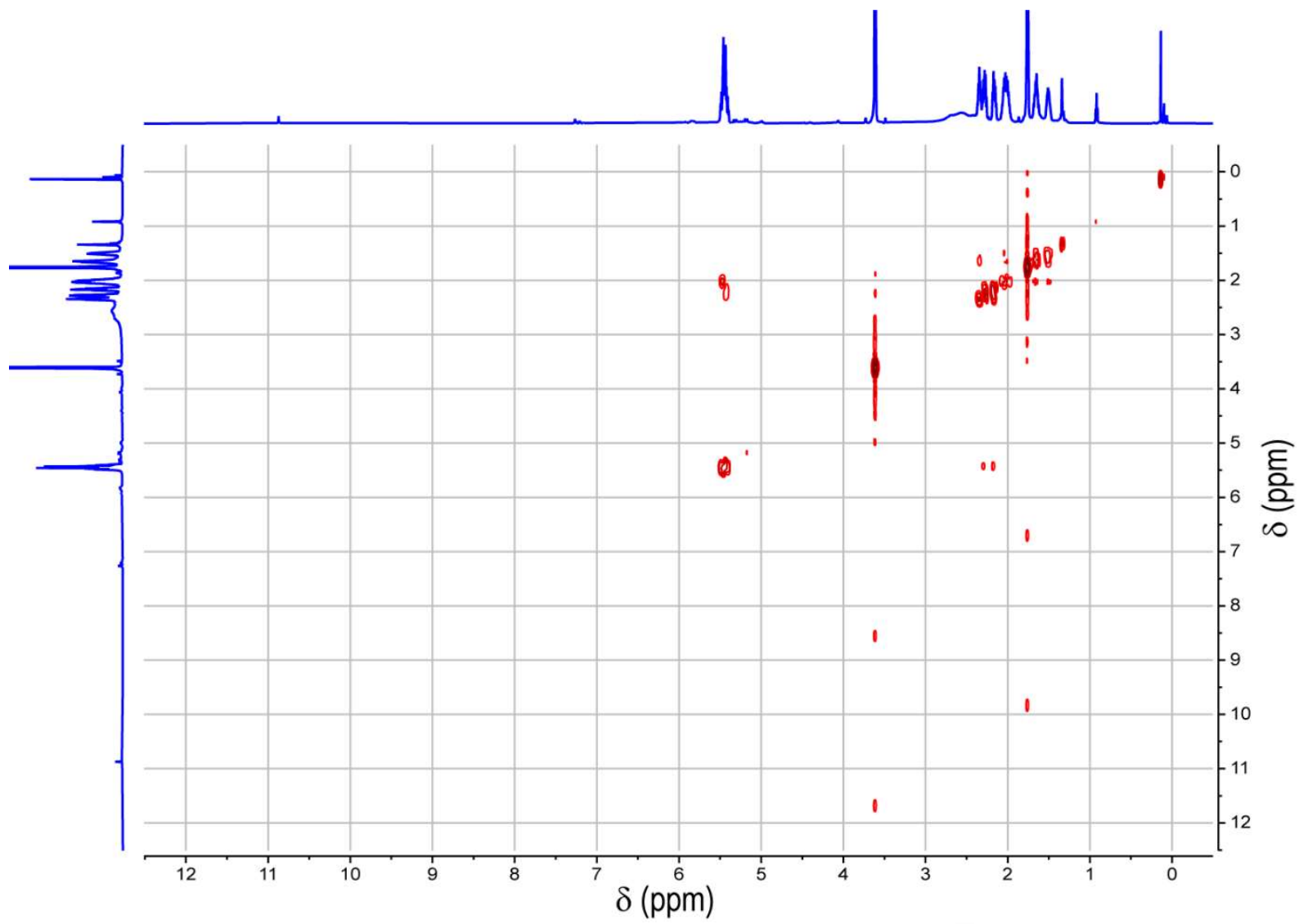

Figure S71. COSY NMR (600 MHz, THF- $\left.d_{8}, 23^{\circ} \mathrm{C}\right)$ spectrum of P1" synthesized from P1. 


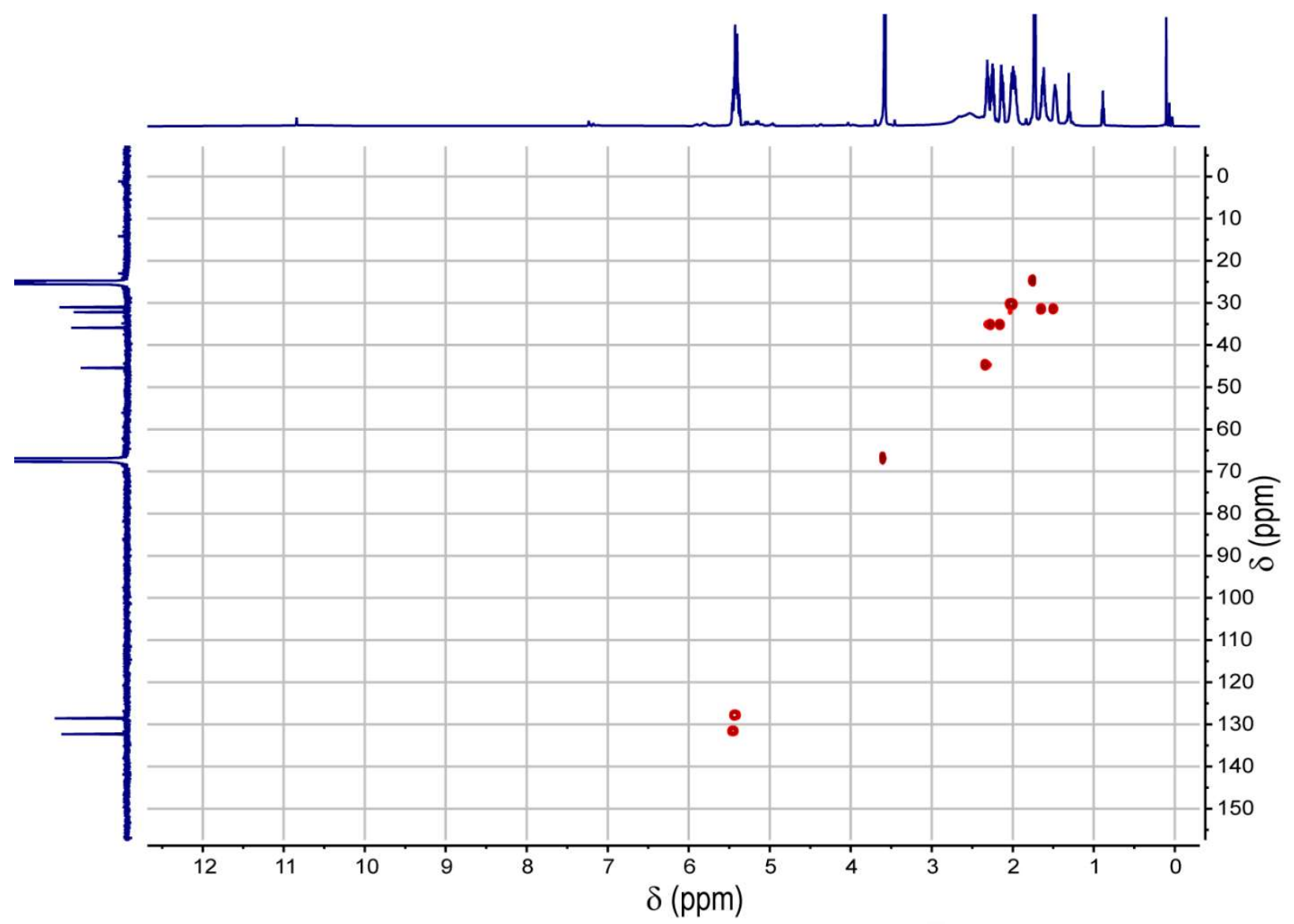

Figure S72. HSQC NMR (600 MHz, THF- $\left.d 8,23{ }^{\circ} \mathrm{C}\right)$ spectrum of P1" synthesized from P1. 


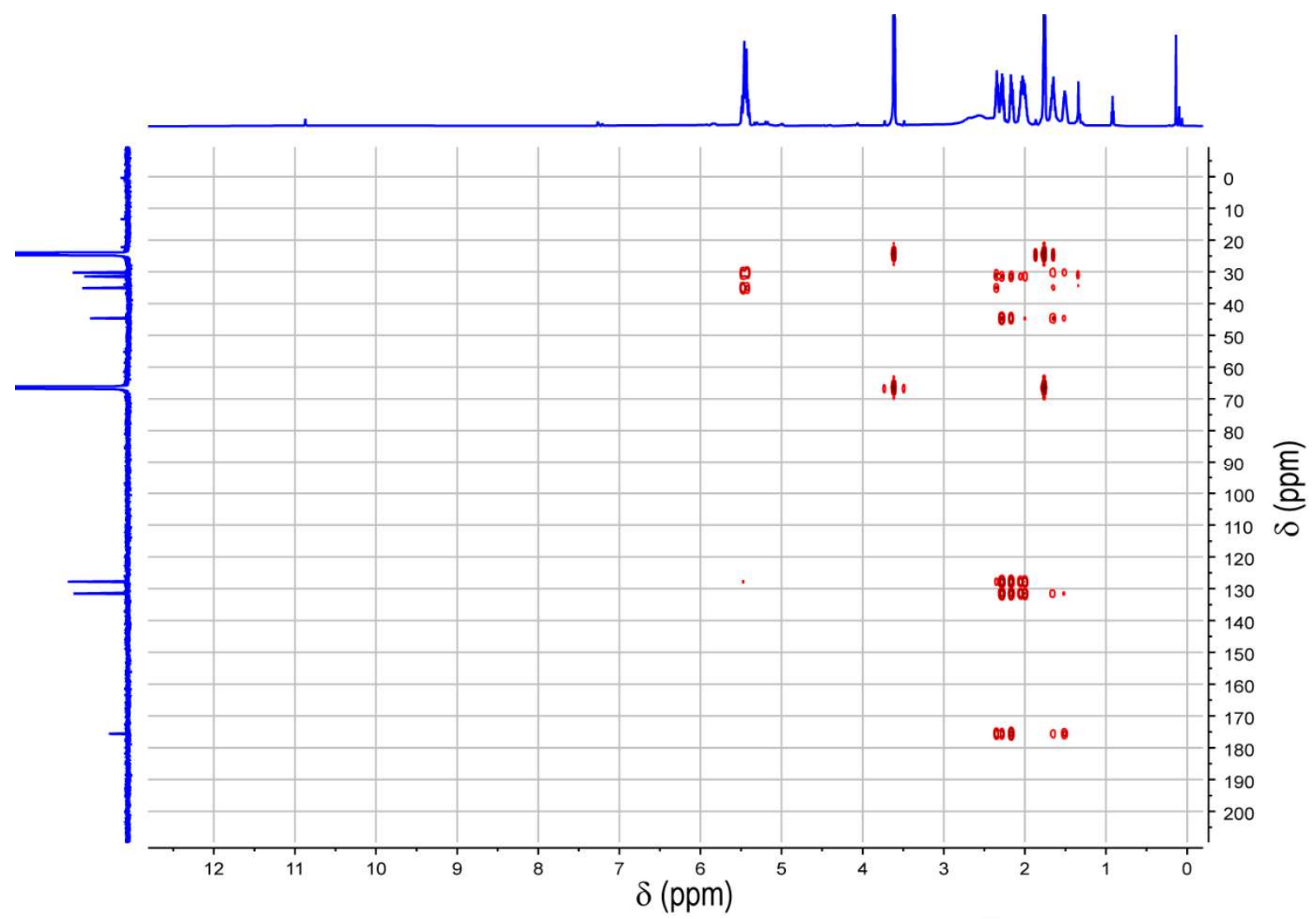

Figure S73. HMBC NMR (600 MHz, THF- $\left.d_{8}, 23{ }^{\circ} \mathrm{C}\right)$ spectrum of P1" synthesized from P1. 


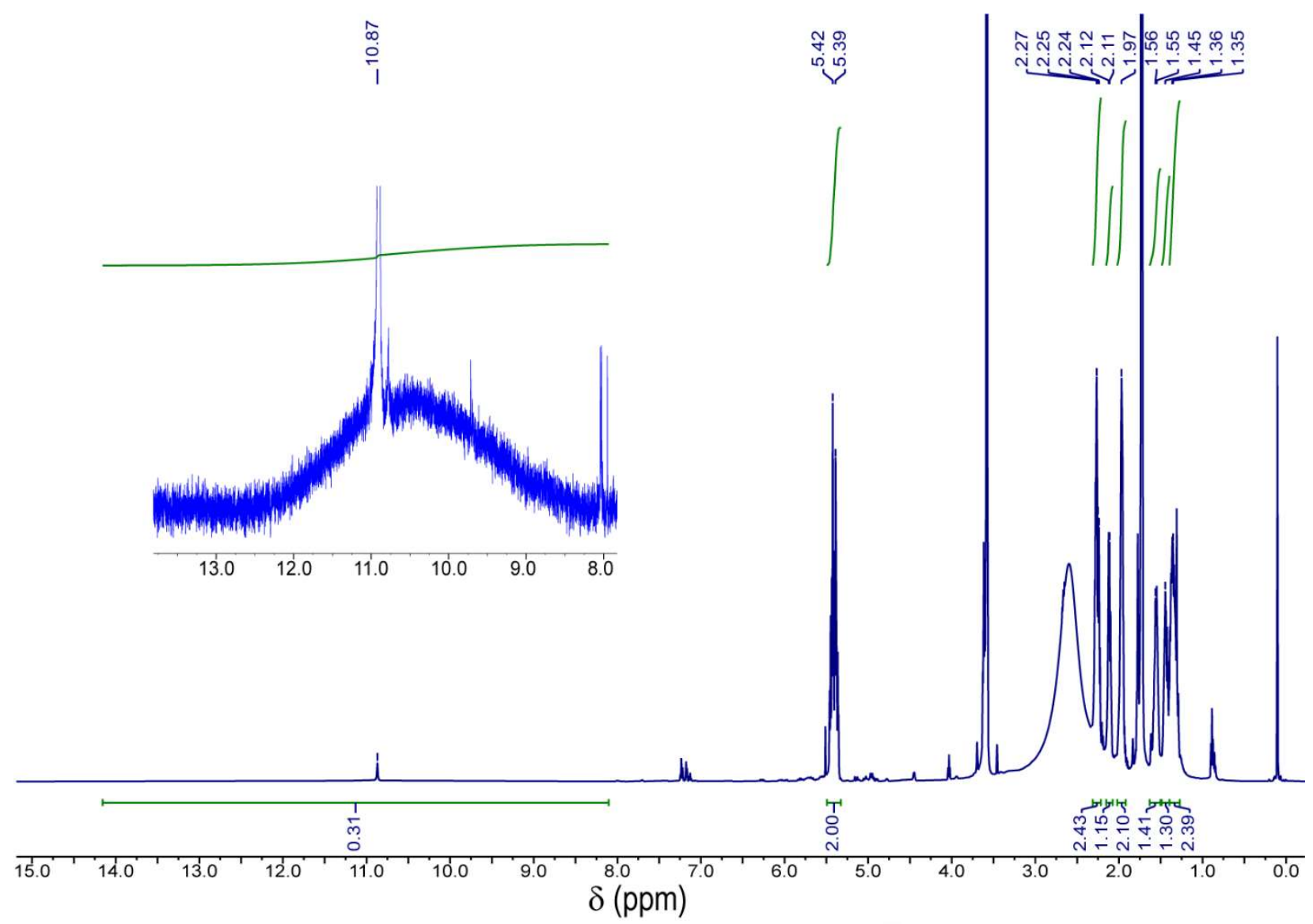

Figure S74. ${ }^{1} \mathrm{H}$ NMR $\left(600 \mathrm{MHz}\right.$, THF- $\left.d_{8}, 23{ }^{\circ} \mathrm{C}\right)$ spectrum of P2" synthesized from $\mathbf{P 2}$ with the region from $13.5-8.0 \mathrm{ppm}$ magnified to show the presence of the carboxylic acid proton. 


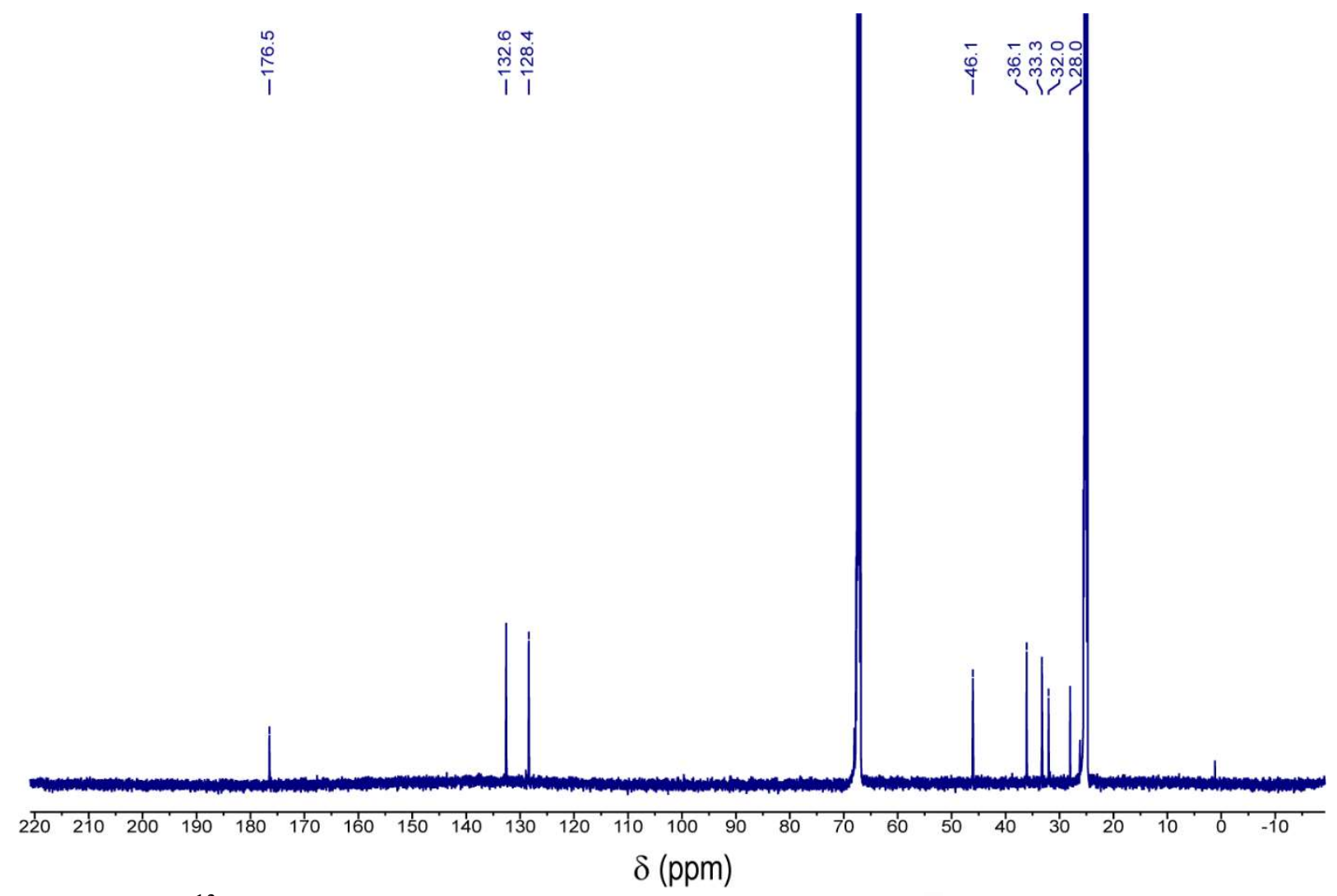

Figure S75. ${ }^{13} \mathrm{C}$ NMR $\left(150 \mathrm{MHz}, \mathrm{THF}-d_{8}, 23{ }^{\circ} \mathrm{C}\right)$ spectrum of $\mathbf{P 2} "$ synthesized from $\mathbf{P 2}$. 


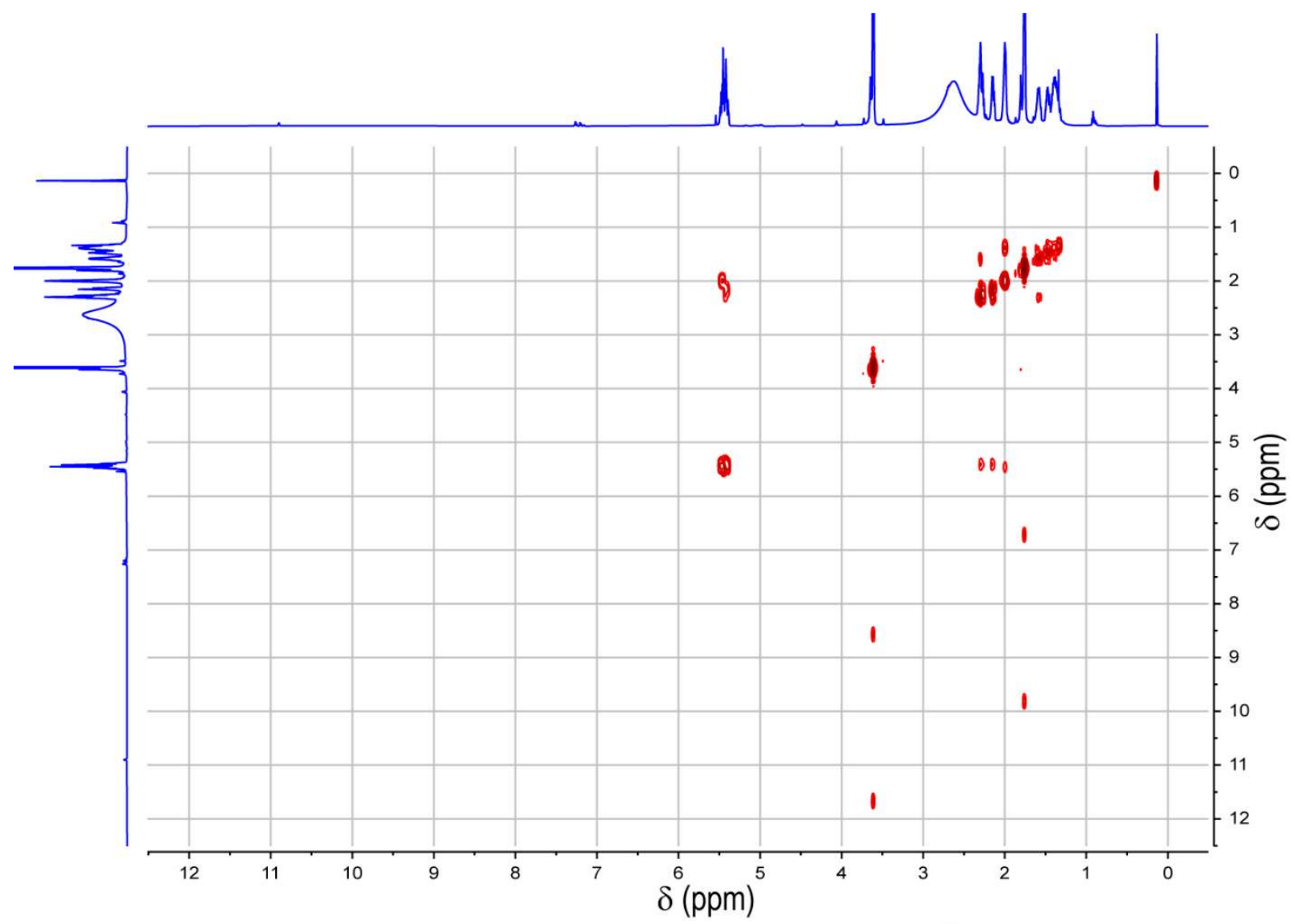

Figure S76. COSY NMR (600 MHz, THF- $\left.d_{8}, 23^{\circ} \mathrm{C}\right)$ spectrum of P2" synthesized from P2. 


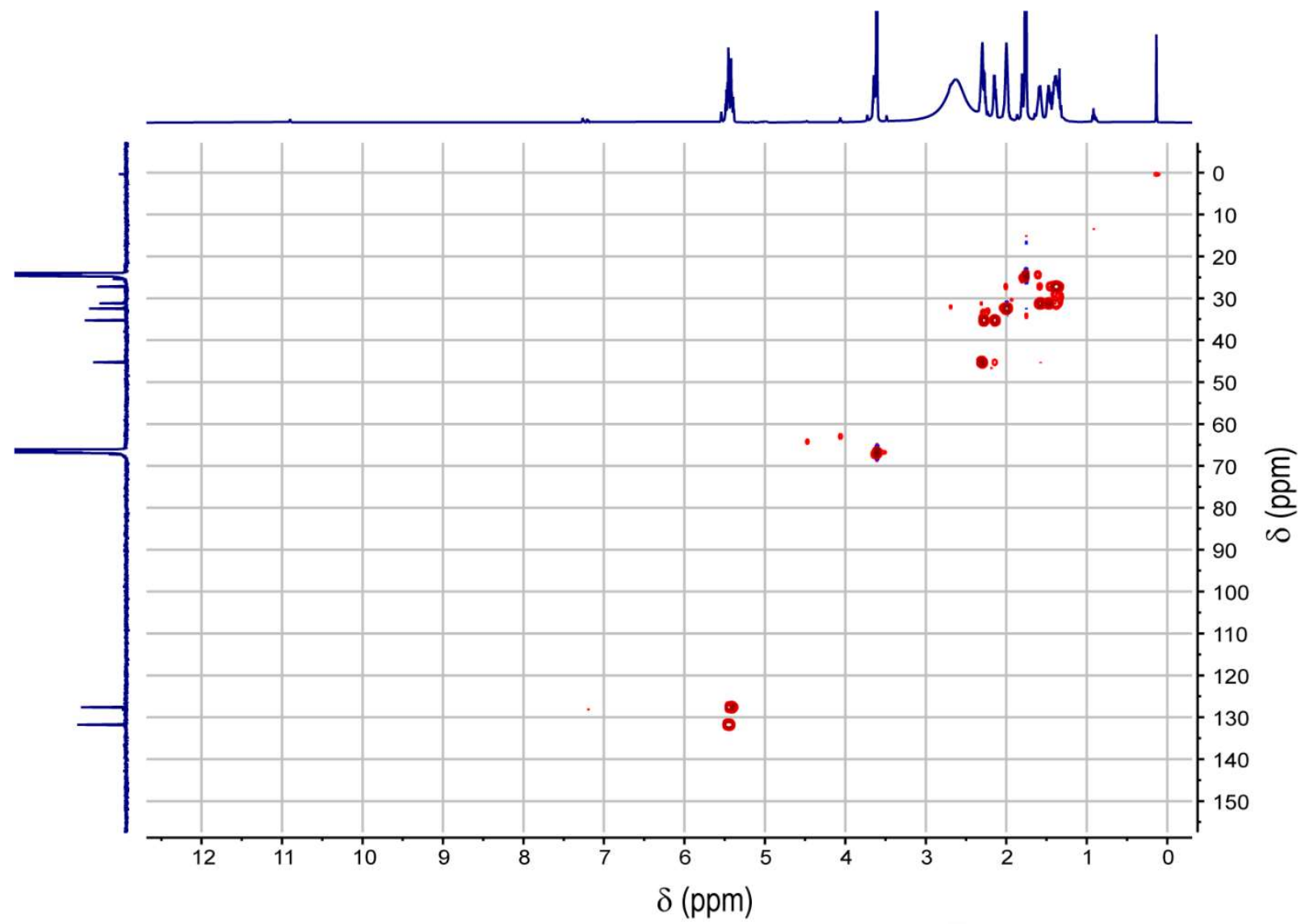

Figure S77. HSQC NMR (600 MHz, THF- $\left.d 8,23{ }^{\circ} \mathrm{C}\right)$ spectrum of P2" synthesized from P2. 


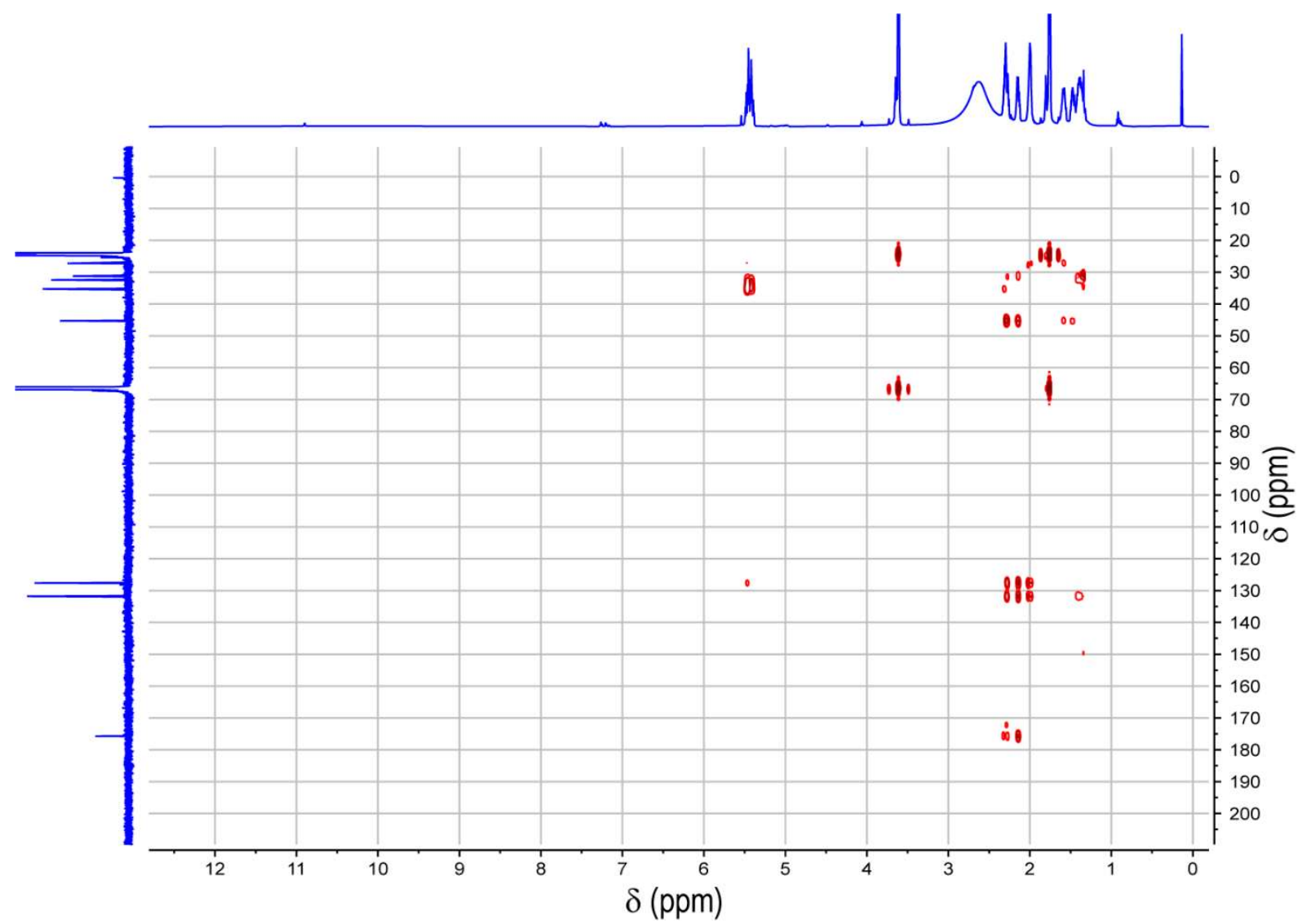

Figure S78. HMBC NMR (600 MHz, THF- $\left.d_{8}, 23{ }^{\circ} \mathrm{C}\right)$ spectrum of P2" synthesized from P2. 


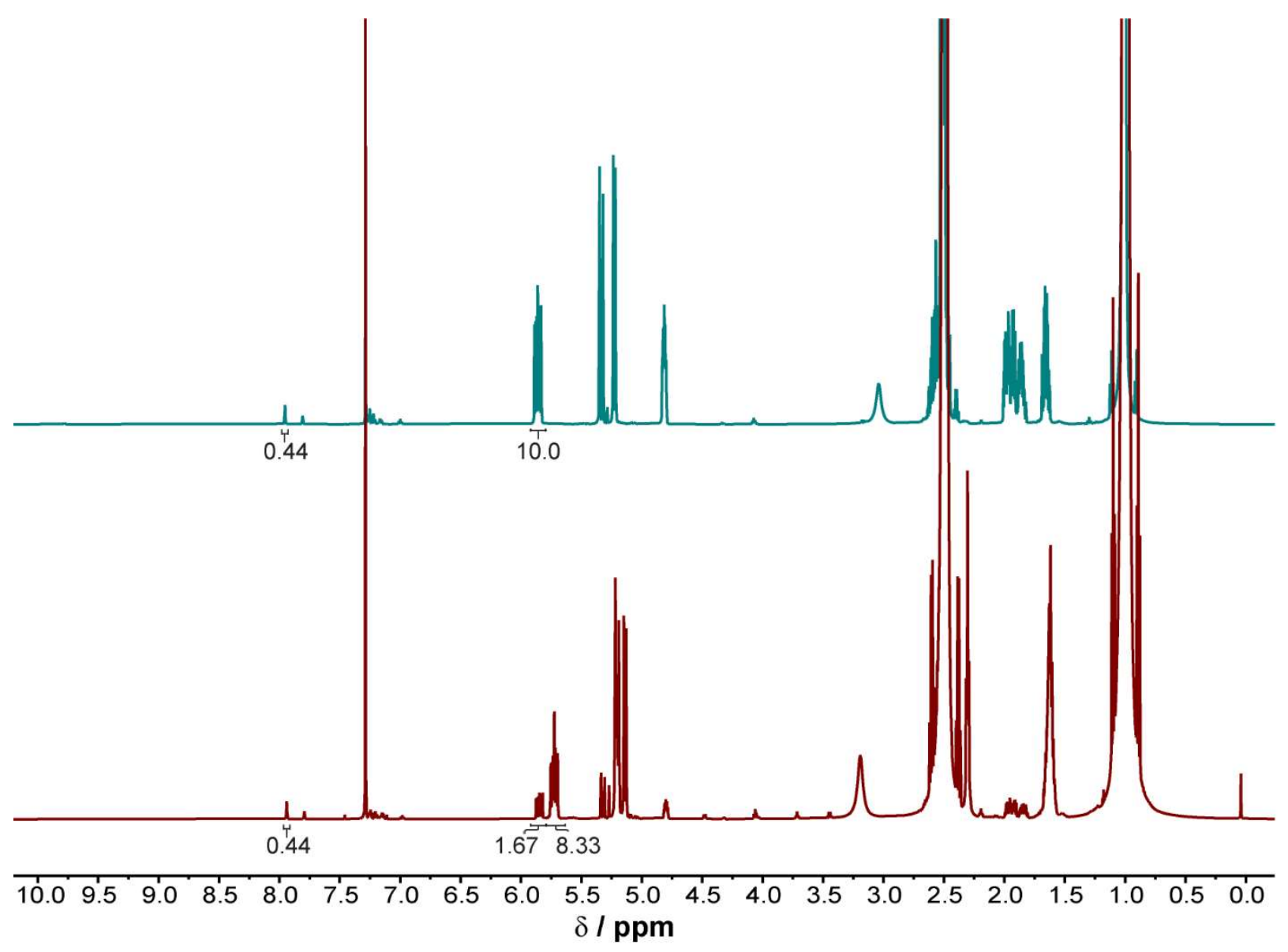

Figure S79. ${ }^{1} \mathrm{H}$ NMR $\left(500 \mathrm{MHz}, \mathrm{CDCl}_{3}, 23{ }^{\circ} \mathrm{C}\right)$ spectrum of the polymerization of 1 with DPP and 3-phenylpropan-1-ol at $60{ }^{\circ} \mathrm{C}$ with a [M]:[I]:[C] ratio of 100:1:1 at the beginning (top) and end (bottom) of the polymerization. No change in the total area of the combined polymer and monomer resonances from 6.0-5.7 ppm were observed compared to the internal standard. 


\section{References}

1. Pangborn, A. B.; Giardello, M. A.; Grubbs, R. H.; Rosen, R. K.; Timmers, F. J., Safe and Convenient Procedure for Solvent Purification. Organometallics 1996, 15 (5), 15181520.

2. Fulmer, G. R.; Miller, A. J.; Sherden, N. H.; Gottlieb, H. E.; Nudelman, A.; Stoltz, B. M.; Bercaw, J. E.; Goldberg, K. I., NMR Chemical Shifts of Trace Impurities: Common Laboratory Solvents, Organics, and Gases in Deuterated Solvents Relevant to the Organometallic Chemist. Organometallics 2010, 29 (9), 2176-2179.

3. Still, W. C.; Kahn, M.; Mitra, A., Rapid Chromatographic Technique for Preparative Separations with Moderate Resolution. J. Org. Chem. 1978, 43 (14), 2923-2925.

4. Trost, B. M.; Verhoeven, T. R. Cyclization Catalyzed by Palladium(0). Initial Studies and Macrolide Formation. J. Am. Chem. Soc. 1980, 102 (14), 4743-4763.

5. Luo, J.; Zhang, Y.; Huang, S.-H.; Zhu, L.; Hong, R. Catalytic Aza-Wacker Annulation: Tuning Mechanism by the Activation Mode of Amide and Enantioselective Syntheses of Melinonine-E and Strychnoxanthine. Org. Lett. 2018, 20 (8), 2386-2390.

6. Mac, D. H.; Samineni, R.; Petrignet, J.; Srihari, P.; Chandrasekhar, S.; Yadav, J. S.; Gree, R. From Vinylpyranoses to Carbasugars by an Iron-catalyzed Reaction Complementary to Classical Ferrier Carbocylization. Chem. Commun. 2009, 4717-4719. 